أثر التفاعل بين توقيت تقديم الألعاب التعليمية الرقمية ثلاثية الأبعاد والسيادة النصفية للمخ فى تنسية الجانبين المعرفى والأدائى لمهارات إنتاج الصورة الرقمية لطلاب

\title{
تكنهولوجيا التمايسم
}

د/ رجاء على عبد العمليم

مدرس تكنولوجيا التعليم كلية التربية النوعية - جامعة أسوان

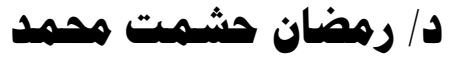

مدرس تكنولوجيا التعليم كلية التربية النوعية - جامعة أسوان

تطبيق أدوات البحث (الاختبار التحصيلى وبطاقة

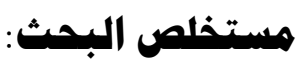

ملاحظة الأداء).

وقد أثبتت النتائج عدم وجود فروق دالة

إحصائيا بين مجموعة الألعاب القبلية والبعدية، كما

توصلت إلى تفوق المجموعة ذات السيادة النصفية

المتكامل على مجموعات السيادة النصفية الأيمن

والأيسر.

الكلمــات الحاكمـة : الألعـاب التعليميـة الرقميـة

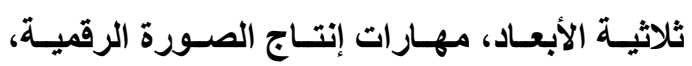

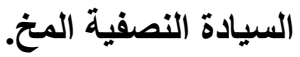

همدهة:

تعد الألعاب التعليمية الرقمية من الخبرات

التعليمية التى توفر التسلية والإنتاجية والمتعة

للمتعلمين من جميع الأعمار، وتضيف الألعاب

التعليمية الجيدة عوامل الإثارة و التحفيز إلى التعلم،

يهذف البحث الحالى إلى التعرف على أثر

التفاعل بين توقيت تقديم الألعاب التعليمية الرقمية

ثلاثية الأبعاد والسيادة النصفية فى تنمية مهارات

إنتاج الصورة الرقمية، وتكونت عينة البحث (VY)

طالبا وطالبة بالفرقة الثالثة شعبة تكنولوجيا التعليم

بكلية التربية النوعية جامعة أسوان، تم توزيعهم

على ست مجموعات بناء على نتائجهم فى مقياس (تورانس للسيادة المخية المعدل)، وقام الباحثان بتصميم برنامجين للألعاب التعليمية الرقمية ثلاثية

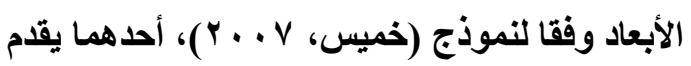
الألعاب قبل المحتوى المعرفى المرتبط بالمهارة، والآخر يقدم الألعاب بعد عرض المحتوى المعرفى المرتبط بالمهارة، وقا استمرت التجربة ثلاثة أسابيع، حيث قام طلاب المجموعات الست بالتعرض بهرب

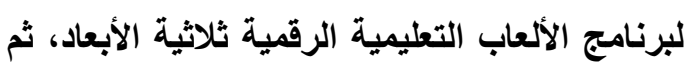


ولقد ظهر الكثير من البحوث التى اهتمت

بالتصميم وتأثير الألعاب الرقمية التعليمية والتي أكلت على ضرورة احتفاظ الألعاب بعنصر الترفيه التي تحفز وتسهل التعلم، وهذا ما أكده علم النفس المعرفى وخصوصا نظرية الحمل المعرفى، والتي أشارت إلى ضرورة التظلب على بعض العوائق للوصول إلى التعلم ذو المعنى. والتي منها الاهتمام بالعمليات المعرفية للتعلم مع عدم التقليل من دافعية (Anja, 2017).المتعلم وتحفيزه كما أن الألعاب الرقمية التعليمية لها القدرة على دعم المتعلمين البالغين للوصول إلى تعلم ذو معنى والتمتع ومشاركة الآخرين، يث يلجأ البالغون إلى الألعاب الرقمية التعليمية لإثباع حاجات متنوعة؛ منها القدرة على التفاعل اجتماعيا مع الآخرين وتحسين الحياة الاجتماعية ولها تأثير إيجابى على إحساس الأفراد بالتحسن، كما أنها تزيا من التواصل الاجتماعى بالآخرين والشعور بالانتماء والتعلق بالآخرين وتقليل مشاعر الوحدة أو الانعزالية. (David, 2017)

ويمكن للألعاب التعليمية الرقمية أن تبنى بيئة

تعليمية قوية وفعالة لعدة أسباب أهمها: تذعيم تعلم نشط يعتمد تعدد الحواس وحل المشكلات، يوظف وينشط المعرفة السابقة للمتعلم كأساس للتقدم في اللعبة، إعطاء تغذية راجعة فورية تمكن المتعلمون لاختبار فرضياتهم والتعلم من الممارسة، توفر الفرصة للتقييم الأتي من خلال إحراز الدرجات والتمكن من تحقيق مستويات مرتفعة، تزيا من
وتوفر تعليما مركزا لمهارات معقدة، وقد أخذت الألعاب التعليمية الرقمية فى الانتشار، وظهرت الحاجة إلى ابتكار ما يتلاعم منها مع موضوعات الاراسة المختلفة وأهداف التعليم، والظروف الاجتماعية والحضارية للمتعلم والمجتمع وبات من الضرورى وجودها كنمط من أنماط التعليم القائم على الحاسب.

والألعاب التعليمية الرقمية شكل من أشكال التعلم القائم على مجموعة من الخطوات والإجراءات المخططة التى يؤديها المتعلم على الكمبيوتز، من خلال الالتزام بقواعد معينة لتحقيق هدف تعليمى محدد فى إطار تنافسى وممتع، وهو نوع من التعلم يتمركز حول المتعلم، ويتيح لله حرية الإستكثاف والتجربه بفاعلية داخل البيئة التعليمية. كما أنها إحدى أشكال استخدام الأنشطة، حيث تقوم بدور مهم في تقديم خبرات للمتعلمين من خلال الأنشطة التعليمية المصممة بصورة جيدة وممتعة، مثل ألعاب التركيب، والألعاب الالكترونية ثلاثية الأبعاد. كما أنها شكل من أشكال التكنولوجيا، التي تساعد على تحسين الإدراك من خلال منصات التكنولوجيا المستخدمة التي تساعد على سهولة Walter, ).'الاستخدام والقبول التكنولوجى

(2016

' استخدم الباحثان في التوثيق وكتابة المراجع الإصدار

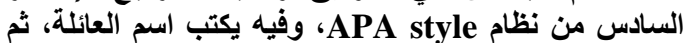

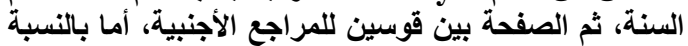

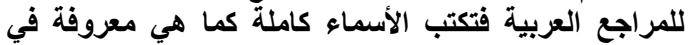
البيئة العربية، وهذا ما يشير إليه النظام.

المجلا السابع و العثرون .... العدد الثانى جr - إبريل - V V . 
المستمر والتي تدعم استخدامها من وجهة نظر نظريات التعلم المختلفة التي تنظر على التعلم كعلية ارتباطية، كما أن هناك الألعاب القائمة على لصى المفاهيم البنائية التي تقدم حجبا تربوية أخرى.

(Lynceo, 2016)

وتعد الألعاب التعليمية مجالا مهما لتطوير

شخصية الطالب واثراء خبراته واكسابه للمهارات واتقاته إياها، ولابد للمعلم من تضمينها وتدريسها. ومع التطور الحادث في تقتيات التعليم والمعلومات ووسائطهما؛ سيصبح استخدامها في العملية التعليمية ضرورة حتمية لا غنى عنها لمعلم المستقبل، ليس فقط لكونها ترسخ المعلومة وتطيل

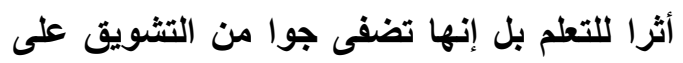
طرق التدريس والتعلم وتؤدي إذا ما أحسن

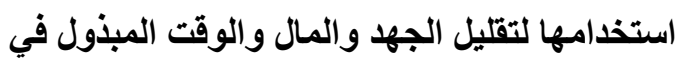

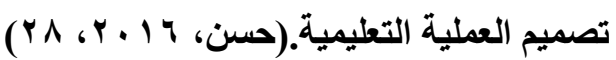

كما أن تصميم الألعاب التعليمية الرقمية وبخاصة ثلاثية الأبعاد تساعد المتعلمين على خوض الصن خبرات جديدة قد تتصف في الواقع بالمخاطرة، كما أنها تساعده على التخيل، والمغامرات التعليمية

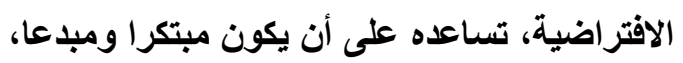

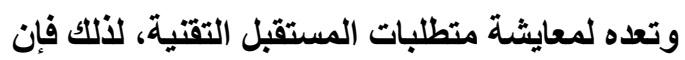
دمج الألعاب في الأنشطة التعليمية تضفي عليها: تفاعلية بين الطالب ومحتوى تلك الألعاب، إيجابية وحيوية، كفاءة في الاستجابة للفروق الفردية بين الطلاب، قدرة على تقليم التغذية الراجعة الفورية، تنوعا في طرق التقديم والتعلم. ) Grable\& (Osborne. 2005
فرص توفر بيئة تعلم اجتماعية، كما تمكن من تطوير مهارات مختلفة من التفكير الابتكارى وحل المشكلات. (Papastergiou, 2009) ويضيف ماتياس(Matthias, 2017) أن من أهم خصائص الألعاب التعليمية الرقمية: التفاعلية، الوسائط المتعددة، المشاركة، التحدى، الخبرة الاجتماعية، المكافأة، والتي تثكل لهم تمكين نتائج التعلم التي لا يمكن تحقيقها مع وسائط ومنتجات تعليمية أخرى. فالتفاعلية يقصد بها تفاعل المتعلمين مع العالم الرقمى للعبة، بحيث يسهم في تعلم الخبرة المباشرة، ويتلقى المتعلم هنا التغذية الراجعة الفورية، كما تساهم خاصية الوسائط المتعددة في الألعاب من مقابلة بعض المشكلات والمهام المعقدة، وتسهر خاصية المشاركة في انغماس المتعلمين واندماجهم مع أقرانهم، كما تضفى خاصية التحدى والمكافأة إمكانيات التكيف مع صعوبة مهمة إلى قدرات المستخلم، وبالتالي تعزيز الدوافع الذاتية وتوفير مكافأة معينة لتحقيق إنى

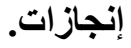

والتفاعل الاجتماعى هو سمة مميزة أخرى للألعاب التعليمية الرقمية التي ترتكز على النظريات البنائية، فالألعاب ليست فقط قادرة على خلق سياق لاكتساب المعرفة، ولكن أيضا لتشكيل مجتمع يربط بينهم. كما أن الاهتمام بتحفيز وتسهيل التعلم كعملية طبيعية يساعد في ذلك توظيف الألعاب في تحفيز التعلم وتثجيع تغيير المواقف تجاه منطقة معينة من المعرفة، كما تتمتع الألعاب بتوفير الدافعية والتعزيز 
وهو تعلم مهارة أو مفهوم أو غير ذلك ثم يبدأ فى ممارسة اللعبة لتحقيق هذه الغاية. النموذج الثاني "(ستجابات، تعليم" وفيه تقدم اللعبة مجموعة من الألعاب المثيرة والأحداث المشوقة التى يستجيب لها المتطم وفى أثناء ذلك يحدث التعلم، ثم يقدم للمتعلم المحتوى المعرفى في شكل أنشطة واستجابات نشطة. وتثثير دراسة

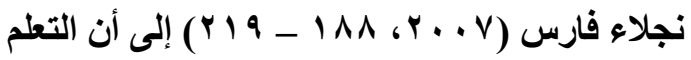
فى النمط الأول (الألعاب البعدية) يتم بثكل موجه ومقصود بينما فى النمط الثانى (الألعاب القبلية) يتم فيه بشكل عرضى غير مباشر.

ويُستمد الأساس النظرى لتوقيت تقديم الألعاب قبليا من خلال نظرية المنظمات التمهيدية Advanced Organizers أوزبل، حيث أن فكرة المنظم التمهيدى تقوم على توفير بناء عقلى ذو دلالة للمتعلم قبل بدء عملية التعلم، مع مراعاة ملائمة هذه المعلومات الجديدة لهية لبنيته المعرفية، كما أن هناتك من وظائف المنظم هماه التمهيدى إلى جاتب الدافعية وهى استدعاء الخبرات السابقة، وتنظيم المجال الإدراكى، وتوجيه الانتباه، وهى الوظائف المتعلقة بالألفة والممارسة والتكرار والتفاعل، أما بالنسبة الألعاب البعدية؛ فهى تطبيق للمنظمات اللاحقة Post Organizers، ويندرج كل من الألعاب القبلية والبعدية فى علم النفس تحت

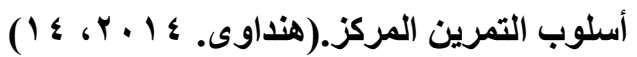
واستخدام المنظمات التمهيدية في تخطيط الألعاب التعليمية له عديد من المميزات منها
ولتصميم اللعبة التعليمية بشكل فعال، يجب أن تتضمن اللعبة أهافا تعليمية واضحة وصريحة وأساليب وجواتب تحفيزية لتسهيل التعلم، ويجب أن تتميز اللعبة بالمتعة والجاذبية، وتساعد على ونى

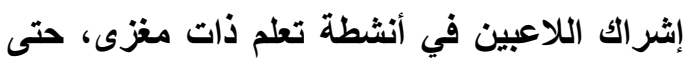
تصبح اللعبة جزءا لا يتجزا من أنشطة التعلم، ولكن تبقى مشكلة توقيت تقديم الألعاب هي الأهم عند

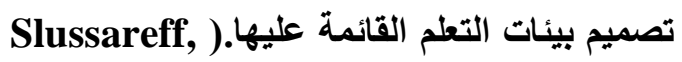
2016)، فهل يفضل استخدام الألعاب التعليمية قبل عرض المحتوى التعليمى أم بعده؟ لم تحدد البحوث

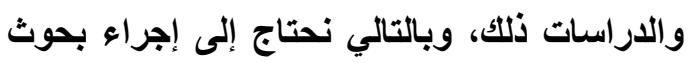
ودراسات، وهو ما يهدف إليه البحث الحالي. وتعتمد الألعاب التعليمية على مجموعة

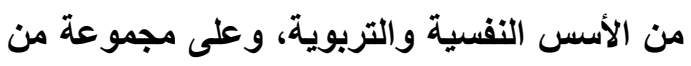

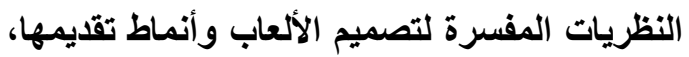

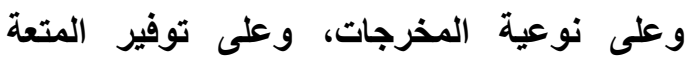

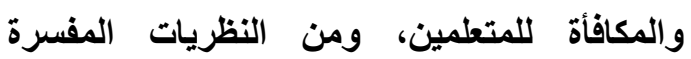
للألعاب نظرية سلايتون والكسندر فى سيكولوجية

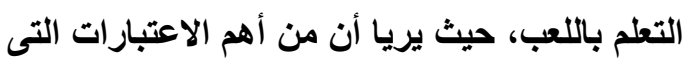
يجب أن تؤخذ فى الحسبان عند تصميم اللعبة

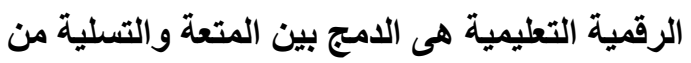
ناحية وتحقيق الهدف التعليمى من ناحية أخرى. وقد صنفا نماذج استخدام الألعاب التعليمية

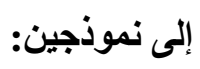
النموذج الأول: "تعليم، استجابات" وفيه يبدأ التعلم بعرض الهدف التعليمى ثم المحتوى، ثم تقدم اللعبة المكونة من مجموعة الأنثطة والاستجابات التدريجية. بمعنى أن المتعلم يعرف الغاية من اللعبة 
تماثل المنظمات التمهيدية في كل خصائصها (حسن

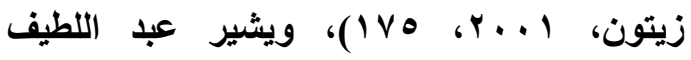

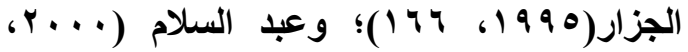
(V) إلى أن المنظمات اللاحقة قد تنظم البنية المعرفية للمتعلم بعد مهمة التعلم الجديدة وبالتالي يمكن أن تزيد التعلم، وبصفة خاصة فى مجال تنمية المهارات، بينما أشارت العديد من الدراسات مثل: Ming \& Yu \& Li, دراسة مينج ويو ولى) 2014؛ زاكروفا وجانيف ومولان Zakirova,\& (Ganiev\& Mullin, 2015 ثلاثية الأبعاد كمنظم تمهيدى متقدم أو متأخر، ولم تجزم بفاعلية أيهما في نواتج التعلم المختلفة. ويمكن أن تصمم الألعاب الرقمية كمنظم متقلم تفسيرى أو قصصى أو تخطيطى لكى تعطى الخلفية العامة للقصة أو المحتوى مع الأهداف الرئيسية ويتم إنجاز ذلك باستخدام أحد الطرق التي تصف المنظم المتقلم ولكنه يتم بصورة منتشرة باستخدام الدمج بين المشاهد والفيديوهات والأصوات، مما يعطى جودة أعلى أحيانا من اللعبة نفسها(Becker,2017). لذلك فاستخدام الألعاب الرقمية كمنظم متقدم لها تأثير إيجابى وقدرة على دمج المحتوى لاستكشاف المفاهيم والمهارات الجديدة. كما أن لها القدرة على تزويد المتعلم بخبرات أولية كمستوى عالى من التجريد أكبر من مهام التعلم الحالية. كما تتميز الألعاب بأنها أدوات دعم التعلم المستقبلي، وكيفية قياس التحول إلى تحسين التعلم، وأكد ماير أن هناك شروط لازمة

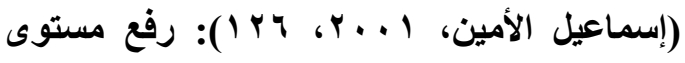
التحصيل والأداء للمتعلمين، تزود من قدرة المتعلمين على التمييز والتحليل والتركيب، تعمل على إعطاء معنى لمحتوى المادة الجديدة، وتسهم في انتقال أثر التعلم. لذلك يمكن تطبيقها على كثير من أشكال التمهيد للألعاب التعليمية. ويضيف لينسيو(Lynceo,2016) أن استخدام الألعاب كمنظم تمهيدى في التعليم يعد فرصة لتقديم مفاهيم مختلفة بطريقة متكاملة، مع إمكانية تقديم أمثلة شاملة وديناميكية يمكن أن يتقاسمها المتطمون والمعلمون، كما أنها تعطى الحرية الأكبر للمعلم للتفاعل الفردى مع المتعلم، كما أنها تلبى الطلب في الوقت نفسه على المعرفة والدافعية. ويؤكد خميس (Y P (11) أن المنظمات المتقدمة تساعد في تنشيط البنية المعرفية القائمة وتجميع التفاصيل وتقديم إطار عمل للتعلم عن طريق المنظمات المقارنة C Comparative .Expository ويؤكد القزنى(7 1 +ץ) أنه قـ ازداد اهتمام الباحثين في تحديد نوع المنظمات التمهيدية الملائمة لبيئة التعلم، فقد تكون غير محددة وصعبة الإعداد وفى نفس الوقت قد تكون مملة وغير ممتعة؛ لذا ظهرت دعوات لتقديم أثكال جديدة ومختلفة منها مثل: الفقرات القصيرة والأسئلة والأفلام والقصص والخرائط والألعاب التعليمية. كما أن المنظمات اللاحقة أو البعدية أو المتأخرة تقوم بالربط و التلخيص لما تم تعلمه، وهى 
أثر ألعاب الفيديو كمنظم تمهيدى في زيادة فاعلية التعلم العسكرى، وتوصلت إلى أن مجموعة الألعاب التي قدمت قبل دراسة المحتوى رفعت من اهتمام المتعلمين في الاستمرار في التعلم، وفى المقابل أدت إلى زيادة الحمل المعرفى بالمقارنة بالمجموعة التي لم تستخدم الألعاب كمنظم تمهيدى، ودراسة كل من

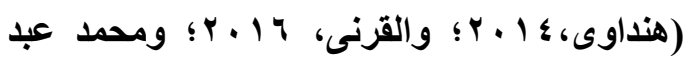

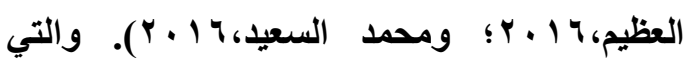
تباينت نتائجها حول دور الألعاب كمنظم تمهيدى متقدم أو متأخر وإن كانت الغالبية منها ركزت على

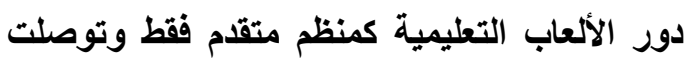
إلى فاعليتها كمنظم متفدم في تنمية بعض نواتج التعلم. وهذا يتطلب إجراء المزيد من البحوث والدراسات لتحديد التوقيت المناسب لتقديم الألعاب

$$
\text { التعليمية في ضوء ما يهذف إليه البحث الحالي. }
$$

كما تناولت العديد من الاراسات فاعلية الألعاب التعليمية الرقمية ثلاثية الأبعاد فى تنمية العديد من

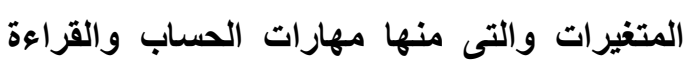
والتحصيل وغيرها مثل دراسة كلا من(هاكن Lucas. et al, ولوكاس Haken et al. 2009 2009)، وقد اتفقت على أن استخدام الألعاب وخاصة فى المقررات ذات الجانب التطبيقى والأدائى مثل مقررات الحساب والرسم والطلوم لها مردود إيجابى على الأداء، حيث تجعل بيئة التعلم أقرب إلى مهلى الواقعية من خلال الرسوم والصور والفيديو والنصوص والصوت، لأن عملية التعلم من خلال الألعاب تتم فى بيئة تفاعلية من خلال إعطاء العديد
للمنظم التمهيدى ليكون لله تأثير إيجابى على التعلم

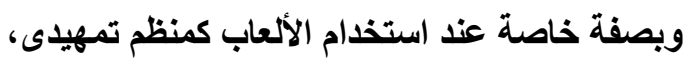
حيث يجب أن تصمم لتحقيق هدفين: الأول يجب أن تسلط الضوء على سياق مفيد للتعلم، الثانى تثجيع المتعلم على استخدام هذا السياق أثناء التعلم، وأن عدم الالتزام بمبادئ التصميم هذه عند إنتاج الألعاب Aقلل من فعالية الألعاب كمنظم تمهيدى. ( Andre, ولقد تزايدت البحوث حول فعالية التعلم القائم على الألعاب التعليمية الرقمية، ومع ذلك ظهر عدم تجانس كبير في أساليب تقييم فعالية التعلم القائم على الألعاب التعليمية الرقمية مما يؤدى إلى البحث في موثوقية صحة وأساليب معينة في تصميم

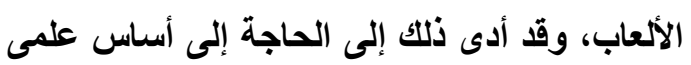
لإجراء هذا النوع من البحوث وتوفير الإجراءات والأطر والأساليب التي يمكن التحقق من صحتها،

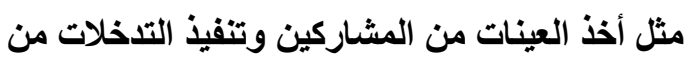

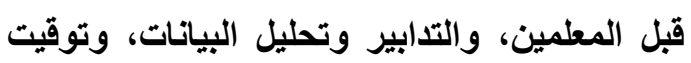
Anissa. ) تقيم الألعاب، والثكل والمحتويات 2016) وقد أكد كنلك هوشاير ( Hooshyar. 2016) على ضرورة البحث في توقيت تقديم الألعاب والاهتمام بالألعاب المعتمدة على لاعب واحد ضد الحاسب.

وتناولت بعض الاراسات أثر الألعاب التعليمة الرقمية كمظم تمهيدى في تنمية بعض جوانب الثخصية والتحصيل وبعض المهارات مثل دراسة: جينفر (Jennifer, 2013) والتي تناولت دراسة ونة 
البحوث المتعلقة بنصفي الدماغ وبعلم الأعصاب، حيث يوجد أسلوبان مختلفان لكنهما متكاملين في معالجة المعلومات، أحدهما خطى (خطوة تلى خطوة)، يحلل الأجزاء التي تتثكل منها الأنماط وهذا يتم في النصف الأيسر من المخ، والآخر يتعرف على العلاقات بين الأجزاء المنفصلة ولا ينتقل بشكل خطى، وقد حرك هذا الاكتثاف قدراً لا بأس به من الإثارة بين المربين وولد لديهم رغبة في استكثاف التطبيقات التربوية للبحوث المتعلقة بنصفي المخ، من هنا ظهرت نظرية جانبي الدماغ. ويستند التعليم الاماغى إلى أن لكل إنسانا دماغا فريدا من نوعل، وهو قادر على التعلم والاكتساب إذا توفرت له الظروف المناسبة، وتزداد قدراته على التعلم بإثارة خلاياه العصبية وتنثيطها على تثكيل أكبر عدد من الوصلات، فالاماغ يمتاز بالقدرة التكيفية مع المواقف المختلفة، وهو نظام تكيفى معقد وفريد قادر على معالجة أكثر من مثير

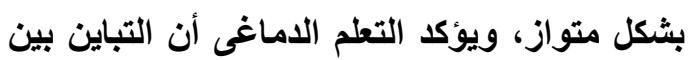

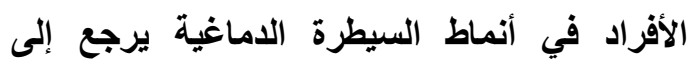
اعتمادهم على أحد نصفى الدماغ في استقبال المعلومات ومعالجتها، ويرى أن الدماغ يتعلم بشكل أفضل عندما يشترك كلا النصفين في معالجة المعلومات. (Oflaz, 2011)

ولقد تباينت النظريات والنماذج التي قدمها الباحثون في إطار تفسير السيادة النصفية فيما بينها حول الافتراضات التي بنيت عليها، فهناك نظريات ترى أن هناك تخصصا جزئيا، وأخرى تفترض
من الأنثطة والتدريبات التى يؤديها المتعلم، كما توصلت دراسة محمد توفيق (10 ب ب) إلى تفوق ألعاب الثبكات الاجتماعية على الألعاب التقليدية وأرجع تلك النتيجة إلى توافر الألعاب ثلاثية الأبعاد أو الثخصية الافتراضية الأفاتار Avatar وكنلك الخطط والسيناريوهات الايناميكية المنتجة من نظام اللعبة للفرد والمتفقة مع احتياجاته المتغيرة. لذلك يمكن القول أن الألعاب التعليمية الرقمية ثلاثية الأبعاد قد تكون بليلا جيدا مناسب لتعلم المهارات الأدائية لمقرر إنتاج الصورة الرقمية لطلاب تكنولوجيا التعليم، وذلك من خلال تصميم مهارات مثل تركيب الكاميرا، وتركيب العدسات المختلفة، وتركيب الفيلم وإخراجه، وتعلم خطوات التصوير، وخطوات معالجة الصور الرقمية، من خلال محاكاة واقعية لتتك المهارات لتضيف خاصية العمق، وذلك عندما تتجمع العديد من النقاط ثلاثية الأبعاد، بحيث يحمل كل منها قيمة عمقه الخاصة، وتضاف لهذا السطح الناشئ العديد من الخواص الإضافية مثل الظل والملمس. ولذلك يستخدم البحث الحالي الألعاب التعليمية الرقمية ثلاثية الأبعاد لتعلم المهارات الأدائية في مقر إنتاج الصورة الرقمية. ويتأثر استخدام الألعاب التعليمية الرقمية ثلاثية الأبعاد بالعديد من العوامل؛ منها: طبيعة المتعلمين، وطبيعة المحتوى، ونمط الأنشطة نفسها، ونوع المادة التعليمية التي يقلم من خلالها المحتوى، ونظرا لأن طبيعة المتعلمين متباينة في تفسيرهم للمواقف والأنشطة، بل إنه ظهرت نتائج بعض 
هناك علاقة بين النصف السائد عند المتعلم وتوقيت تقديم الألعاب له؟ وهذا ما سيتم بحثه في البحث

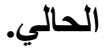

وترتبط الألعاب التعليمية بنظرية النشاط

التي تسعى إلى تحقيق أقصى قر من المشاركة للمتطلم، والتي من أهم مبادئها: أن النشاط نظام يضم عدة نظم فرعية بينها علاقات مترابطة، وتعدد وجهات النظر في الموضوع الواحد، والتغير الملازم للنشاط عبر الفترات الزمنية خاصة بعد ظهور الإنترنت والاتصالات والمعرفة، والتناقضات التي هي مصدر التغيير تؤدي إلى الابتكارات في مجال الممارسة (Gary M, 2011)

كما ترتبط الألعاب التعليمية بالنظرية المعرفية القائمة على التمركز حول المتعلم فهي بالهي تثجعه على المشاركة النشطة والفعالة، وتراعي ما بين المتعلمين من فروق فردية، وأهمية مراعاة نمط التعلم الخاص بكل متعلم، والاهتمام بالعمليات العقلية، كما تعتمد على تخزين المعرفة في ذاكرة الطالب واسترجاعها للمواقف الجديدة (سرايا، .$(r \cdots v$

وكنلك ترتبط الألعاب التعليمية بالنظرية البنائية؛ حيث ترى أن المعرفة عبارة عن شيء يتم بناؤه بواسطة كل متعلم في إطار فهمه، من خلال خطوات نشطة في العملية التعليمية، والمتعلمون في هذه الحالة يعتمدون على أنفسهم في بناء المعرفة عن طريق ربط المعلومات الجديدة بما لديهم من معرفة سابقة بالاً من قبول المعلومات من المعلم،
التخص التام، واتجاه ثالث يرى أن هناك تعاونا بين النصفين الكرويين ويؤكد على الطبيعة التكاملية

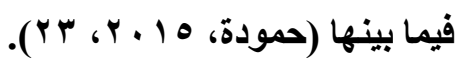
ويوضح تورانس بأن وظائف جانبي المخ تختلف؛ ففي حين تؤكد الدراسات أن النصف الأيمن يختص بالتعلم التجريبى عن طريق الأداء والتعلم عن طريق العرض العملى، نرى أن النصف الأيسر يهتم بالتعلم عن طريق الاستدلال المنطقى والتعلم عن طريق الفحص والتجريب (مراد، ؛99 19 1،

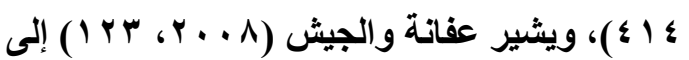
ضرورة أن تكون الأنشطة بيئة التعلم القائمة على السيادة المخية متنوعة تقوم على دراسة التشابهات والمتناقضات والتعلم التعاوني واستراتيجيات ما وراء المعرفة، كما يجب أن تنظم الأنشطة في ضوء

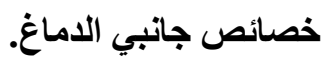
وهناك العديد من العوامل التي تؤدى إلى سيادة أحد النصفين على الآخر فمن أسباب سيادة أحد النصفين على الآخر محتوى المناهج التعليمية، بينما صممت الأساليب والمواد والممارسات التقليدية لتعزز نمط معين على نمط آخر، وأكد هذا ولهاب الاتجاه كونيل (Connell, 2002) حيث أكد على ضرورة إعادة النظر في تصميم التعلم، من أجل تصميم أنثطة تعليمية لصالح الأفراد الذين يستخدمون وظائف النصف الأيسر للمخ. لألك كان من الضرورى البحث في متغيرات توقيت تقديم الألعاب التعليمية الرقمية ثلاثية الأبعاد

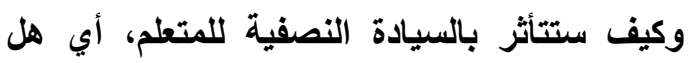


الجمعية المصرية لتكنولوجيا التعليم

الألعاب فبعض البحوث أثتبت فاعلية نمط الألعاب الرقمية التعليمية القبلية حيث تقدم لتقوم بدور المنظم التمهيدى (لينسيو Ming Lynceo,2016 مينج ويو ولى \& \&u \& Li, 2014 ومولان Zakirova,\& Ganiev\& مولان 2015 Mullin, Becker,2017). والبعض الآخر أكد على فاعلية نمط الألعاب البعدية حيث تعرض الألعاب بعد دراسة المحتوى التعليمى (اندرى Andre, 2017 جينفر

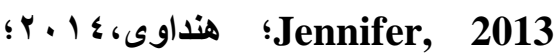
والقرنى،

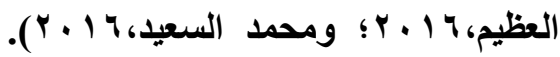
وصنف آخر من البحوث لم يجد فروقا بين النمطين لتحديد النمط الأفضل لتقديم الألعاب الرقمية التعليمية. ؛) تصنف الألعاب الرقمية التعليمية إلى عدة مستويات حسب البساطة والتعقيد فمنها الألعاب السطحية البسيطة ثنائية البعد، ومنها الألعاب ثلاثية الأبعاد، وقد أثبتت البحوث والاراسات أن الألعاب ثلاثية الأبعاد هي الأكثر فاعلية خاصة في تعلم المهارات (هاكن Haken et al, 2009 ولوكاس Lucas, et al, 2009 محمد

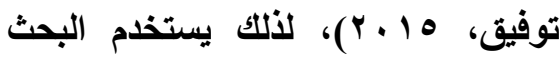
الحالي الألعاب الرقمية التعليمية ثلاثية
وفي هذا ترى البنائية الاجتماعية أن التعلم نشاط اجتماعي، حيث أن المتعلمين يجدون المعنى من الخبرات الفردية للمتعلم، ومن خلال التفاعلات الاجتماعية، ومن خلال عمل المتعلمين في فرق العمل التي تمكنهم من الاستفادة من معلومات وخبرات الآخرين. (عايش. V. V. . V) مشكلة البحث من العرض السابق بمقدمة البحث يتبين الآتى: 1) أن البحوث والدراسات السابقة قـ اتفقت على فاعلية استخدام الألعاب الرقمية التعليمية في التعلم، على كافة المستويات وفى مختلف الموضوعات مثل دراسات كل من (هاكن Haken et al. 2009 ولوكاس Lucas. et al, 2009 محمد

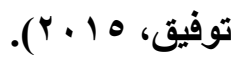
Y) ونظرا لاتفاق نتائج البحوث والدراسات

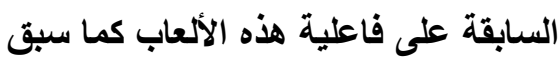
الأكر، فقد اتجه البحث نحو دراسة متغيرات تصميمها بهدف زيادة فاعليتها وتحسين جودتها، خاصة ما يناسب خصائص المتعلمين ونوعية المحتوى، ومن هذه المتغيرات، توقيت تقديم الألعاب الرقمية التعليمية، حيث يوجد نمطان لها لهان هما الألعاب القبلية، والألعاب البعدية. r) ولكن نتائج هذه البحوث قد اختلفت في تحديد التوقيت المناسب لاستخدام هذه 
وفى هذا الإطار يعد تحقيق أكبر فائدة

ممكنة من سعة بيئة الألعاب التعليمية الرقمية كأحد

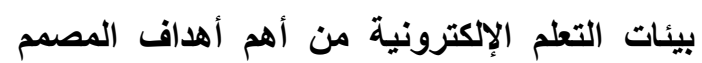

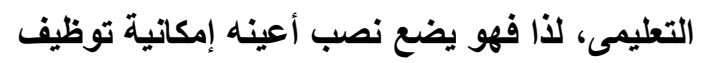
سعة هذه البيئات في تحقيق نواتج التعلم المختلفة،

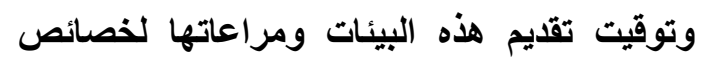
المتعلمين يعدان من الخصائص الأساسية التي تميز

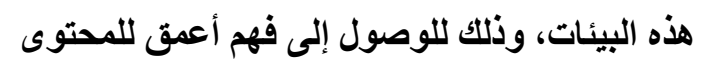
وتنمية المهارات بسهولة ويسر، وبذلك يوفر المصمم التعليمى أيسر الطرق التي يمكن إتاحتها

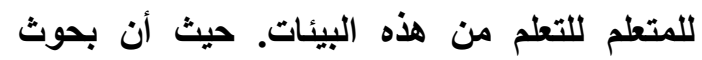
تكنولوجيا التعليم تهذف إلى حل المشكلات التعليمية، وتحسين الأداء والممارسات التكنولوجية

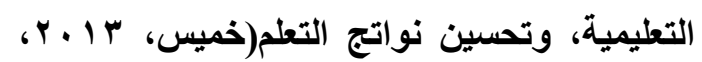

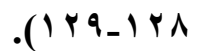

وعلى ضوء ما سبق يمكن تحليد مشكلة

البحث وصياغتها في العبارة التقريرية التالية:

توجد حاجة لاستخدام الألعاب الرقمية

التعليمية لتعلم مهارات إنتاج الصورة الرقمية بمقرر التصوير الرقمى وتحديد النمط الأنسب لتقديم هذه الألعاب القبلى والبعدى، في ضوء السيادة النصفية للمخ لاى طلاب تكنولوجيا التعليم.

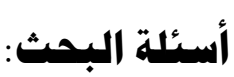

ويمكن صياغة أسئلة البحث فيما يلى:

ا. ما مهارات إنتاج الصورة الرقمية اللازمة لطلاب تكنولوجيا التعليم في مقرر التصوير

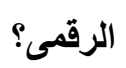

الأبعاد في تعلم مهارات إنتاج الصورة الرقمية لطلاب تكنولوجيا التعليم. ه) ومن خلال المقابلات المقتنة مع طلاب تكنولوجيا التعليم، حول رأيهم فى العوائق والمشكلات التي تعترضهم عند ممارسة مهارات إنتاج الصورة الرقمية، أبدى الغالبية منهم عدم توفر الوقت الكافى الهورة الوفيه بالمحاضرات العملية لممارسة المهارات المرتبطة، كما أن الأعداد الكبيرة لا تسمح للطلاب بالتعامل مع الكاميرات المتوفرة بالمعمل، أو معالجة الصور باستخدام برنامج (Photoshop)، كما أبدى نسبة كبيرة منهم رغبتهم في ممارسة الألعاب

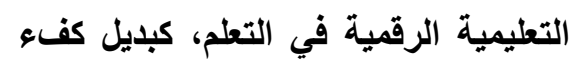
لتعلم تلك المهارات العملية بجانبيها

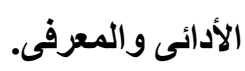

كما أن المقررات المرتبطة بتكنولوجيا التعليم يغلب عليها الجانب التطبيقى وتحتاج إلى

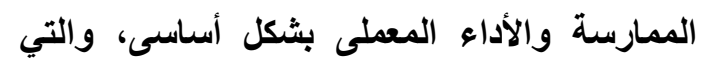
منها مقرر التصوير الرقمى، لذلك لاحظ الباحث

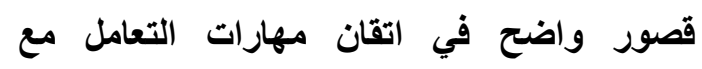

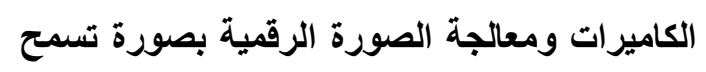
بإنتاج صورة رقمية ذات جودة عالية، كما أن اختلاف طبيعة المتعلمين وتباينهم في تفسير المواقف والأنثطة المختلفة دفع الباحث للبحث في تأثير بعض نتائج المخ ودلالاتها عند تقديم الأنشطة بيئة الألعاب ثلاثية الأبعاد. 
r- أنسب نمط لتوقيت تقديم الألعاب التعليمية

الرقمية (قبلى مقابل بعدى) بدلالة تأثيره

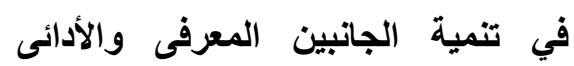

لمهارات إنتاج الصورة الرقمية.

؟- أنسب نمط سائد لاى المتعلم (أيمن- أيسر-

متكامل) بدلالة تأثيره في تنمية الجانبين

المعرفى والأدائى لمهارات إنتاج الصورة

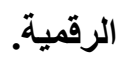

هـ أنسب نمط لتوقيت تقديم الألعاب التعليمية

الرقمية (قبلى - بعدى) في إطار تفاعله

مع النمط السائد لاى المتعلم (أيمن- أيسر-

متكامل) بلالائة تأثيرهما في تنمية الجانبين

المعرفى والأدائى لمهارات إنتاج الصورة

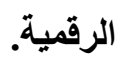

\section{أهميهة البمث:}

تتضح أهمية البحث الحالى فيما يلى:

ا ـ قد يساعد هذا البحث فى معرفة اختيار أفضل

طرق تقديم الألعاب التعليمية الرقمية فى ضوء

السيادة النصفية للمخ لطلاب تكنولوجيا

التعليم.

r- يوجه نظر مصمى برامج الألعاب التعليمية الرقمية ثلاثية الأبعاد إلى أهمية دمج النظريات التربوية عند تصميم بيئات التعلم الرقمية وذلك لزيادة فعالية وكفاءة هذه البيئات. r- قـ تسهم نتائج البحث في تبنى المؤسسات التعليمية استراتيجيات وأنماط وأدوات جليدة لهية لتصميم بيئات الألعاب الرقمية كأحد بيئات r. ما معايير تصميم بيئة الألعاب الرقمية ثلاثية

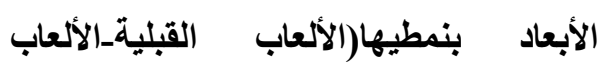
(البعدية)؟

r. ما مأثر توقيت تقديم الألعاب التعليمية الرقمية

ثلاثية الأبعاد (قبلى - بعدى) فى ثلى تنمية

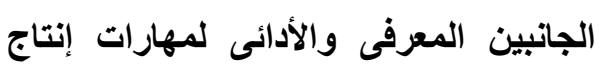

الصورة الرقمية لطلاب تكنولوجيا التعليم؟

؛. . ما أثر السيادة النصفية للمخ (أيمن -أيسر -

متكامل) لطلاب تكنولوجيا التعليم فى تنمية

الجانبين المعرفى والأدائى لمهارات إنتاج

الصورة الرقمية لطلاب تكنولوجيا التطليم؟ •. ما أثر التفاعل بين توقيت تقديم الألعاب

التعليمية الرقمية ثلاثية الأبعاد (قبلى-بعدى)

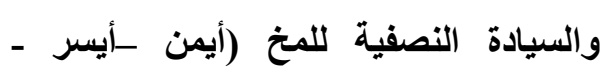

متكامل) فى تنمية الجانبين المعرفى والأدائى

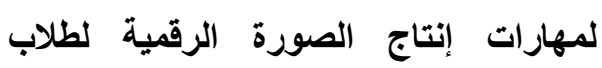

تكنولوجيا التعليم؟

يهدف البحث الحالى إلى تحديد:

1- المهارات الأساسية لإنتاج الصورة

الرقمية لطلاب تكنولوجيا التعليم بمقرر

$$
\text { التصوير الضوئى. }
$$

r- قائمة بمعايير تصميم بيئة الألعاب

التعليمية الرقمية ثلاثية الأبعاد بنمطيها

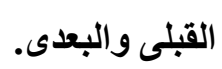


المعالجات التجريبية باستخدام نموذج خميس

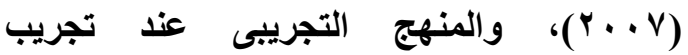
المعالجات وقياس أثر المتغير المستقل والمتغير التصنيفى على المتغير التابع.

\section{متغيرات البحث: - مت}

1ـ المتغير المستقل: ويشتمل البحث الحالى على متغير مستقل بنمطين: (الألعاب القبلية_الألعاب

$$
\text { (البعدية). }
$$

r- المتفير التصنيفى: الطلاب ذذى السيادة النصفية بأنماط: (الأيمن، الأيسر، المتكامل).

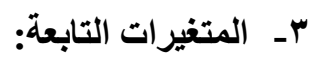

- التحصيل المرتبط بالجاتب المعرفى لمهارات إنتاج الصورة الرقمية باستخدام اختبار

$$
\text { تحصيلى. }
$$

ـ معدل الأداء المهارى لمهارات إنتاج الصورة الرقمية مقاسا باستخدام بطاقة ملاحظة الأداء.

\section{التصشيم التجريبى للبحث:}

فــي ضــوء المتغيـر المسـتقل والمتغيـر

التصنيفى للبحث، تـم استخذام التصـيم التجريبى

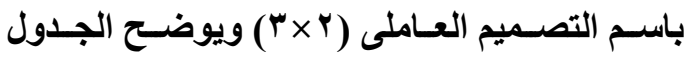

$$
\text { التالى التصميم التجريبى للبحث الحالي. }
$$

التعلم الإكترونية، سعيا للارتقاء بمستوى

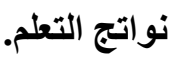

ع- قد تفيد نتائج هذا البحث في تقديم بعض الأسس والمبادئ العلمية المقنتة في تصميم بيئات الألعاب الرقمية للمقررات التي تثضمن جانبين معرفى وأدائى، كما قد تزود مصمىى ومطورى هذه البيئات بمجموعة من الأسس والمبادئ العلمية عند تصميم هذه البيئات.

يقتصر البحث الحالى على الحدود التالية :

1- حدود بثرية: طلاب تكنولوجيا التعليم

بالفرقة الثالثة بكلية التربية النوعية جامعة أسوان. r- حدود موضوعية: الجوانب المعرفية والأدائية لمهارات إنتاج الصورة الرقمية. r- حدود زمنية: تم تطبيق تجربة البحث في الفصل الاراسى الثانى للعام الاراسى $. r+19 / 4 \cdot 10$

\section{هنهج البحث والتصسيم التجريبى له:}

ينتمى هذا البحث إلى فئة البحوث

التطويرية التي تستخدم بعض مناهج الدراسات الوصفية (المسح الوصفى وتحليل النظم) في مرحلة الدراسة والتحليل وأسلوب المنظومات في تصميم 
الجمعية المصرية لتكنولوجيا التعليم

جدول (1) التصميم التجريبى للبحث (التصميم العاملى r × r)

\begin{tabular}{|c|c|c|c|}
\hline السيادة النصفية & 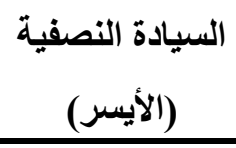 & 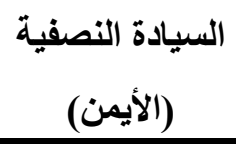 & نمط السب \\
\hline مجr & مجr & مجا & الألعاب القبلية \\
\hline مجף & مجه & مج؛ & الألعاب البعدية \\
\hline
\end{tabular}

فيما يلى الخطوات التى تم اتباعها لتحقيق

$$
\text { أهداف البحث: }
$$

-

والدراسات والبحوث السابقة وثيقة الصلة بموضوع البحث ومتغيراته لإعداد الإطار النظرى له، والاستدلال بها في توجيه فروض

$$
\text { البحث. }
$$

- تحليل الأهداف العامة والإجرائية للجاتب

التطبيقى لمهارات إنتاج الصورة الرقمية وعرضها على المحكمين ثم إعادة صياغتها

بعد إجراء التعديلات اللازمة وإجازتها. إعداد قائمة بمهارات إنتاج الصورة الرقمية وفقا لمقرر التصوير الضوئى للفرقة الثالثة شعبة تكنولوجيا التعليم.

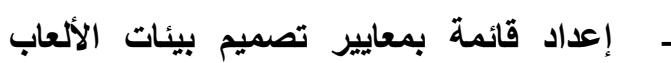
التعليمية الرقمية ثلاثية الأبعاد. - تحليل للاراسات والبحوث الخاصة بتصميم بيئة الألعاب الرقمية ثلاثية الأبعاد، وإعداد قائمة بمعايير تصميم بيئة الألعاب التعليمية

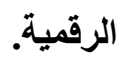

تم استخدام تحليل التباين في اتجاه واحد "one way Analysis of variance" من تكافؤ المجموعات التجريبية الست، فيما يتعلق بالتحصيل المرتبط بالجانب المعرفى للمهارة

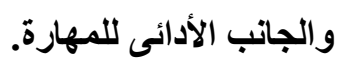

تم استخدام تحليل التباين ثنائى الاتجاه

"two way Analysis of variance" (ANOVA) المستقل والتصنيفى للبحث فيما يتعلق بتأثيرهما على المتغيرات التابعة للبحث في ضوء التصميم

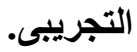

$$
\text { أدوات القياس: }
$$

تمثلت أدوات البحث الحالى فى الأدوات التالية:

$$
\text { • مقياس تورانس للسيادة النصفية المعدل. }
$$

• اختبار تحصيلى موضوعى إلكترونى (لفظى)

$$
\text { مصور). (من إعداد الباحثين) }
$$

• بطاقة ملاحظة الأداء العملى مهارات إنتاج

$$
\text { الصورة الرقمية. (من إعداد الباحثين) }
$$


اليسرى، مجموعة الألعاب القبلية ذ ذوى السيادة المتكاملة، مجموعة الألعاب البعدية ذوى السيادة اليمنى، مجموعة الألعاب البعدية ذوى السيادة اليسرى، مجموعة الألعاب

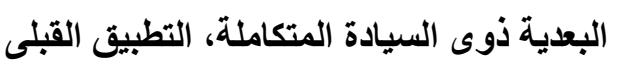

$$
\text { لأدوات البحث على المجموعات. }
$$

تطبيق الاختبار التحصيلى؛ وبطاقة ملاحظة الأداء قبليا بهدف التأكد من عدمبام إلمام المجموعات التجريبية للجوانب المعرفية

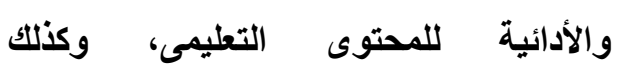
لاستخدامه في التأكد من تكافؤ مجموعات

$$
\text { البحث. }
$$

- عرض المعالجات التجريبية على عينة البحث

الأساسية، وفقا للخطة الزمنية الموضوعة.

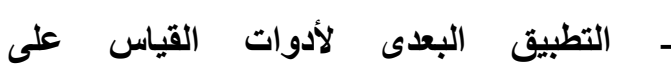
المجموعات الست.

- رصد نتائج التجريب ومعالجتها إحصائيا ومناقشتها وتفسير ها. - تقديم التوصيات والبحوث المقترحة.

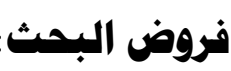

ا- لا توجد فروق ذات دلالة إحصائية عند مستوى 0,05 بين متوسطات درجات المجموعتين التجريبيتين فى الاختبار التحصيلى للجانب المعرفى لمهارات إنتاج

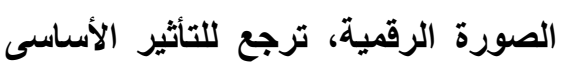
لاختلاف توقيت تقديم الألعاب التعليمية الرقمية ثلاثية الأبعاد (قبلى - بعدى).
- - إعداد أدوات القياس المتمثلة فى: مقياس تورانس للسيادة النصفية المعدل، الاختبار التحصيلى للجاتب المعرفى لمهارات إنتاج الصورة الرقمية، بطاقة ملاحظة أداء المهارة، بطاقة تقييم منتج. - تصميم السيناريو المثترك لبيئة الألعاب الرقمية وفقا للتصميم التجريبى للبحث وتحكيمه ووضعه في صورته النهائية.

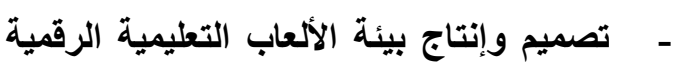
ثلاثية الأبعاد لمهارات إنتاج الصورة الرقية لئية وفقا لنموذج تصميم (خميس، V. . . Y). - خبراء في تكنولوجيا التعليم لإجازتها ثم إعداد

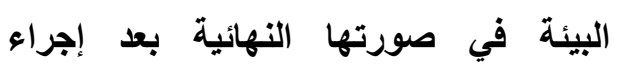

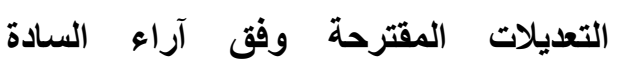
المحكمين. - إجراء التجربة الاستطلاعية لاستكمال ضبط أدوات البحث، وتقويم تصميم الألعاب التعليمية لالجية الرقمية ثلاثية الأبعاد، وتحديد الخطة الزمنية

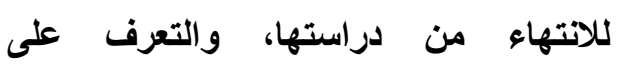
الصعوبات التى قد تحدث أثناء التطبيق وإجراء التعديلات اللازمة. - اختيار عينة البحث الأساسية وتقسيمهم إلى إلى ست مجموعات تجريبية بناء على نتائجهم فى ولى مقياس تورانس للسيادة النصفية المعدل وذلك كالتالى: مجموعة الألعاب القبلية ذوى السيادة اليمنى، مجموعة الألعاب القبلية ذوى السيادة 
لتأثير السيادة النصفية للمخ (أيمن- أيسرمتكامل) بمجموعات التعلم.

\- توجد فروق ذات دلالة إحصائية عند

مستوى 0,05 بين متوسطات درجات

المجموعات التجريبية فى معدل أداء

مهارات إنتاج الصورة الرقمية، ترجع

للتأثير الأساسى للتفاعل بين توقيت تقديم

الألعاب التعليمية الرقمية ثلاثية الأبعاد

(قبلى- بعدى)، والسيادة النصفية للمخ

(أيمن- أيسر- متكامل) للطلاب.

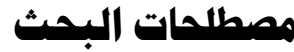

اللعبة التعليمية الرقمية ثلاثية الأبعاد:

هى بيئة رقمية تفاعلية تستند إلى

مجموعة من القواعد والقيود، موجهة نحو هدف

واضح والذى غالبا ما يكون تحديا ويمد بتغذية راجعة فورية من خلال تجميع الارجات أو التغير في عالم اللعبة، للسماح للاعبين بمراقبة تقدمه نحو

الهُف(Douglas, 2016)

وتعرف إجرائيا بأنها: بيئة تعليمية

تنافسية تفاعلية تحفيزية تعرض رسوميا بالأبعاد

الثلاثة (الارتفاع والعرض والعمق)، وتمكن من

استكشاف مهارات إنتاج الصورة الرقمية مع تمثيل أكثر للواقعية لتنمية كل من الجانب المعرفى والأدائى لمهارات إنتاج الصورة الرقمية لطلاب

تكنولوجيا التعليم. r- توجد فروق ذات دلالة إحصائية عند

مستوى 0,05 بين متوسطات درجات

المجموعات التجريبية فى الاختبار

التحصيلى للجانب المعرفى لمهارات إنتاج

الصورة الرقمية، ترجع لتأثير السيادة

النصفية للمخ (أيمن- أيسر- متكامل)

بمجموعات التعلم.

r- توجد فروق ذات دلالة إحصائية عند

مستوى 0,05 بين متوسطات درجات

المجموعات التجريبية فى الاختبار

التحصيلى للجانب المعرفى لمهارات إنتاج

الصورة الرقمية، ترجع للتأثير الأساسى

للتفاعل بين توقيت تقديم الألعاب التعليمية

الرقمية ثلاثية الأبعاد (قبلى- بعدى)،

والسيادة النصفية للمخ (أيمن- أيسر-

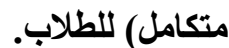

ع- لا توجد فروق ذات دلالة إحصائية عند

مستوى 0,05 بين متوسطات درجات

المجموعتين التجريبيتين فى معدل أداء

مهارات إنتاج الصورة الرقمية، ترجع

للتأثير الأساسى لاختلاف توقيت تقديم

الألعاب التعليمية الرقمية ثلاثية الأبعاد

$$
\text { (قبلى - بعدى). }
$$

هـ توجد فروق ذات دلالة إحصائية عند

مستوى 0,05 بين متوسطات درجات

المجموعات التجريبية فى معدل أداء

مهارات إنتاج الصورة الرقمية، ترجع 


$$
\text { بحوث المخ }
$$

هي نثاط المراكز العصبية بأحد النصفين وتأثيرها فى سلوك الفرد عن النصف الآخر، وقد يسيطر أحدها على سلوك الفرد. (الحازمى، Y . . . T)، كما تعرف بأنها الجنبية، بمعنى أن وظيفة معينة نتمركز فى جاتب معين من نصف الاماغ، وهى تتأثر بعوامل بيئية ومحددات جينية، مثل هيل هئ الجنس، وهو مفهوم نسبى وليس مطلقا. (عطال،

يعرفها الباحث إجرائيا بأنها: هي البحوث التي تفسر طبيعة عمل النصفين الكرويين للمخ وتعنى ميل الفرد أن يستخدم أحد النصفين الكرويين للمخ (الأيمن والأيسر) بقدر أكبر من الآخر أو لو كليهما معا (المتكامل) في العمليات العقلية والسلوك، وهذا يعكس أسلوب التفكير والأسلوب المعرفى للفرد وتفضيلاته واتجاهاته في حل

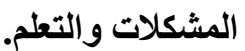

\section{الإطار النظرى لابمث:}

نظرا لأن البحث الحالى يهدف إلى قياس

أثر التفاعل بين توقيت تقديم الألعاب التعليمية الرقمية ثلاثية الأبعاد فى تنمية بعض مهارات إنتاج الصورة الرقية والسيادة النصفية للمخ ، لذلك سينقسم الإطار النظرى إلى مجموعة من المحاور هى، أولاً: مهارات إنتاج الصورة الرقمية، ثانياً: اللعبة التعليمية الرقمية ثلاثية الأبعاد، وتوقيت تقديمها، ثالثاً: السيادة النصفية للمخ، رابعاً: العلاقة
مهارات إنتاج الصورة الرقمية

هي المهارات المرتبطة بإنتاج الصورة مباشرة من خلال كاميرا رقمية أو لقطة فيلم فيديو، أو ماستح ضوئى، بجاتب مهارة إضافة العديد من المؤثرات الخاصة من خلال برامج الرسم، والطباعة على طابعة عادية، أو من خلال استديو تصوير، وتحميلها وعرضها على مواقع الإنترنت. Weboppidia Computer Dictionary, ) (2017

وتعرف إجرائيا في هذا البحث بأنها: قرةة المتعلم على تركيب وتثنيل الكاميرا الرقمية وإنتاج ومعالجة وتخزين ومشاركة وطباعة الصور الرقمية بهذف إنتاج صورة رقمية باستخدام كل من الكاميرا الرقمية وبرنامج "Photoshop". درجات الكسب في التحصيل المعرفى: يعرفها الباحث إجرائيا بأنها: درجات التحصيل التي يمكن الحصول عليها من خلال حساب الفرق بين كل من القياسين البعدى والقبلى للاختبار التحصيلى، وتعبر درجة الكسب عن من لئ

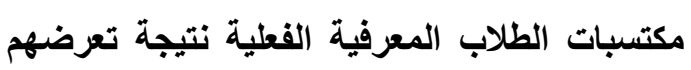
لبيئة الألعاب الرقمية.

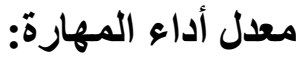
يعرفها الباحث إجرائيا: بأنه الارجة أو التقدير الذى يحصل عليه المتعلم عن أدائه الصحيح لخطوات المهارة مقسوما على الزمن الذى استغرقه في أداء هذه الخطوات. 


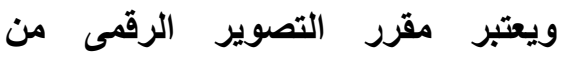

المنطلبات الأساسية لأخصائى تكنولوجيا التعليم، حيث يحتاج طبيعة التخصص الأكاديمى إلى توظيف الصورة الرقمية في مجال بناء البرامج التعليمية وبناء المواقع التعليمية على الإنترنت وبالتالي يواجه عقبات قوية في سوق العمل، حيث لا يتلاءم إعداد الطالب أكاديميا مع منطلبات سوق العمل ومع طبيعة العصر ولا يتلاعم مع متطلبات معايير الجودة الشاملة للمقررات الأكاديمية في الجامعة (مصطفى،

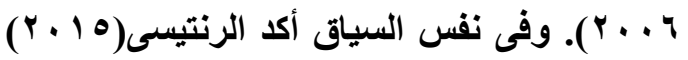
على أهمية تنمية مهارات إنتاج الصورة الرقمية، ومحاولة حوسبة مقرراتها والاعتماد على شبكات

التواصل الاجتماعى ومواقع الإنترنت في تنميتها. ومما يزيد من أهمية تنمية مهارات المتعلمين في مجال إنتاج الصورة الرقمية كونها تمكنهم من دمج الصورة الرقمية في أنشطة المناهج الار اسية، لزيادة الإتتاجية والتعلم، وكيف يمكن أن تساهم الكاميرات الرقمية في إثراء جوانب التعلم المتعددة لاى الطلاب، كما أوصى التقرير النهائي حول التدريس بالصورة الرقمية بأن التعليم بالصورة الرقمية مهارة يجب أن تتعلم من قبل المعلمين والمتخصصين في مجال تكنولوجيا التعلي.

(Green, David, 2006: p.99)

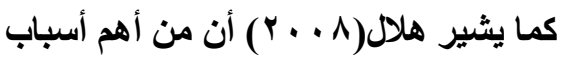

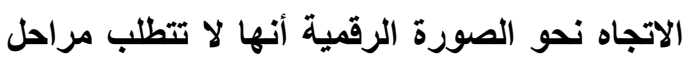
وسيطة للاستخذام الرقمى المباشر، كما يسهل عمل العديد من النست، ويسهل انتشارها إلى فئات كثيرة
بين توقيت تقديم اللعبة التعليمية الرقمية ومهارات إنتاج الصورة الرقمية والسيادة النصفية للمخ. أولاً: مهارات إنتاج الصورة الرقمية الصورة الرقمية هى شكل من أثكال التصوير الضوئى الذى يستخدم التكنولوجيا الرقمية لمعالجة الصور دون المعالجة الكيميائية، والصورة الرقمية يمكن معالجتها وتخزينها ومشاركتها

وطباعتها. وعرف قاموس الحاسب Webopedia الصورة الرقمية على أنها: "الصورة التي يمكن إنتاجها مباشرة من خلال كاميرا رقمية أو لقطة فيل فيديو، أو ماسح ضوئى لصورة تقليدية، ويضاف إلى الصورة الرقمية العديد من المؤثرات الخاصة من خلال برامج الرسم، كما يمكن طباعتها على

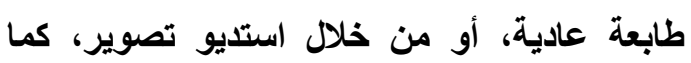
يمكن تحميلها وعرضها على مواقع الإنترنت. Weboppidia Computer Dictionary, ) 2017). كما تعرف الصورة الرقمية بأنها تمثيل بصرى أيقونى رقمى لأشياء أو أشخاص أو أحداث

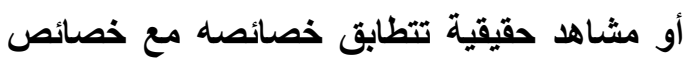

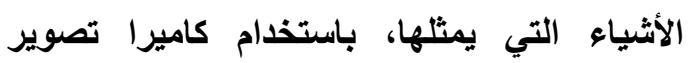
رقمية، أو ماسحات ضوئية أو لقطة شاثة، أو رسم حر باليد، على هيئة شبكة من النقاط (البكسلات)

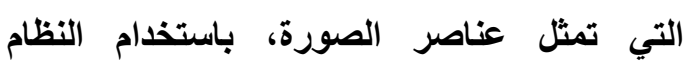
الثنائى، لتحقيق أهداف تعليمية محددة، وتوصف لهفي هذه الصور بالواقعية، لأنها تمثل واقعا طبقا للإدراك

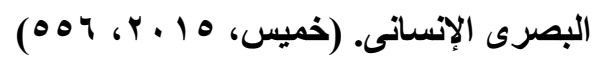


وللصسورة الرقميـة وظـائف واسـتخدامـات

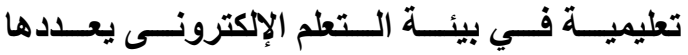

خميس(0 10 • (Y) في: جذب الانتباه والا(فعية، تصور

الأثياء والأحداث والأفكار، وصف الحركة وتثبيتها،

تحسـين المهــارات وتقويــة المفـردات والتعبيـرات

اللغوية، اكتساب المعارف الإجرائية، دعم التفاعلية

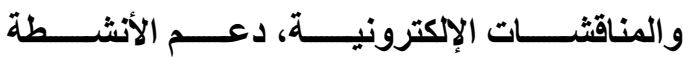

والمشروعات التعليميـة والعمـل في فريـق، تحقيق

التعلم الحقيقى، التقويم والاختبارات، تنمية مهار ات

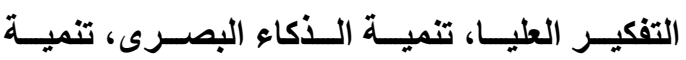

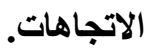

معايير إنتاج الصورة الرقمية

للصورة الرقمية معايير يجب تحقيقها إذا

أردنـا الحصـول على صسور رقميـة تعليميـة هادفة، وهى: أن تستخدم لتحقيق وظـائف تعليميـة محددة، وأن تكـون مطابقة للمحتوى النصسى وتلدعـه، وأن تكون مناسبة لقدرات المتعلمين، أن تقدم توضيحا ذاتيا للرسالة التعليمية، وأن تكون واضحة العناصر والمكونات وبمساحة مناسبة، أن تكون بسيطة قدر الإمكان، وأن تستخدم سلسلة من الصور والرسـوم البسـيطة بـدلا مـن صسورة واحدة معقدة، أن تقـدم الصــور معلومــات ومثيـرات جديــدة مــع مراعــاة التوازن بين الجدة والألفة، أن تثجع المتعلمين على التفاعـل الإيجـابـى، أن تعـرض بشــل متـزامن مـع النص المـرتبط بهـا، أن توضع في المكان المناسـب

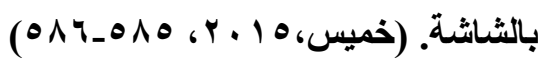

ومتنوعة من الجمهور، وتضفى قرا كبيرا من المصداقية على الموضوعات التي ت تتناولها، والمساهمة في تحقيق الأثز المرجو، وتثنوع الوسائط التي ترتبط بها مما يساهم في تحقيق معدل كبير من الوصول إلى الكثير من الفئـات.

ولا تكمن أهمية إنتاج الصورة الرقمية بثكل أساسي في شكلها الفني، بل في قرتها على تشكيل أفكارنا، والتأثير على سلوكنا، وتحديا مجتمعنا، فإنتاج الصورة الرقمية هو إعطاء الأهمية والتركيز (Share, 2015).

\section{وتتسم عمليات إنتاج الصورة الرقمية}

بالعديد من الخصائص والمميزات، فقد حدها كل من "كلارك وآخرون (Clark, et al,2000)؛ عفيفى(9 + . P) على النحو التالى: تتيح الكاميرات الرقية التصوير الفوري، بحيث تستخدم في لحظة التعلم، كما يمكن حذف الصور غير المرغوب فيها بكل سهولة، كما يمكن رؤية الصور قبل حفظها، سهولة معالجة الصورة الرقمية وإعادة تحريرها بإضافة مؤثزات رقمية عليها أو دمجها مع برامج الحاسب الأخرى، إمكانية التخزين بعدة طرق مختلفة كما في الذاكرة الاخلية للكاميرا أو وسائط التخزين المحمولة مثل الأكرة الخارجية أو القرص المرن أو الصلب أو بطاقات الفلاش المدمجة، أو بطاقات الوسائط المتعددة الأكية، كما تتمتع بانخفاض التكلفة حيث يمكن استثمارها في عملية التعليم لعدة سنوات، وتساهم الصورة الرقمية في تعزيز مفهوم تنشيط الأكرة (Supon,2006). 
هذه ينتج عنها أبنية عقلية تخضع لقوانين الإدراك وبصفة خاصة قانون التشابه والتماثل، ينتج عنها تكوين أشكال جليدة تكون أسهل للحفظ في الذاكرة نتيجة تحويلها إلى لغة رمزية، واللغة الرمزية تعني التواصل إلى معنى واحد متفق على دلالته في عملية الاتصال لاى أفراد المجموعة الواحدة. لذلك فإن تعلم مهارات قراءة الصور يحتاج إلى قدر أكبر من الاهتمام لأن جزءًا كبيرًا من عبء تعليم المعرفة يقع على وسائل الاتصال البصري غير اللغوي، وهناك العديد من المؤثرات المعرفية في ثقافة الصورة يمكن ذكرها على النحو

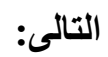

الذاكرة Memory : هي مخزن ربط الواقع بالصور المرئية مسبقاً، حيث استخدمت الصور كمعينات للأكرة. التوقع Expectation : فوجود توقعات حول مشاها معينة أو أحداث معينة يؤدي بالفرد إلى إدراكات بصرية زائفة أو مضللة أحياناً. الانتقائية Selectivity : كثير من عمليات الإدراك تكون غير واعية،والصور تدخل إلى العقل بطريقة تلقائية والاستدعاء يكون انتقائي. الإسقاط Projection الماضية والمعاني المدركة من الصور. التعود : Habituation يؤدي إلى النفور والملل والانتقائية إلى الحماية من ذلك وحماية للنشاط العقلي أيضا. السيادة : كلما زاد الدول المعنى Meaning للمثير البصري كلما تم إدراكه بسهولة. التنافر Dissonance : تعدد الرسائل
تمثيل الصورة الرقمية بالكمبيوتر :

يوجـــ نوعـان لتمثيـل الصــورة الرقميـة وعرضـها وحفظها بـالكمبيوتر همـا الصور النقطية

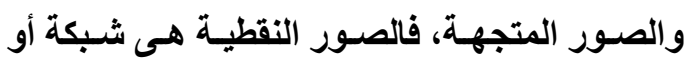
مصـفوفة مــن آلاف بــل ملايسيـين المربعــات أو البكسـلات، لتمثيـل الصـورة أو على هيئة خطوط متوازيـة، أمسا الصسور المتجهـة فتسـتخدم المتجهـات Vectors الأشكال الهندية المضلعة، لذلك فالصور المتجهة هى صور إلكترونية رقمية تستخدم التمثيل الخطى. وتحفظ ملفـات الصـور الرقميـة بتنسيقات

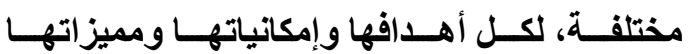
وعيوبهـا ومسن أهمهـا: تنسـيق JPEGJJPG،

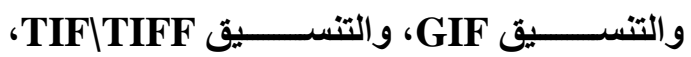
والتنسـيق RAW، والتتسـيق PNG، والتنسـيق BMP، والتتسـيق PSD. ويتوقـف اختيـار نـوع التسـيق المناسـب بنـاء على نـوع الضــط الخـاص

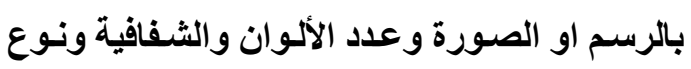

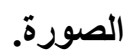

والاحتفاظ بالصورة واسترجاعها يتمثل في قرة الفرد على الترميزSymbol وذلك بتحويل الشيء المراد إلى رمز له معنى semantic وهذا ما يعرف باسم تمثيل المطومات داخلياً Information processing على الذاكرة والتذكر والاسترجاع وتخزين Storage بموضوع الصورة في الذاكرة وأن عملية التخزين 
وتوصيات البحوث التي تناولت تصميم مهارات إنتاج الصورة الرقمية والتي منها (دراسة حسين،

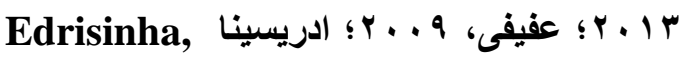

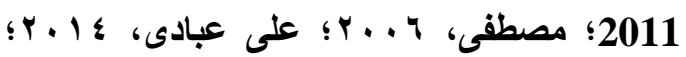

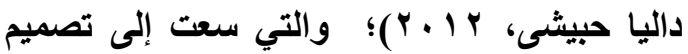
موديولات خاصة بتصميم مهارات إنتاج الصورة الرقمية وإعداد قائمة بمهاراته.

وقد تكونت القائمة من المحاور التالية: مهارات التعامل مع الكاميرا وتثغيلها، مهارات Adobe ) تحيل عناصر شاشة البرنامج Photoshop)، مهارات تحديد أبعاد التصميم وخصائصه، مهارات تصحيح ومعالجة الصور الرقمية باستخدام قائمة Image، مهارات استخدام التحديد فى الصور الرقمية، مهارات التحكم فى الطبقات وخصائصها، مهارات حفظ الصور الرقمية،

$$
\text { مهارات استخدام أدوات البرنامج. }
$$

ثانياً: اللعبة التعليمية الرقمية ثلاثية

$$
\text { الأبعاد وتوقيت تقديمها: }
$$

تعد الألعاب التعليمية الرقمية من أكثر الألعاب شيوعا فى هذا العصر، وتسمى بألعاب الكمبيوتز، وتتمثل فى عرض أحداث وأنثطة على الثاشة، وتمكن المتعلم من التحكم فى مجريات الأحداث فيها. تعريف اللعبة الرقمية ثلاثية الأبعاد: تعرف اللعبة الرقمية التعليمية بأنها بيئة رقمية تفاعلية تستتد إلى مجموعة من القواعد
البصرية يجذب العين والأنن والعقل، ويحوز الاهتمام خلال وقت واحد. الخبرة Experience تغطي جوانب عديدة منها التفاعل الاجتماعي وممارسة المعتقات والأعراف. وكلما زادت الحواس المشتركة في عملية الإدراك ازدادت إمكانات حدوث اتصال أكثر فعالية، وتعلم وتعليم أشد إيجابية ووضوحاً، كما تزداد إمكانية التذكر، " فالتعلم والتذكر كلاهما يعتمد بدرجة مباشرة على نوع مصادر الإدرالك الحسية وقوتها (محمد صالح : (0) $\leqslant r$. مهارات إنتاج الصورة الرقمية باستخدام برنامج Photoshop: اعتمد الباحثان فى اشتقاق قائمة مهارات

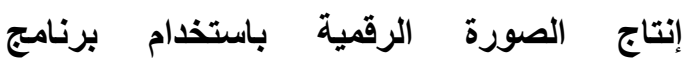
على تحليل الأدبيات والاراسات (Photoshop) ذات الصلة بالبحث الحالى والتى تناولت برنامج كبرنامج تطبيقى، مثل دراسة أكرم (Photoshop) عبد القادر (Y Y Y Y)، أحمد سعد عبد الهادى

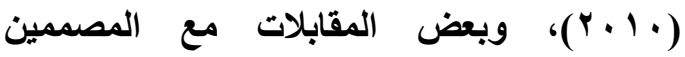
التعليميين الذين يعتمدون على برنامج (Photoshop)، ثم بناء قائمة بمهارات إنتاج الصورة الرقمية وصياغة بنودها من خلال المقابلات والأدبيات المرتبطة وروعى فيها الدقة والوضوح. وقد اعتمد الباحثان في إعداد قائمة مهارات إنتاج الصورة الرقمية على آراء الخبراء والمتخصصين في تكنولوجيا التعليم ونتائج 
والتعلق بالاخرين وتقليل مشاعر الوحدة أو الانعزالية(David, 2017 )، والألعاب الرقمية التعليمية هي بيئات يخلق من خلالها المتعلمون مشاكلهم الخاصة ويقومون بجمع المعلومات الضرورية لحل مشاكلهم ذاتيا والقيام بحلها، من خلال دمج أهداف التعلم مع الترفيه والتسلية في تعلم الموضوعات الأكاديمية، والتمركز حول المتعلم(Ebru, 2017 )، كما أنها شكل من أشكال التكنولوجيا، التي تساعد على تحسين الإدراك من خلال منصات التكنولوجيا المستخدمة التي تساعد على سهولة الاستغدام والقبول التكنولوجى.

(Walter, 2016)

كما يعرفها عزمى (10 ب (Y) بأنها أنثطة مزودة بمحتوى تعليمى فعال يستخدم الوسائل المتعددة التفاعلية فى ضوء معايير معينة لتحقيق أهداف محددة يتفاعل معها المتعلم وتقدم له تغذية راجعة وفقا لاستجابته. فى حين يرى أسامة عبد

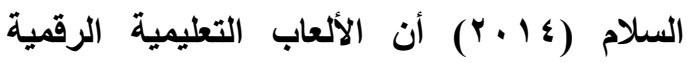
برمجية إلكترونية تثتمل على مجموعة من الأنشطة التعليمية (الفردية أو الجماعية) المطروحة من خلال مواقف مخططة تربويا وتقتيا، ويوظفها المطم بهدف تنمية المهارات والمعارف الخاصة بالمتطمين من خلال الكمبيوتر. ويلخص أبو خطوة

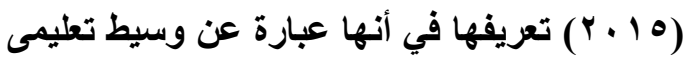
يعتمد على التسلية والترفيه، وهى نشاط موجه لتحقيق أهداف تعليمية ومحددة كما أنها تثير الخيال وتتحدى القدرات وتنمى التفكير وصولا للفوز
والقيود، موجهة نحو هدف واضح والذى غالبا ما يكون تحديا ويمد بتغذية راجعة فورية من خلال تجميع الدرجات أو التغير في عالم اللعبة، للسماح Douglas, للاعبين بمراقبة تقدمه نحو الههف 2016)، كما أنها بيئة تدمج المتعلمين في نثاط وتمكن المعلم من تعقب سلوكهم وأعمالهم ضمن هذا النشاط للتأكد من حدوث وتقييم التعلم، وتثجع من اللاعبين على الاستمرار لحل المشكلة عن طريق Rowe, تبنى مستويات عالية من التفكير والإبداع) 2016)، وتعرف اللعبة الرقمية التعليمية أيضا بأنها أي تزاوج بين المحتوى التعليمى وألعاب الكمبيوتر مع الأخذ في الاعتبار التثابه الكبير بين المفاهيم الخاصة، وهذه المصطلحات يجب أن تفهم كمرادف الف الفيار أو ملخص تحت مظلة مفهوم اللعبة الرقمية التعليمية(Matthias, 2017)، وهى بيئة تعلم يحدث بمساعدة اللعبة الرقمية. ويجب أن يتضمن تعلم بممارسة الألعاب كما أنه يتيح التعلم عبر بناء الألعاب باستخدام ألعاب كاملة وعادة ما يكون داخل سياق تعليمى كامل(Katrin, 2017 )، كما أن اللعبة الرقمية التعليمية لها القدرة على دعم المتعلمون البالغين للوصول إلى تعلم ذو معنى

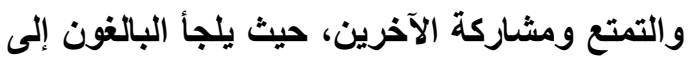
الألعاب الرقمية التعليمية لإشباع حاجات متنوعة؛ منها القدرة على التفاعل اجتماعيا مع الآخرين

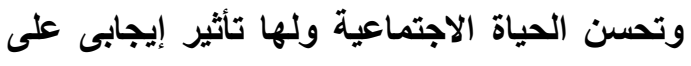
إحساس الأفراد بالتحسن، كما أنها تزيد من التواصل الاجتماعى بالآخرين والشعور بالانتماء 
فى أجوائها، وتتطلب منه اتخاذ قرارات متكررة وهامة، حيث لها أهداف محددة وتتكيف مع كل وتل لاعب على حدة، وتتميز عن الوسائل الأخرى من

أهمها:

1- الألعاب ممتعة ومرحة ومتحدية وتكافئ من

يقوم بها، وهى من عناصر هامة للتعلم، وطبقا

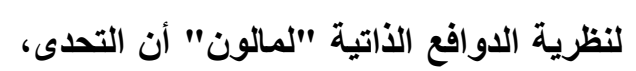

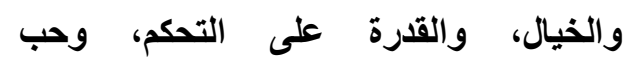

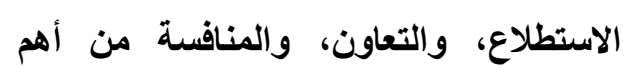
العناصر التى تجعل ممارسة تلك الألعاب ممتعة وتحفيزية وتعزز دوافع اللاعبين

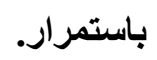
r- تعد الألعاب التعليمية الرقمية بيئة تعلم

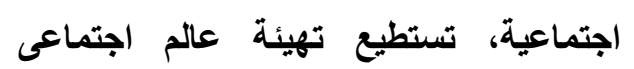
وثثافى أكثر يساعد على تعلم الأفراد من خلال دمج تفكيرهم وتفاعلاتهم الاجتماعية. r- الألعاب تجريبية بطبيعتها، فمن يمارس الاجئهاعله

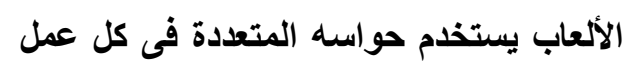

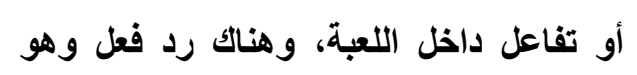

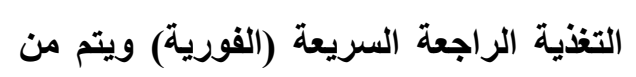
خلالها اختيار البدائل.

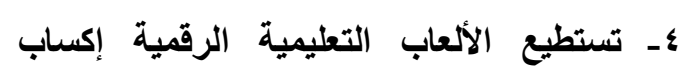
المتعمين العديد من المعارف والمهارات، والتشارك والاتصال مع لاعبين جدد داخل اللعبة أو خارجها، كما يقوم المتعلمون تحليل المعلومات وتطبيق المعرفة و والمهارات لصياغة استراتيجيات وصنع القرارات ومن ثم وانميت دراسة النتائج.
باللعبة. ويعرفها خميس (11) بأبأنها نشاط تنافسى محكوم بقواعد معينة، بين فردين أو باته

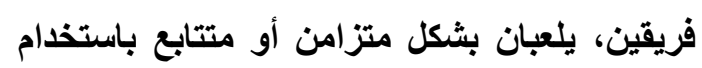
الكمبيوتر، أو بين المتعلم والكمبيوتر، أو بين بين المتعلم والبرنامج نفسه. وتتطلب أن يستجيب لها المتعلم استجابة صحيحة وموقوتة لتحقيق أهداف ولتئن تعليمية معينة. مميزات اللعبة التعليمية الرقمية:

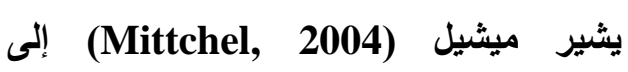
مميزات الألعاب الإكترونية ثلاثية الأبعاد والتي منها: تحسن نواتج التعلم، وتزيد ثقة المتعلم بنفسه، وتقلل من وقت التعلم وعبئه وذلك من خلال توفير فرص أكثر على التدريب والممارسة، كما تساعد على تصوير الواقع بشكل جيد من خلال ما تثمل عليه من وسائط جيدة، فضلا عن أنها تحسن من قدرة المتعلمين على التعلم، وتستخدم لتقوية العلاقات الاجتماعية من خلال توفير بيئة محاكاة تفاعلية مع لاعبين آخرين.

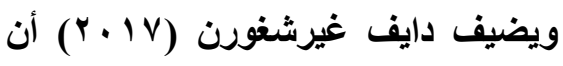
ألعاب القيديو ثلاثية الأبعاد، يمكن أن تحسن الأداء

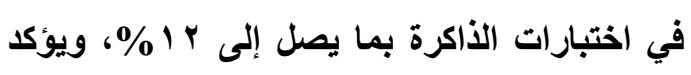
أن القدرة على حفظ وتذكر تفاصيل الأحداث تصبح أفضل بمجرد ممارسة إحدى ألعاب الفيديو ثثلاثية الأبعاد واستكثاف العالم الأى تحويه.

كما تتميز الألعاب التعليمية الرقمية بيناء بيئة تعلم فعالة، وذلك لأنها توفر انغماس اللاعبين 
التصنيف حسب الدور المطلوب من

اللاعب: وينقسم إلى ( ) ألعاب الحركة مثل ألعاب القتال أو المضرب والكرة، والمتاهات، ؟) ألعاب المبه

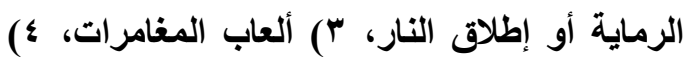
ألعاب الالغاز، ه)ألعاب تمثيل الأدوار، ج) ألعاب المحاكاة، V الألعاب الاستراتيجية. والتصنيف حسب الهُف منها ويندرج تحتها ( ) الألعاب

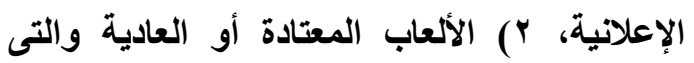
الغرض منها غالبا التسلية، ب) ألعاب التمارين الرياضية. والتصنيف حسب عدد اللاعبين، فقد تكون ألعاب فردية أو ثنائية أو جماعية. والتصنيف حسب درجة تعقدها فقد تكون ألعاب بسيطة ثنائية البعد أو معقدة ثلاثية الأبعاد.

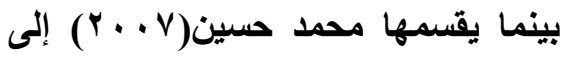

ألعاب تعليمية تعتمد على قصة أو شخصية كرتونية، و ألعاب فكرية (ملاحظة وتركيز) وتعمل هذه النوعية على تقوية الذاكرة والنشاط الذهنى، وألعاب تعتمد على استراتيجيات منظمة، وهى التى تحتاج إلى خطوات منظمة لتحقيق الأهداف المرجوة من اللعبة، كما تحتاج لنضج عقلى يتدرج بلرجة الصعوبة أثثاء أداء اللعبة.

ويمكن القول بأن البحث الحالي اعتمد

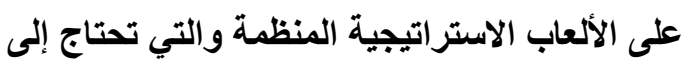
خطوات منظمة لتحقيق الأهداف الخاصة بها وهى الته تنمية مهارات إنتاج الصورة الرقمية، كما أنها ألعاب فردية من حيث عدد اللاعبين، حيث يتطلب تفاعل المتعلم مع بيئة اللعبة فقط.
0ـ تستطيع الألعاب تلبية احتياجات الجيل الجديد من المتعلمين، الذين أصبحوا متآلفين مع التكنولوجيا الرقمية منذ سن مبكر، وأصبحت لهن التكنولوجيا هى لغتهم يتواصلون من خلالها، ويعبرون عن أنفسهم وهم يلعبون، ويشاركون بحماس فى الألعاب عبر الإنترنت، وكذلك الاور الأى تلبعه الألعاب التعليمية الرقمية فى الإبري اكتساب المعرفة، وفى الفهم والتحليل والتركيب والاكتثاف وإصدار الأحكام وحل

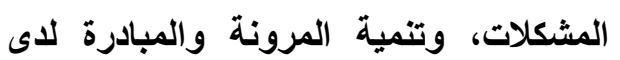
المتعمين من خلال التحرر من القيود

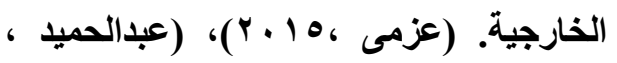

$$
(r \cdot . v
$$

وأشار عبد العال، الجباس، باخوم

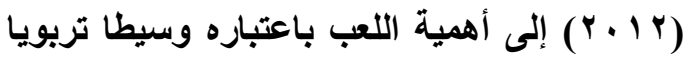
يعمل بدرجة كبيرة على تثكيل شخصية المتعلم بأبعاد ها المختلفة، حيث تؤدى الألعاب التربوية دورا فاعلا فى تنظيم التعلم واكتساب المعرفة والمهارات إذا أحسن تنظيمها والتخطيط لها والإشراف عليها. ويقتضى بناء النشاط وفقا لأسلوب التعلم باللعب. تصنيف اللعبة التعليمية الرقمية التعليمية: هناك تصنيفات عديدة للألعاب الرقمية، حيث يمكن أن تصنف بحسب الدور المطلوب من اللاعب، أو بحسب الهُف منها، أو بحسب عدد ان بلد

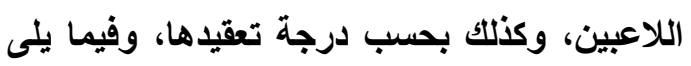
عرض مبسط لهذه التصنيفات: (عزمى، 10 م ب ) 
المعروفة، وهو الأمر الأى يسبب شعور

المتعلم بالغموض، ويولد الفضول لايه.

צ- استخلاص المعلومات: تتضمن اللعبة

جلسات تقييمية لاستخلاص المعلومات بعد

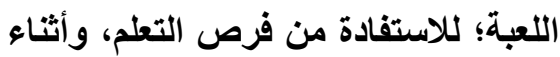

التقييم يقوم المتعلم والمعلم بالتناقش

وتبادل الحوار حول خبرات ونتائج اللعبة.

معايير تصميم اللعبة التعليمية الرقمية:

هناك مجموعة من المعايير عند تصميم اللعبة

التعليمية، لكى تحصل الفائدة التربوية، والتي منها:

ا- أن تكون اللعبة مسلية وممتعة وذات هدف

$$
\text { تعليمى. }
$$

r- أن تتوافق مع عدد المتعلمين سواء كانت

$$
\text { فردية أو جماعية. }
$$

r- أن ت تتناسب مع المستوى المعرفى

$$
\text { والعمرى والجسدى للمتعلمين. }
$$

ـ ـ أن تكون قابلة للقياس، أن تكون ذات طابع

منطقى، أن تعثمد على حسن التفكير

$$
\text { وليس الحظ. }
$$

هـ أن تجمع بين الدقة العلمية والجمال القني. ج- أن يتم اختيار اللعبة على أساس فائدتها

التعليمية وإمكانية تطبيقها.(عبد السميع،

( $r .19$

كما يجب أن يتمركز محتواها حول

اهتمامات المتعلمين وميولهم، وتثبع حاجاتهر

ومطالبهم البيولوجية والنفسية، ويكون أنشطتها
عناصر اللعبة التعليمية الرقمية:

كما أن هناك عناصر يجب توافرها

في الألعاب التعليمية الرقمية نظراً لاستغنائها عن لهن

دور المعلم في الغالب، ومن هذه العناصر

(Moreno, et al., 2008) (فوزى، محمد.

$$
:(r+19,1)
$$

1- المثيرات والاستجابة الإيجابية: وهو أن

الموقف التعليمي في اللعبة الرقمية التي

تُعرض على المتعلم يُعد مثيراً ويتطلب

استجابة إيجابية حتى ينتقل إلى خطوة

جليدة.

r- التفذية الراجعة والتعزيز الفوري: بما أن

المتعلم يكون قد استجاب للمثير، لذلك فإن

اللعبة التعليمية تعرض له التتيجة الفورية

وتكون بمثابة التعزيز للمتعلم الذي يدفعه لهيه

لمواصلة اللعب.

r- الصراع: يواجه المتعلم أثناء ممارسة

اللعبة مشكلات قابلة للحل، ويتم الصراع

من قبل اللعبة ذاتها (مثل الألغاز) أو من ولن الهند

خلال المتعلمين الأخرين.

ع- التحكم: تسمح اللعبة للمتعلم باتخاذ

مجموعة من القرارات والخيارات أثناء

القيلم بمعالجة نشطة ومباشرة لبعض ماتس

جوانب اللعبة، ومن أجل تحقيق السيطرة

$$
\text { على اللعبة. }
$$

هـ الغموض: أي الفجوة بين المعلومات

المتاحة في اللعبة والمعلومات غير الير 
الجمعية المصرية لتكنولوجيا التعليم

- - التخل من قبل المتعلم بشكل يتسم

بالحساسية والمعرفة والتوجيه.

- التخطيط السليم وتنظيم بيئات اللعب لإتاحة

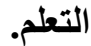

- - - إتاحة الوقت الكافى للمتعلمين لتطوير

لعبهم، والملاحظة الدقيقة لأنشطة

المتعلمين لتسهيل عملية التقييم والتخطيط

من أجل التقدم والاستمرارية.

-

حيث يجب أن تراعي أنماط التعلم المختلفة

للطلاب، واختلاف معلوماتهم السابقة،

واختلاف توقعاتهم وأهدافهم. (نيفيل بينت،

$$
\text { تصميم اللعبة الرقمية: }
$$

ويتم تصميم الألعاب التعليمية الرقمية إما باستخدام التصميم ثنائى الأبعاد 2D أو التصميم ثلاثى الأبعاد 3D عند إنتاجها، وانتثر التصميم ثلاثى الأبعاد حيث أصبحت الرسوم ثلاثية الأبعاد من أهم المجالات التى تتمتع بخصوصية وتميز واضحين بين مصممى الألعاب التعليمية الرقمية وخصوصا ألعاب Second Life. وهذا المجال يتضمن الدراسات والتقنيات والأساليب والبرمجيات التى تهتم بتوليد وبناء وتعديل ومعالجة وعرض الأجسام والأثياء ثلاثية الأبعاد من خلال وسائط تتجمع فيها النقاط لتضيف خاصية العمق. وعندما تتجمع العديد من النقاط ثلاثية الأبعاد، بحيث يحمل كل منها قيمة عمقه الخاصة، تكون النتيجة ظهور
جديدة ومبتكرة، وتؤكد على تعلم المفاهيم والمهارات القبلية قبل تعلم الجديد، وتعرض بطريقة شيقة وتستخدم الأسئلة والأمثلة المحاكاة والدعابة، كما لابد أن تقدم التغذية الراجعة مباشرة لزيادة الدافعية، وتتبه المتعلم لخطئه وتوجهه إلى الطريقة الصحيحة، مستخدمة المثيرات البصرية كالصور والأثكال والرسوم، وتكون تفاصيلها قليلة حت لا لهابه تثتت انتباه المتعلمين ومعبرة عن فكرة واحدة غير متثعبة، محتوية على خاصية الأصوات في عملها ومشاهدة البيئة المحيطة، تكون سهلة الاستخدام من حيث تثغيلها والاخول والخروج منها، والتعامل

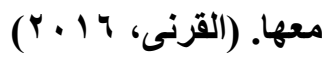

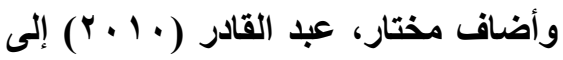
ضرورة احتواء اللعبة بعض الألغاز والحيل من خلال ألعاب الواقع الافتراضى، والتى تزود المتعلمين بفرص ثرية للتعلم، ومن خلال هذه الألغاز يظور مهارات حل المشكلة والمهارات المكانية، ويشجع المتعلمين على الفضول والاستكشاف. وتضيف الغوالبى(r I • Y) مجموعة من الأسس التربوية للألعاب (الإيجابية والتفاعل، الإدارة والتوجيه، رفع مستوى الدافعية، التنظيم، تقويم الذات، تمثيل الواقع، العمل فى فريق، رئ، التساؤال وفرض الفروض، لعب الأدوار). ويصرح تقرير "رامبولد" بأنه من أجل إدراك القيمة المحتملة للألعاب، يجب تحقيق بعض لهربئ

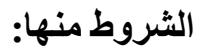


(Hainey, 2015 )، لذلك سعى البحث الحالي إلى (لقى وضع نوع من التحدى عند تصميم الألعاب التعليمية، حيث تم عرض أجزاء مختلفة للكاميرا في اللعبة الأولى وطلب من المتطم اختيار وتجميع الأجزاء الصحيحة لتكوين الكاميرا، ونفس المنوال مع باقى الألعاب، مع وجود تغذية راجعة مناسبة عند اختيار كل جزء صحيح، وإعطاء درجات لكل خطوة صحيحة يقوم بها المتعلم داخل اللعبة. محددات استخدام اللعبة التعليمية الرقمية: على الرغم من الأهمية المتزايدة للألعاب التعليمية الرقمية، إلا أنه ينتج عند استخد/مها بعض السلوكيات السلبية مثل الغش والإزعاج والصراع أو الاهتمام باللعبة وعدم الانتباه للهدف التعليمى لها، لذلك يجب مراعاة الأمور التالية: يجب أن لا لا لهابل يتحول استخدام الألعاب إلى نثاط ترويحى أو ترفيهى فقط، يجب أن لا تتحول اللعبة إلى فوز وخسارة فقط، يجب أن تتوافق اللعبة مع القيم السائدة بالمجتمع، يجب أن توضح التعليمات أن الألعاب التعليمية عبارة عن أنثطة هادفة، لذلك لوناب فالمهم هو تحقيق الأهداف وليس الاهتمام باللعبة

$$
\text { فقط. (العبسى، } 9 \text {. . P ) }
$$

توقيث تقديم اللعبة التعليمية الرقمية: يهتم البحث الحالى بنمط توقيت تقديم الألعاب القبلى والبعدى والتي عبر عنها جابر

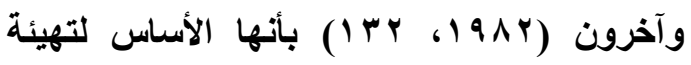
المتعلمين، حيث حدد تلك التهيئة إلى التهيئة
سطح ثلاثى الأبعاد، بل وتضاف لهذا السطح الناشئ العديد من الخواص الإضافية مثل الظل والملمس لابعال بلص (Mautone, et al., 2005) ويبدأ التصميم ثُلاثى الأبعاد فى الألعاب التعليمية الرقمية بيناء نموذج مشابه تماما للواقع ويكون ذللك باستخدام برامج متخصصة لتكوين النموذج الرقمى ويتم تزويده بالعمليات المطلوية والتى تجعله يشبه الواقع تماما، ويتعلم المتعلمون من خلال تفاعلاتهم مع الألعاب أو مع الآخرين،

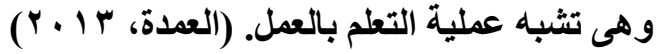
بل إن تاريخ دراسات المحاكاة قدم المعرفة التي قد تسهم في تصميم ألعاب التعلم ثُلاثية الأبعاد، فقد

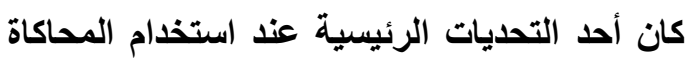
هو كيفية توليد فهم متعمق للمحتوى، ويدون التفاعل الصحيح بين المتعلمين، قد تظل الإمكانيات الكاملة للمحاكاة، مثل مدى ملاعمتها لممارسة لهنة مهارات الاستقصاء بعيدة المنال، وفي ضوء هذه التحديات، يصبح من الضروري الاهتمام بكيفية تصميم بيئات الألعاب ثلاثية الأبعاد لتعميق فهر التهري Hamalainen, \& ) المتعلمين للمحتوى. (Oksanen. 2014 وعند تصميم لعبة تعليمية من الضرورى النظر في كيف يتم التعلم دون فقدان المتعة كجزء من اللعبة، حتى يمكن الحفاظ على دافعية المتعلمين، ولحدوث ذلك يجب دمج المادة التعليمية مع اللعبة حتى تصبح المادة التعليمية جزء من Soflano, Thomas, ) التحدى داخل اللعبة. 
( ) تقديم المنظم المتقدم بعد توضيح

الأهداف، وقث يكون هذا المتقدم على شكل لعبة تربوية أو أي وسيلة أخرى، أو على شكل

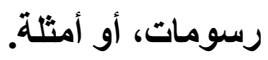

r ت تقايم الموضوع الجديد من خلال

ترتيب الأفكار وتوضيجها في أثناء التقديم وهنا قد

تلخل الألعاب التعليمية كوسائل تعليمية مع ولئ المحافظة على استمرارية انتباه المتعلمين. r) تقوية النسق أو النظام المعرفى من خلال ربط المادة الجديدة بالمادة السابقة لاى المتطلم، وهنا قد يستخدم المعلم الألعاب التطليمية كأحد البدائل المتاحة. لذلك يرى اوزوبل إن أهم عامل يؤثز في التعلم هو ما يعرفه المتعلم من قبل،

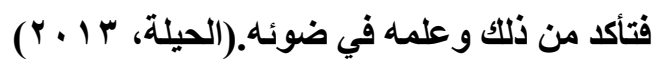

$$
\text { الألعاب القبلية: }
$$

يُستمد الأساس النظرى لتوقيت تقديم الألعاب

قبليا من خلال نظرية المنظمات التمهيدية Advanced Organizers أوزبل، حيث أن فكرة المنظم التمهيدى تقوم على توفير بناء عقلى ذو دلالة للمتعلم قبل بدء عملية التعلم، مع مراعاة ملائمة هذه المعلومات الجديدة لبنيته المعرفية، كما أن هناك من وظائف المنظم التمهيدى إلى جاتب الدافعية وهى استدعاء الخبرات السابقة، وتنظيم المجال الإدراكى، وتوجيه الانتباه، وهى الوظائف المتعقة بالألفة والممارسة والتكرار
التوجيهية (القبلية)، وتستخدم لتوجيه المتعلمين في باية الارس، والنوع الثانى هو التهيئة الانتقالية، وتستخدم لتسهيل الانتقال التدريجى من المادة التي سبقت معالجتها إلى المادة الجديدة، والنوع الأخير التهيئة التقويمية وتقدم في نهاية الارس وتستخدم لتقويم ما تم تعلمه قبل الانتقال إلى أنشطة أو خبرات

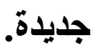
ويندرج توقيت تقديم الألعاب التعليمية تحت مفهوم المنظمات التمهيدية التي تسهل العملية التعليمية، ويستطيع المعلم من خلالها نقل كم كبير من المطلومات إلى المتعلمين وتهيئته للموضوع الجديد وجطله مألوفا لهم، بالإضافة إلى أنها تنمى

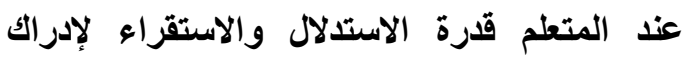
العلاقات وربط المعلومات ليكون التعلم ذو معنى، كما تمكن المتعلم على السيطرة على موضوع التعلم وتسهم في نموه المعرفى؛ بحيث جعل المعلومات

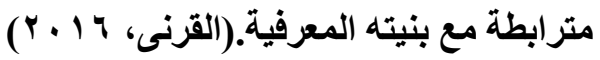
كما أن ما تقدمه المنظمات المتقدمة من ارتباط المعلومات الجديدة التي يحصل عليها المتعلم بالمعلومات السابقة ومدى تنظيم المعلومات والتزابط داخل البناء المعرفى يؤدى إلى سرعة التعلم وفاعليته، واكتساب المتعلم المعانى والدلالات والمعلومات الجديدة الحيوية. وتثتتمل عملية التعلم، من وجهة نظر "أوزويل" على ثلاث مراحل هي:

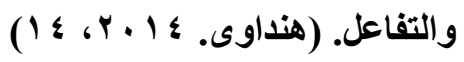


سياق مفيد للتعلم، الثانى تثجيع المتعلم على استخدام هذا السياق أثناء التعلم، وأن عدم الالتزام بمبادئ التصميم هذه عند إنتاج الألعاب يقلل من فعالية الألعاب كمنظم تمهيدى. (Andre, 2017)

$$
\text { الألعاب البعدية }
$$

يستمد الأساس النظرى لتوقيت تقديم الألعاب

بعديا؛ من خلال تطبيق للمنظمات اللاحقة Organizers والبعدية فى علم النفس تحت أسلوب التمرين

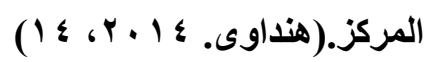

وتتميز المنظمات اللاحقة أو البعدية أو المتأخرة بأنها تقوم بالربط والتلخيص لما تم تطلمه، وهى تماثل المنظمات التمهيدية في كل خصائصها، كما أنها تنظم البنية المعرفية للمتعلم بعد مهمة التعلم الجديدة وبالتالي يمكن أن تزيد التعلم، وبصفة خاصة فى مجال تنمية المهارات(حسن زيتون،

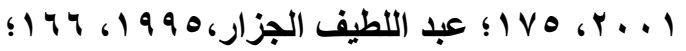

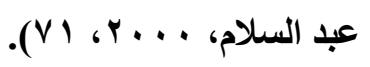

وتثير العديد من الدراسات مثل: (دراسة مينج ويو ولى Ming, Yu, Li, 2014 Gakirova, Ganiev, وجانيف ومولان (إلى أهمية الألعاب ثلاثية الأبعاد كمنظم تمهيدى متقلم أو متأخر، ولم تجزم بفاعلية أيهما في نواتج التعلم المختلفة.

كما ظهرت دعوات لتقديم منظمات تمهيدية ملائمة لبيئة التعلم الرقمية، وفى نفس الوقت تكون
ويتميز استخدام المنظمات التمهيدية القبلية برفع مستوى التحصيل والأداء للمتعلمين، وتزود من قرة المتعلمين على التمييز والتحليل والتركيب، وتعمل على إعطاء معنى لمحتوى المادة الجديدة، وتسهم في انتقال أثر التعلم. لذلك يمكن تطبيقها على كثير من أشكال التمهيد للألعاب التعليمية.

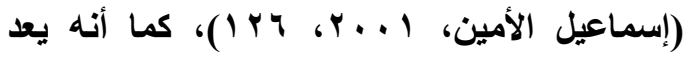

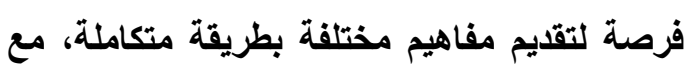
إمكانية تقديم أمثلة شاملة وديناميكية يمكن أن يتقاسمها المتعلمون والمعلمون، كما أنها تعطى الحرية الأكبر للمعلم للتفاعل الفردى مع المتعلم، وتلبى الطلب في الوقت نفسه على المعرفة والدافعية (Lynceo,2016). ويؤكد خميس (Y P (11) أن المنظمات المتقدمة تساعد في تنشيط البنية المعرفية القائمة وتجميع التفاصيل وتقديم إطار عمل للتعلم عن طريق المنظمات المقارنة C Comparative .Expository كما أن لها تأثير إيجابى وقدرة على دمج المحتوى لاستكشاف المفاهيم والمهارات الجديدة. كما أن لها القدرة على تزويد المتعلم بخبرات أولية كمستوى عالى من التجريد أكبر من مهام التعلم

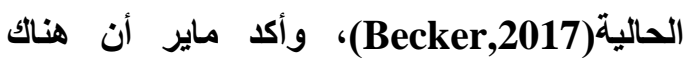
شروط لازمة للمنظم التمهيدى ليكون له تأثير إيجابى على التعلم وبصفة خاصة عند استخدام الألعاب كمنظم تمهيدى، حيث يجب أن تصمم لتحقيق هدفين: الأول يجب أن تسلط الضوء على 
والحوافز، وكلما تم تعزيز الاستجابات الإجرائية الإيجابية كلما تم التعلم بسرعة أكبر، وهو ما توفره الألعاب التعليمية الرقمية من تحفيز وقدرة على الائى توفير الانغماس والغمر للمتعلمين، وتحتوى على تنوع غنى من المحفزات السمعية والحسية والفكرية، والثعور بالمتعة أثناء الأداء، وسرعة لهن الاستجابة للتفاعلات، مما تخلق لاى المتعلمين مستويات متقدمة من المثابرة على الفوز وتحقيق لابقي النصر. أما النظرية المعرفية فهى ترى أن المعرفة تتثكل عن طريق المنطق الاستنتاجى وترتكز على العمليات الاخلية لاى المتعلمين كالإدراك والتفسير والمعالجة واتخاذ القرارات التى فى ضوئهها يتحدد السلوك، كما ترى أنه لابد من التدرج فى تقديم المعرفة من خلال مستويات متسلسلة من الأبسط إلى الأصعب، وهذا ما يحدث فى الألعاب التعليمية مدية الرقمية، والتى تحتوى على كثافة عالية من التفاعل، وذات أهداف محددة، فهى تحتوى على مستويات لعب متدرجة من السهل إلى الصعب. وفى وفى وفي

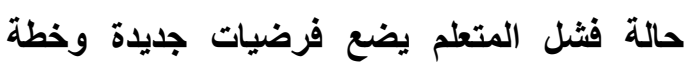
إجراءات قد تساعده على حل المشكلة، واختبار الفرضيات، وقت يحتاج المتعلم إلى مساعدة فى بداية اللعبة ولكن مع الوقت يكتسب المهارات ويصبح مسئولا عن تعلمه. أما النظرية البنائية فترى أن المعرفة تحدث من خلال التفاعل مع البيئة المحيطة وكذلك التفاعل مع الأقران واكتساب خبرات جديدة لتجديد المعرفة للمتعلمين، والألعاب التعليمية الرقمية ثلاثية الأبعاد تقدم بيئة محاكية عالية
غير مملة وممتعة لذا ظهرت دعوات لتقديم أشكال جديدة ومختلفة منها مثل: الفقرات القصيرة والأسئلة والأفلام والقصص والخرائط والألعاب

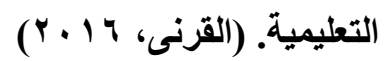

ولقد سعت بعض الدراسات إلى قياس تأثير الألعاب كمنظم تمهيدى متقدم أو متأخر مثل دراسات: (دينهام: Denham, 2017؛ جينفر :Jucas 2009 لوكاس :Jennifer, 2013 زاكروفا

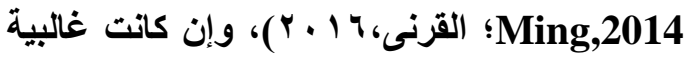
تلك الاراسات ركزت على استخدام الألعاب الرقمية كمنظم تمهيدى متقدم، والقليل منها حاول قياس أثر الثراب استخدامها بعديا، ولكنها لم تقم بمقارنة أو أثر التفاعل بين استخدام الألعاب كمنظم تمهيدى متقدم ومتأخر وفاعليتها في تنمية بعض جوانب الشخصية. وهذا ما يسعى إليه البحث الحالي.

المبادئ النظرية التى تستتد إليها الألعاب

$$
\text { التعليمية الرقمية: }
$$

يمكن القول أن الألعاب التعليمية الرقمية تدعم مبادئ النظرية السلوكية والمعرفية والبنائية كما يلى: فيلكيا (Fellicia 2009)، تريسى( (Traci. 2011

فالنظرية السلوكية ترتكز على السلوك التجريبى للمتعلم، كما ينبى التعلم بلعم وتعزيز

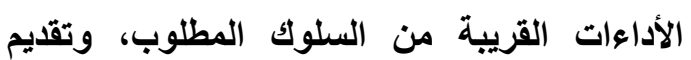
محتوى يتوافر فيه إثارة الاهتمام والميول 
التصفين الكرويين بالمخ في عملية توظيف وتثنغيل

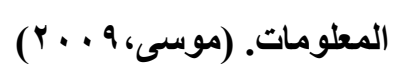

\section{تعريف السيادة النصفية:}

تعرف السيادة النصفية بأنها ميل الفرد إلى

أن يعتمد على أحد نصفى المخ أكثر من الآخر فى لئ

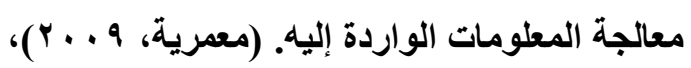
كما يقصد بها نشاط المراكز العصبية بأحد النصفين وتأثيرها فى سلوك الفرد عن النصف الآخر، وقد

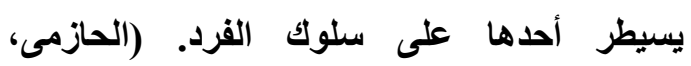

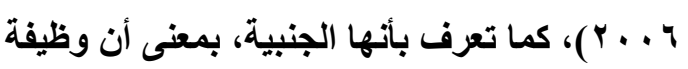
معينة تتمركز فى جانب معين من نصف الدماغ، وهى تتأثر بعوامل بيئية ومحددات جينية، مثل هئل الجنس، وهو مفهوم نسبى وليس مطلقا. (عطال،

لألك يمكن القول أنه لا يمكن الفصل بين وظائف النصفين الكرويين للمخ، رغم تخصص كل نصف فى وظيفة محددة وطريقة معالجة مختلفة، إلا أن الحصيلة النهائية هى سلوك نفسى أو معرفى أو حركى على درجة عالية من الوضوح والتكامل،

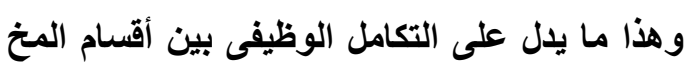

المختلفة.

النظريات المفسرة لأنماط السيادة النصفية: لقد تعددت النظريات التى حاولت تفسير كيفية حدوث السيادة النصفية، أو أنماط معالجة المعلومات الخاصة بكل نصف كروى، فنجد اتجاهين رئيسيين تمثلا فى وجهة النظر البيولوجية، ووجهة

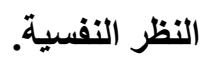

مشابهة للبيئة الفعلية للمتعلمين مما يجعهم يشعرون وكأنهم فى عالمهم الحقيقى، كما أنها تثجع على التعلم التثاركى من خلال الألعاب الجماعية مثل لعب الأدوار عبر الإنترنت، فيتثارك اللاعبون الأفكار والآراء ووجهات النظر مما يثرى الادور الآترنت المعرفة لايهم. ثالثاً: السيادة التصفية للمخ: الاماغ هو مركز العقل الذي يميز الإنسان عن باقي المخلوقات الحية، ومن المعروف لاى هري العلماء والتربويين أن الاماغ البشري يتكون من جانبين أحدهما أيمن والآخر أيسر، وهما جزئين لا

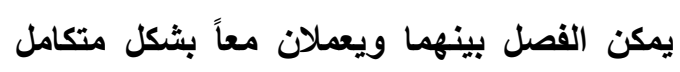
وكلي، حيث يذكر عبيد وعفانة (r . . . ب) أن الإنسان يمتلك دماغاً يتكون من نصفي كرة لمعالجة

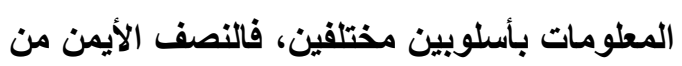
الاماغ يتخصص في إعادة بناء وتركيب الأجزاء

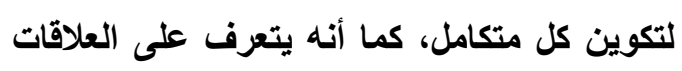
بين الأجزاء المنفصلة، وهو لا ينتقل بصورة خطية وإنما يعمل بثكل كلي متوافق ومتوازٍ، بينما يبدي النصف الأيسر للكرة الدماغية فاعلية في عمليات

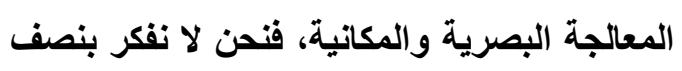
واحد دون الآخر، فكلاهما يشترك في العمليات العقلية العليا. لذا ظهرت نظرية السيادة النصفية، والتي تنص على أن السيادة النصفية مصطلح يستخدم لوصف الخصائص المميزة للأفراد الذين لديهم

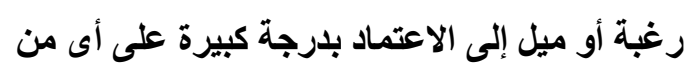

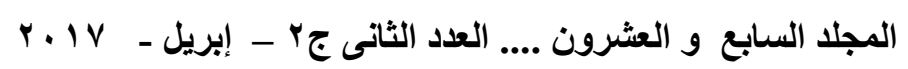


المعلومات يوافق كل منها نصف كروى محدد، عندها يحدث توزيع لعبء التجهيز والمعالجة فيما

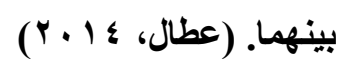

العلاقة بين توقيت تقديم الألعاب التعليمية الرقمية والسيادة النصفية للمخ:

طبقا لنظرية الملكات والقوى العقلية، تؤكد هذه النظرية أن العقل الإنساني يتألف من ملكات متعددة تختص كل ملكة بمقدرة أو نوع معين من التفكير، وهذا يشبه ما أكده (أوزويل) بأن البنية المعرفية للمتعلم هي عبارة عن مجموعة من الأفكار والمفاهيم المتخصصة التي تزوده بمحاور يستوعب

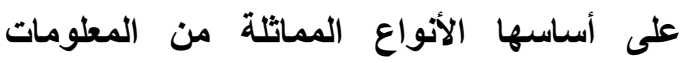

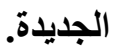

كما يؤكد اوزوبل أن المنظم المتقدم (الألعاب القبلية) يجب أن تقدم المعلومات بطريقة مناسبة للمتعلم حتى يتمكن من معالجتها، لذلك ترتبط الألعاب التعليمية الرقمية بالأسلوب وطريقة التفكير المفضلة لاى المتعلمين، حيث تتأثر تلك

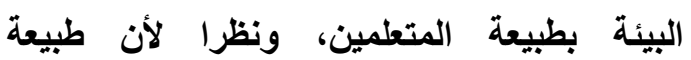
المتعلمين متباينة في تفسيرهم للمواقف والأنشطة، بل إنه ظهرت نتائج بعض البحوث المتعلقة بنصفي الاماغ وبعلم الأعصاب، وجعلتنا نعي أنتا نمتلك أسلوبين مختلفين لكن متكاملين في معالجة المعلومات، وقد حرك هذا الاكتشاف قدراً لا بأس بـ ميه من الإثارة بين المربين وولد لديهم رغبة في استكثاف التطبيقات التربوية للبحوث المتعلقة بنصفي المخ.
فالاتجاه البيولوجى يمثله العديد من

الباحثين المختصين بعلم الأعصاب والفيزيزلوجيا، والطب النفسى العصبى، وبذوره يحتوى على عدة اتجاهات أو نظريات حاولت تفسير ظاهرة السيادة النصفية، ومنها النظرية التثريحية والهرمونية والإحصائية. أما الاتجاه النفسى فيرتكز على أنماط معالجة المعلومات لنصفى الكرة المخية، عند أدائها لمهام معرفية مختلفة من الانتباه إلى الإدراك لمعالجة معلومات لفظية أو غير لفظية، ومن هذه

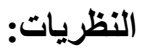

نظرية النزعة الانتباهية: والتى تفترض أن هناك نزعة انتباهية لكلا النصفين الكرويين نحو الجانب العكسى من المجال البصرى تتسبب فى أسبقية الجاتب الأيسر فى معالجة المعلومات اللفظية، وأسبقية للجاتب الأيمن فى معالجة المعلومات غير اللفظية. أما النظرية البنائية: فترى أن الوظائف العقلية المختلفة يتم تجنيبها إلى أحد نصفى المخ بسبب طبيعة البناء الخاص بالجهاز العصبى، وتركز النظرية على الفروق التشريحية

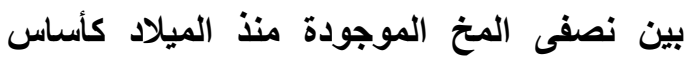
لوجود فروق بينهما فى الوظائف، والوظائف النفسية تتواجد داخل أحد نصفى الاماغ، ثم يتم تجنيبها، أى يختص بأدائها واحد من نصفى المخ.

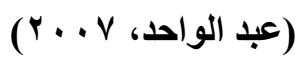

أما النظرية التكاملية للنصفين الكرويين: فتفترض أن هناك طبيعة تكاملية للنصفين وأنهما لا يعملان بمعزل عن بعضهما، بل يعملان كمنظومة

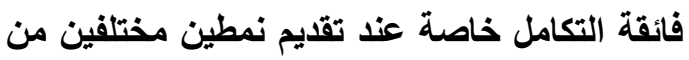




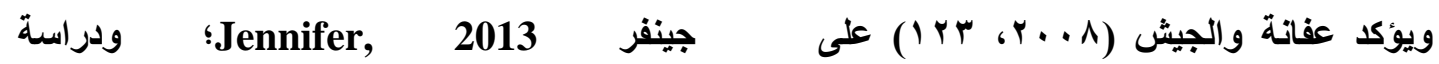
لوكاس Lucas. Et al, 2009 ودراسة أبو

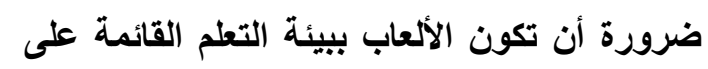

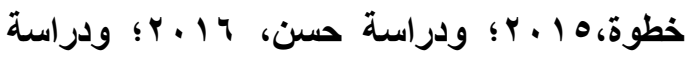
السيادة المخية متنوعة تقوم على دراسة التشابهات عبد السميع، 17 • ب) والتي تناولت فاعلية الألعاب والمتناقضات والتعلم التعاوني واستراتيجيات ما التعليمية الرقمية ثلاثية الأبعاد فى تنمية العديد من وراء المعرفة، كما يجب أن تنظم الألعاب في ضوء المتغيرات والتى منها المهارات مثل مهارات خصائص جانبي الدماغ. كما أن هناك العديد من الحساب والقراءة ومهارات الحس العددى، وقث العوامل التي تؤدى إلى سيادة أحد النصفين على اتفقت على استخدام الألعاب وخاصة فى المقررات ذات الجانب التطبيقى والأدائى مثل مقررات الحساب والرسم والعلوم لما لها من مردود إيجابى على الأداء، كما أنها تجعل بيئة التعلم أقرب إلى الواقعية من خلال الرسوم والصور والقيديو والنصوص

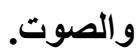

كما تعد الألعاب التعليمية الرقية مجالا

مهما لتطوير شخصية الطالب واثراء خبراته واكسابه للمهارات واتقانه إياها، وسيصبح استخدامها في العملية التعليمية ضرورة حتمية لا غنى عنها لمعلم المستقبل، ليس فقط لكونها ترسخ المعلومة وتطيل أثرا للتعلم بل إنها تضفي جوا من التشويق على طرق التدريس والتعلم وتؤدي إذا ما أحسن استخدامها لتقليل الجها والمال والوقت المبذول في تصميم العملية التعليمية.(حسن.

وهناك مجموعة من المبررات الخاصة باستخدام الألعاب التعليمية الرقمية فى التعليم ويصفة خاصة في تنمية المهارات، منها: التطبيقات الناجحة للألعاب الرقمية فى مجالات أخرى مثل الآخر فمن أسباب سيادة أحد النصفين على الآخر محتوى المناهج التعليمية، بينما صممت الأساليب والمواد والممارسات التقليدية لتعزز نمط معين على Connell, ) نمط آخر، وأكد هذا الاتجاه كونيل 2002) حيث أكد على ضرورة إعادة النظر في تخطيط التعلم من أجل تصميم أنشطة تعليمية لصالح الأفراد الذين يستخدمون وظائف النصف الأيسر للمخ. لذلك كان من الضرورى البحث في متغيرات تقديم الأنثطة ببيئة الألعاب التعليمية الرقمية ثلاثية الأبعاد وبصفة خاصة توقيت تقديمها وكيف ستتأثر بالسيادة النصفية للمتعلم، أي هل هناك علاقة بين النصف السائد عند المتعلم وتوقيت تقديم الأنشطة له؟ وهذا ما سيتم بحثه في البحث الحالي. العلاقة بين توقيت تقديم الألعاب التعليمية الرقمية ومهارات إنتاج الصورة الرقمية: تعد بيئات الألعاب التعليمية الرقمية ثلاثية الأبعاد من أكثر أنواع بيئات التعلم الملائمة لتعلم المهارات العملية بجانبيها الأدائى والمعرفى، وهذا لهان ما أشارت إليه نتائج العديد من الاراسات منها: (دراسة هاكن Haken et al, 2009 
أولاً : تحديد قائمة مهارات إنتاج الصورة الرقمية لطلاب تكنولوجيا التعليم

تم الاعتماد في إعاد قائمة مهارات إنتاج

الصورة الرقمية من خلال الاطلاع على العلديد من

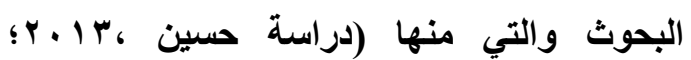

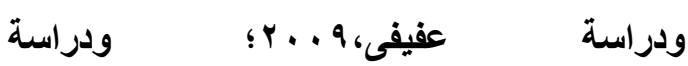

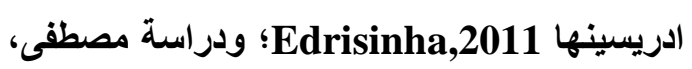

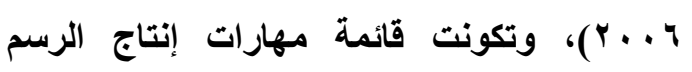
الرقمى من (^) محاور رئيسية وهى كالتالى:

أولاً: مهارة التعامل مع الكاميرا الرقمية وطرق إنتاج الصورة الرقمية ثانياً: مهارات تحديد عناصر شاثة البرنامج .(Adobe Photoshop)

ثالثا: مهارات تحديد أبعاد التصميم وخصائصه. رابعاً: مهارات تصحيح ومعالجة الصورة الرقمية Image باستخدام قائمة خامساً: مهارات استخام التحديد فى الصورة الرقمية.

سادساً: مهارات التحكم فى الطبقات وخصائصها. سابعاً: مهارات حفظ الصورة الرقمية. ثامناً: مهارات استخدام أدوات البرنامج.

واشتملت محاور القائمة على (1/1) مهارة لازمة لإتتاج الصورة الرقمية، وارتبطت هذه المهارات بالوظائف الأساسية للكاميرا الرقمية +

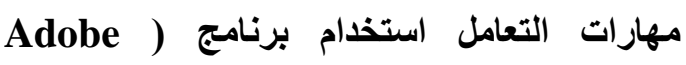
Photoshop في إنتاج الصورة الرقمية.
المجالات العسكرية وتدريب رجال الإطفاء،

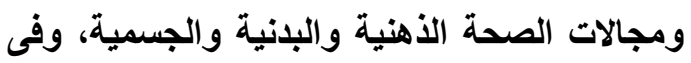
رفع مستوى الوعى لاى المواطنين، وكذلك الدور الذى تلبعه الألعاب التعليمية الرقمية فى اكتساب المعرفة، وفى الفهم والتحليل والتركيب والاكتثاف لكابل وإصدار الأحكام وحل المثكلات، وتنمية المرونة والمبادة لاى المتطمين من خلال التحرر من

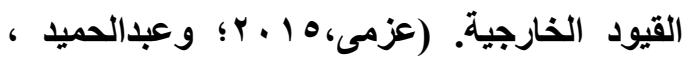
(r...v الإجراءات المنهجية للبحث: تتضمن إجراءات البحث العناصر التالية: لطلاب تكنولوجيا التطليم بمقرر التصوير

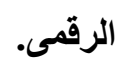
الرقمية ثلاثثة الأبعاد لتنمية مهارات إنتاج

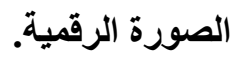
الرقمية ومعالجات البحث (الألعاب القبلية والبعدية) لإتتاج الصورة الرقمية بمقرر أساسيات التصوير باستخدام نموذج محمد لإنتاج الصورة الرفية

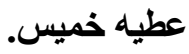

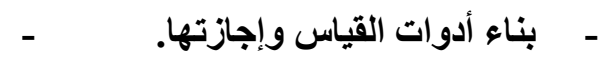
التجرية الاستطلاعية للبحث. - التجربة

$$
\text { الأساسية للبحث. }
$$
- المعالجة الإحصائية للبيانات. 


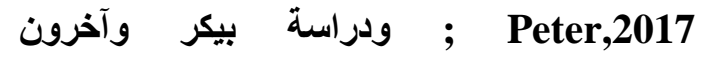

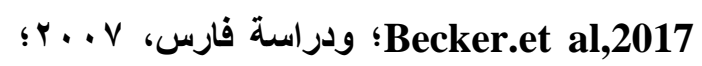

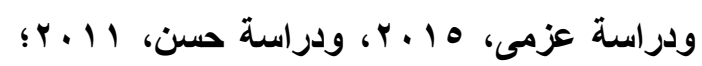

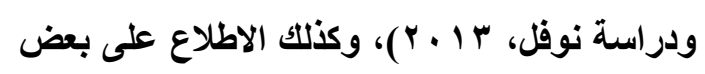

البرمجيات التعليمية التي توظف البيئات ثلاثية الأبعاد وبعض الألعاب التعليمية ثلاثية الأبعاد، مثل لتئل

موقع عربى للألعاب التعليمية ثلاثية الأبعاد، وموقع الابع الابعاديه

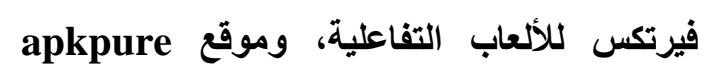
للصور ثلاثية الأبعاد.

r- تم اشتقاق مجموعة من المعاييز الرئيسية والفرعية: حيث قام الباحثان بتجميع المعايير ووضعها تحت قائمة

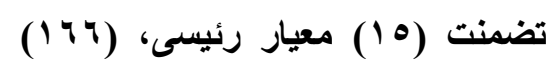
معيارا فرعيا، وبذلك تم الاتفاث على مئى

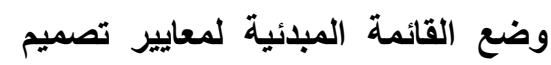
الألعاب التعليمية الرقمية ثلاثية الأبعاد.

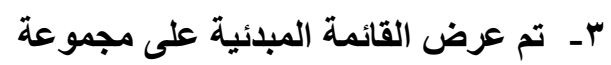
من المحكمين: للتأكد من سلامة القائمة

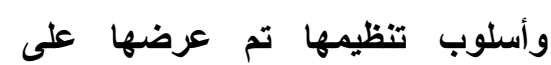
خمسة محكمين في تكنولوجيا التعليم،

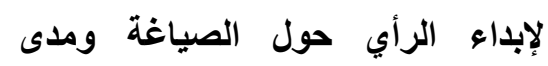

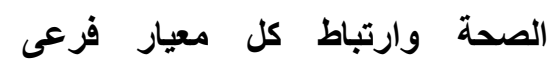
بالمعيار الرئيسى، مع وضع المقترحات

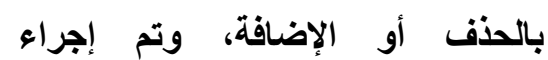
التعديلات وحذف معيار رئيسى وعدد

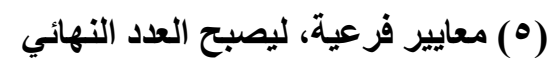

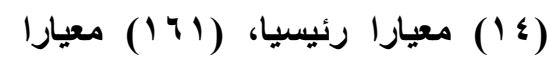
فرعياً.
التأكد من صدق القائمة: للتأكد من صدق

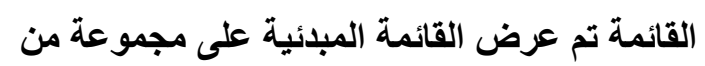
المحكمين من المتخصصين فى مجال تكنولوجيا

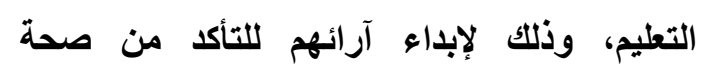
الصياغة اللغوية والدقة العلمية لكل مهارة ومؤشراتها، وتحديد درجة أهميتها، وقا اتفقوا

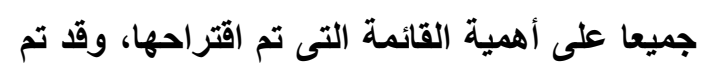
القيام بجميع التعديلات المطلوبة والتى تمثلت فى أميه تعديل صياغة بعض العبارات وحذف المؤشرات

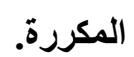

ثانياً: معاييز تصميم الألعاب التعليمية الرقمية ثلاثية الأبعاد لتنمية مهارات إنتاج الصورة الرقمية

تم إعداد قائمة المعايير اللازمة لتصميم

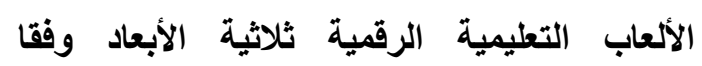
للخطوات التالية: - الاب 1- ـ تحديد الهدف من القائمة: تهدف القائمة إلى حصر المعايير والمؤشرات اللازمة لتصميم الألعاب التعليمية الرقمية ثلاثية الأبعاد اللازمة لتنمية مهارات إنتاج الصورة الرقمية لطلاب

$$
\text { تكنولوجيا التعليم. }
$$

تحديد موضوعات محتوى القائمة: لتحديد

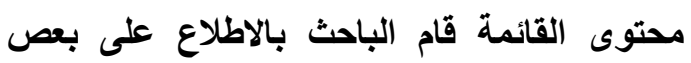
الأدبيات والبحوث الخاصة التي تناولت تصميم الألعاب التعليمية الرقمية ثلاثية الأبعاد ومنها: (دراسة بيكر Becker,2017 ; ودراسة ماتياس الاستة

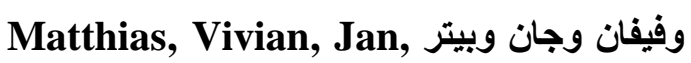


إنتاج الصورة الرقمية، إلا أن تطوير هذه البيئة يتطلب تحديد الأسلوب الأمثل لتوقيت تقديم الأنثطة المصاحبة للألعاب الرقمية (القبلية مقابل البعدية)، وكنلك أسلوب التفكير المصاحب لهب لكل متعلم ذو سيادة مخية (أيمن - أيسر-

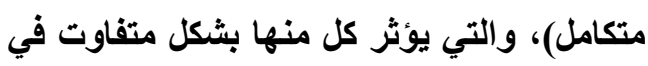
معدلات أداء المتعلم، لذا لابد من الوقوف على على لونى هذه البدائل ودراسة تأثيراتها وتقدير فاعليتها لانتقاء الحلول الأكثر تأثيرا والأكثر فاعلية في تنمية المهارات المرتبطة بإنتاج الصورة الرقمية لطلاب تكنولوجيا التعليم.

r-1 تحليل المهات التعليمية: ارتكز البحث الحالي على بعض المهمات التعليمية التي يجب التبل أن يلم بها طالب الفرقة الثالثة بقسم تكنولوجيا التعليم وتتمثل هذه المهمات في دراسة المفاهيم والخصائص والمكونات بالكاميرات وأجزائها وتركيب العدسات، والإخراج الفني للصور الرقمية وزوايا التصوير.

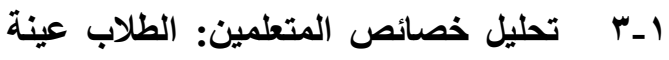
البحث الحالي من طلال الفرقة الثالثة بقسم تكنولوجيا التعليم بكلية التربية النوعية بجامعة أسوان، وقت تمت مقابلة هؤلاء الطلاب لمناقشتهم في بعض الموضوعات التي لها علاقة بتطبيق البحث الحالي، وقد أشارت نتائج هذه المقابلات إلى أن الطلاب يجيدون استخدام الكمبيوتر بنسبة ( · م \%) ويستخدمون الألعاب

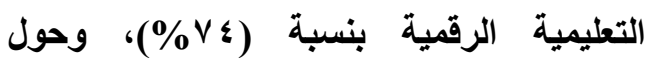

ثالثاً: التصميم التعليمى لبيئة الألعاب التعليمية الرقمية ثلاثية الأبعاد وتطويرها (مواد المعالجة التجريبية)

للحصول على بيئة ألعاب تعليمية رقمية ثلاثية الأبعاد على مستوى عالى من الكفاءة من حيث التصميم والإنتاج فإن الأمر يتطب بناءً تعليميا على نحو محكم لهذه البيئة، لذلك تبنى الباحث

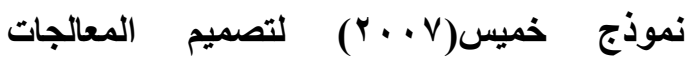
التجريبية الست. بعد تعديل ودمج بعض الخطوات الفرعية بما يتماثى مع طبيعة المعالجات التجريبية

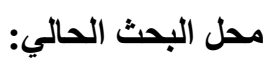
1- مرحلة الدراسة والتحليل: وتهدف هذه

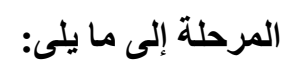

1- 1 تصليل المشكلة وتقدير الحاجات: استهدف البحث الحالي تطوير بيئة ألعاب رقمية ثلاثية الأبعاد بهدف تنمية مهارات إنتاج الصورة الرقمية لاى طلاب تكنولوجيا التعليم، حيث لاحظ الباحث من خلال نقاشات متنوعة مع طلاب تكنولوجيا التعليم وجود قصور في إلمام المتعلمين ببعض الجوانب المهارية الخاصة بتركيب الكاميرا وأجزائها وتركيب العلسات وتحديد الزوايا والإخراج الفني للصور الرقمية، ونظرا لما تتميز به الألعاب التعليمية الرقمية ثلاثية الأبعاد من إمكانيات تجعلها قادرة على لهمير مشاركة المتعلمين في بناء مهاراتهم، فقد توجه الهوله الباحث نحو تطوير بيئة ألعاب رقمية ثلاثية الأبعاد يمكن الاستفادة منها في تنمية مهارات 
قواعد التصوير الفوتوغرافي الرقمي ومهارته وتقنياته، التصوير الرقمي وتطبيقاته التربوية)، وقد تم مراعاة الشروط والمبادئ التي ينبغي مراعاتها في صياغة الأهداف التعليمية، وتم عرضها على السادة المحكمين، ثم تعديلها على ضوء ما أبلوه، ملحق (T) قائمة الأهداف التطليمية. Y-Y تنظيم محتوى بيئة الألعاب التعليمية الرقمية: يصمح محتوى الألعاب التعليمية الرقمية غالبا بحيث يقدم عنوان اللعبة والهـف منها وتعليمات وخطوات تعلمها ثم عرض النشاط المصاحب، ويقترن مع خطوات أدائها التعزيز المصاحب، وفى نهاية اللعبة تقدم التفذية الراجعة المناسبة للأداء، وقد تم تنظيم المحتوى تبعا للموديولات الثلاث كما يلى: - الموديول الأول: مبادئ التعامل مع الكاميرات

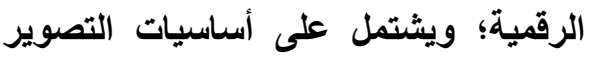
الرقمي، مزايا التصوير الرقمي، أجزاء الكاميرا الرقمية الأساسية؛ وغير الأساسية،

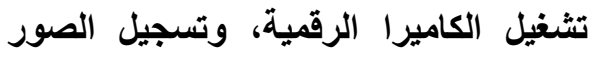
الرقمية بسهولة، توصيل الكاميرا الرقمية بجهاز الحاسب وعرض الصور، توصيل الكاميرا الرقمية بجهاز الفيديو بروجيكتور Data Show الصور الرقمية، صيانة الكاميرا الرقمية.

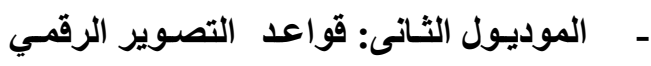
ومهارتـه وتقتياتهـ؛ ويثـتمل على عناصر تكوين الصور الرقمية، قواعد التكوين في ويتهي

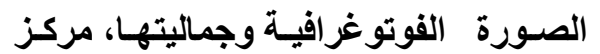

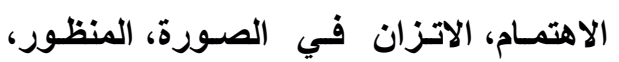

رغبتهم في دراسة بعض المهارات عبر بيئة الألعاب التعليمية الرقمية ثلاثية الأبعاد أكد

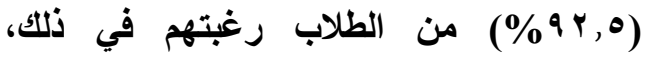
وخاصة المهارات التي تحتاج إلى الممارسة

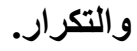

1-ـ تحليل الموارد والقيود في البيئة التعليمية: قام الباحث بتطوير بيئة الألعاب التعليمية الرقمية ثلاثية الأبعاد محل البحث الحالي على ضوء ما يتوافر لايه من مهارات خاصة بعملية التصميم وتطوير قواعد البيانات وبرامج التصميم ثُلاثية الأبعاد الخاصة بيئة الألعاب التعليمية الرقمية ثلاثية الأبعاد، بالإضافة إلى ما تفرضه طبيعة المستلزمات الإدارية والمالية والبثرية المتعلقة بتصميم وتطوير بيئة الألعاب التعليمية الرقمية والتي استطاع الباحث توفيرها في حدود قراته الثخصية. كما تم التأكد من صلاحية أجهزة معل الحاسب بمعمل تكنولوجيا التعليم، ووجود المقاعد الملائمة والتهوية، والاستعداد القني للتظلب على المشكلات التي قـ تواجه المتعلمين أثناء التعلم.

r- مرحلة التصميم التعليمى: وتثنتمل على الإجراءات التالية:

r ـا إعداد قائمة الأهداف السلوكية: تم إعداد قائمة بالأهداف التعليمية التي يجب أن يصل إليها

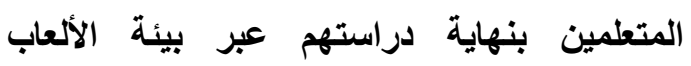

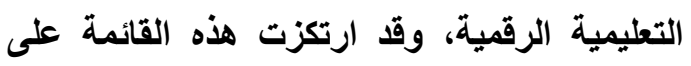
موضوعات (مبادئ التعامل مع الكاميرات الرقمية، 
الأهداف، ومدى ملاءمة تحويل المحتوى إلى ألعاب تعليمية رقمية، وقد تقرر اختيار المحتوى الذى يجمع عليه (•^\%) أو أكثر من المحكمين فيما

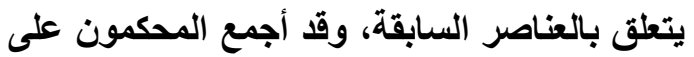

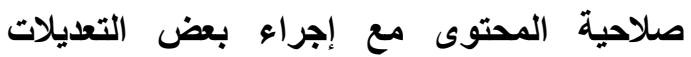
المتعلقة بالصياغة، وإعادة تقسيم بعض الدارئ بروس،

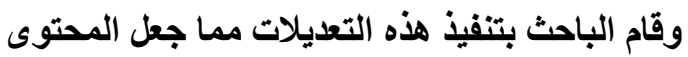
جاهزا في صورته النهائية للاستعانة به عند بناء بيئة الألعاب التعليمية الرقمية. تصميم المعالجات التجريبية وفق توقيت تقديم الألعاب التعليمية والسيادة النصفية: قام الباحث بتصميم بيئتين مختلفتين للألعاب

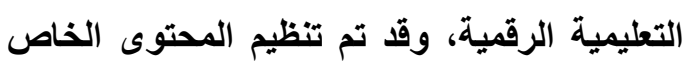
بتنمية مهارات إنتاج الصورة الرقمية في نمطين الأول نمط الألعاب القبلية والآخر نمط الألعاب

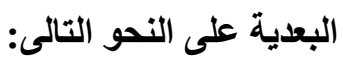

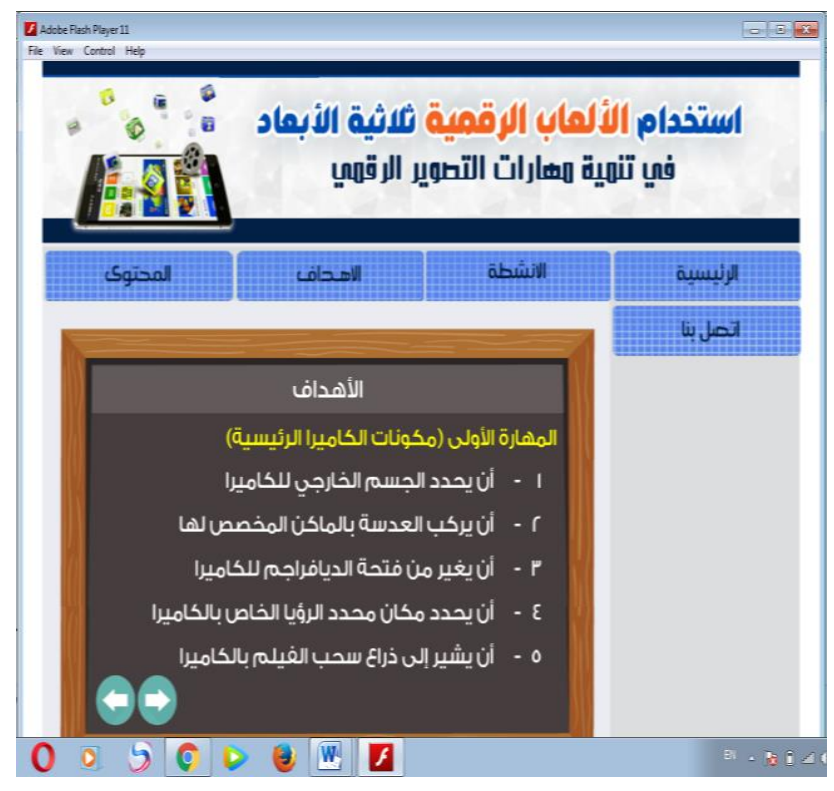

شكل (1) الثاشة الأولى بعد تسجيل الدخول
المقدمـة والخلفيـة، عمق الميدان، التمييز بالتباين، تقنيات التصوير الرقمي، تقنية

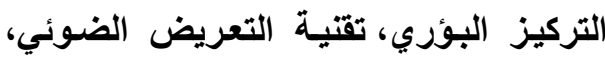
تقنية ضبط اللون( تأثيرات الإضساءة)، تقتية ضبط الفلاش، تقنية ضبط جودة الصورة، تحرير الصور الرقمية ومعالجتها. - الموديول الثالث: التصوير الرقمي وتطبيقاته لتهيه التريوية؛ ويشتمل على أهمية الصور الرقمية في عملية التعليم والتعلم، تطبيقات الصور التمبه الرقمية في أنثطة التعلم بالفصول الدراسية، معايير إنتاج الصور الرقمية التعليمية

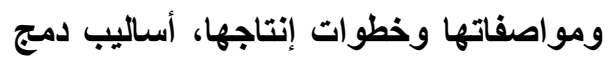
الصور في أنشطة المناهج الدراسية، مشاريع وتطبيقات عملية في التدريس باستخدام الصور الرقمية، نشر الصور الرقمية في في التوبية المحتوى التشاركي بالمدرسة، مشاريع وخطط الرئي

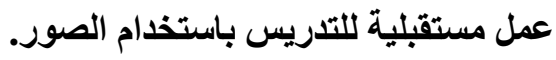
وللتأكد من صدق المحتوى المختار وترابطه تم عرضه على مجموعة من المحكمين

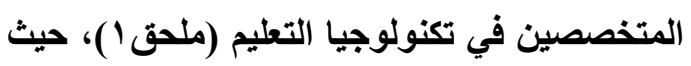
عرض عليهم المحتوى التعليمى مع أهدافه وذلكئ

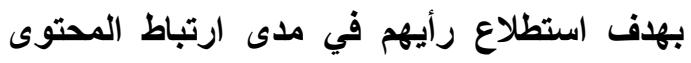

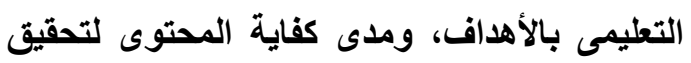


يسمح للطالب الانتقال السريع بين الصفحات، حيث يستطيع الطالب الانتقال إلى الألعاب المختلفة، أو لونين الأهداف حسب نوعية البرنامج وخصائص الطالب. كما تضم صفحة المحتوى، وهى صفحة فعالة ونشطة في حالة تقديم الألعاب البعدية ولن تنشط في حالة الألعاب القبلية إلا بعد انتهاء الطالب من استكمال كل المهارات الخاص بإنتاج الصورة الرقمية. كما تحتوى كذلك على رابط لصفحة مناقشة ومكتبة إلكترونية وصفحة للبحث من خلا محرك

$$
\text { البحث "google" }
$$

تصميم نمطى تقديم الألعاب الرقمية:

وفقا للمتغير المستقل الأول موضع البحث الحالي وهو تصميم نمطى تقديم الألعاب الرقمية

$$
\text { على النحو التالى: }
$$

$$
\text { النمط الأول: الألعاب القبلية: }
$$

ويشتمل هذا النمط على خمس مكونات رئيسية: (1) تقديم الألعاب كأنشطة سابقة للتطلم من خلال وسائط سمعية ومرئية ثلاثية الأبعاد متنوعة وتغذية راجعة فورية وتعزيز عقب كل خطوة باللعبة حتى يصل المتعلم إلى الفوز وتجميع النقاط، ؟ ب) عرض أهداف التعلم، ؟r) عرض المحتوى بتوظيف تتابعات الفيديو والشرائح وبعض الفلاشات وبعض الأنثطة الإضافية، ؛ ) التقويم الأتي من خلال تقديم سؤال أو عدد من الأسئلة الموضوعية، مع مراعاة تقديم التظذية الراجعة المباشرة، ه) الملخص summary ويقدم ملخصا وافيا لما تم عرضه

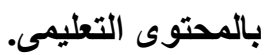

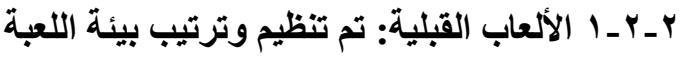
الرقمية بحيث تقدم عنوان اللعبة الرقمية ثم تعرض اللعبة مباشرة، ويقترن مع خطوات أدائها التعزيز المصاحب، مع تقديم التغذية الراجعة المناسبة للأداء، وبعد الأداء تقام للمتعلم أهداف اللعبة والمحتوى المعرفى المرتبط بها.

Y Y-Y الألعاب البعدية: ويتم هنا تقديم عنوان اللعبة والهذف منها وتعليمات وخطوات تعلمها ثم عرض المحتوى المعرفى المرتبط بمهارات إنتاج الصورة الرقمية، يلى ذلك تقديم الألعاب التعليمية الرقمية بحيث يقام ثم عرض النشاط المصاحب،

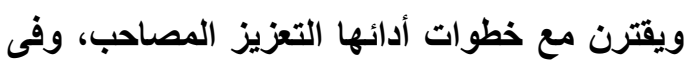
نهاية النثاط تقدم التغذية الراجعة المناسبة للأداء. وقد تم تصميم هذه البيئات وفقا للخطوات التالية: الصفحة الرئيسية: وهى صفحة البداية التي تظهر للطالب، ويتم ظهورها بمجرد كتابة عنوان الموقع، وتتضمن اسم البرنامج الدراسى، والأنشطة، والأهداف، والمحتوى، والجهة المسئولة

$$
\text { عن عرضه. }
$$

صفحة التسجيل: بمجرد اختيار الطالب للرابط الخاص بالتسجيل عليه أن يكتب اسم المستخدم وكلمة المرور ليقوم البرنامج بإدخاله إلى بلى بله نمط البرنامج الخاص به. تصميم صفحات بيئة الألعاب التعليمية الرقمية: تثنتمل بيئة الألعاب التعليمية الرقمية على عديا من الصفحات يتضمن كل منها شريط أدوات 
الجمعية المصرية لتكنولوجيا التعليم

r-0 تصميم سيناريو استراتيجيات التفاعلات التعليمية: على ضوء معالجات البحث الحالي الذى تم تصميمه، تم تحديد طبيعة التفاعلات التعليمية القائمة على تفاعل المتعلم مع المحتوى، وتم ذلك من خلال روابط داخلية توفر قدر من التفاعل مع المحتوى، مع توافر التقويم الذاتي، والتفاعل بين المتعلم وواجهة التفاعل بالموقع. Y_ד تصميم نمط التعليم وأساليبه: في ضوء تصميم

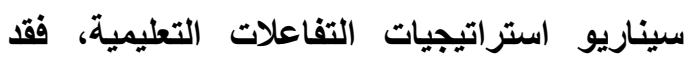
اعتمد اكتساب الأهداف التعليمية ضمن بيئات الألعاب التعليمية الرقمية محل البحث الحالي على نمط التعلم الفردى والتعلم في مجموعات صغيرة. V-Y تصميم الاستراتيجية العامة للألعاب الرقمية: اعتمد الباحث في تصميم الاستراتيجية العامة على: استثارة الدافعية والاستعداد للعب عن طريق استخدام أساليب جذب وتوجيه الانتباه نحو تنفيذ مهام الألعاب التعليمية الرقمية محل البحث الحالي،

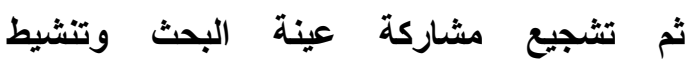

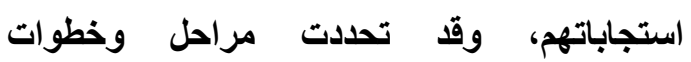
الاستر اتيجية العامة في النقاط التالية:

اختيار اللعبة: حيث تم اختيار محتوى الألعاب بناء على الهُف من البحث الحالي وهو تنمية مهارات إنتاج الصورة الرقمية وملاعمة اللعبة لمستويات الطلاب، ومدى توافر عنصر التشويق بلاخلها. تقديم اللعبة: من خلال توضيح طبيعة محتوى اللعبة، وأهدافها وقواعد العمل فيها، والمفاهيم والمشكلات التي قد تحتويها. توزيع الأدوار: بين
النمط الثانى: الألعاب البعدية:

يتضمن هذا النمط نفس المكونات الرئيسية السابقة ولكن بترتيب مختلف، حيث يتم

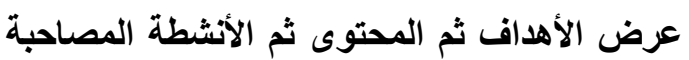
ويتم فيها تقديم الألعاب الرقمية، ثم عرض الملخص الوافى في نهاية الموديول. r-r تحديد أسلوب التفكير للمتعلمين طبقا لالسيادة النصفية للمخ: تم تطبيق اختبار أساليب التفكير

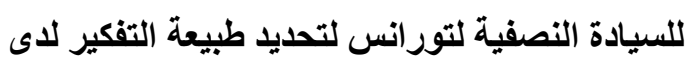
عينة البحث الحالي وتقسيمها طبقا لنتائج الاختبار إلى طلاب ذوى السيادة النصفية (الأيمن)، وطلاب ذوى السيادة النصفية (الأيسر)، ووطلاب ذوى السيادة النصفية (المتكامل). ץ-؛ تحديد طرائق واستراتيجيات التعليم والتعلم: فيما يخص استراتيجيات التعليم عند استخدام الألعاب التعليمية الرقمية اعتمد البحث الحالي على استراتيجية التعلم الفردى، حيث يتحمم المتعلم في الرياب خطوه الأتي، وبالتالي يتحكم في تتابع عرض

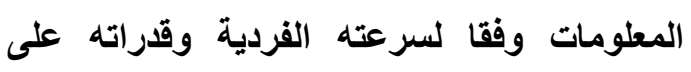
التحصيل والإنجاز، بالإضافة إلى استخدام استراتيجية التعلم الاستكشافى والقائم على إتاحة الفرصة لعينة البحث لاستكثاف مكونات اللعبة وإمكاتياتها المختلفة، و والتعرف على مناطق لونق التحديات داخل اللعبة، والتي تستطيع خلق حوافز ودانيان ودوافع إيجابية. 
منها (الألعاب القبلية) والثانى (الألعاب البعدية) بينما تم تقسيم عينة البحث بناء على نتائج اختبار تورانس إلى ثلاث مجموعات وكل مجموعة تقسم إلى مجموعتين أحدهما تعرض على التصميم الأول والثانية للتصميم الثانى. وقد تم الاستعانة باستخدام لغات البرمجة والبرامج التالية في إنتاج الألعاب الرقمية ثلاثية الأبعاد والموديولات مواد المعالجة التجريبية: 2012 Visual Studio MS PowerPoint 'Adobe Photoshop لإنتاج المحتوى، Sound forge لإنتاج الصوت. r-r التخطيط للإنتاج: تم انتقاء بعض المصادر والمحتويات المتاحة عبر الويب تخدم المحتوى ووثيقة الصلة به، تحديد بعض خصائص البرامج الخاصة بإنشاء بيئات الألعاب التعليمية الرقمية بهابة

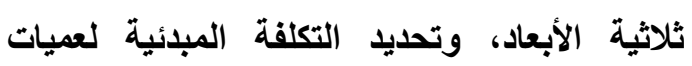

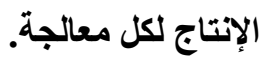

r-r الإنتاج الفعلى: شملت عملية الإنتاج المراحل التالية: إنتاج بيئة الألعاب التعليمية الرقمية، وإعداد الاد واجهة التفاعل وتحليد خصائص النصوص التص وألوانها، وإعداد قناة النقاش والاتصال، إعداد قوائم الإبحار بالمحتوى وفقا لكل معالجة بالبحث

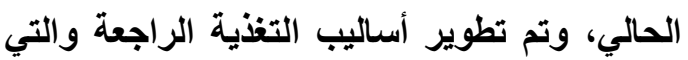
تستخدم في تحفيز المتعلمين أثناء ممارسة الأنثطة المختلفة ببيئة الألعاب التعليمية الرقمية. r-ـ عملية التقويم البنائى: تم عرض بيئات الألعاب التعليمية الرقمية محل البحث على بعض الخبراء

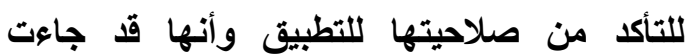

المشاركين في اللعبة وتحديد المطلوب تنفيذه من كل مشارك. الملاحظة والتسجيل: حيث قامت الباحث برصد كافة جوانب الأداء للطلاب في أثناء تنفيذ اللعبة وتحليل التقارير الخاصة باللعبة ذاتها. تقويم اللعبة: ويتم ذلك أثناء اللعبة (تقويم مرحلى)، وبعد الاتتهاء من اللعبة (تقويم نهائي). Y_N وصف بيئة الألعاب التعليمية الرقمية محل البحث الحالي: تم وضع مواصفات الألعاب التعليمية الرقمية محل البحث الحالي والتي تتناسب مع أهداف البحث وخصائص المتعلمين، وقد ارتكزت هذه الخصائص على النحو التالى: ضرورة أن تقدم اللعبة حوافز مستمرة للمتعلم نحو إكمال المهمة النهائية، ضرورة أن تثجع اللعبة المتعلم على ممارسة مهارات التثارك والتعاون مع الأقران، تقديم تغذية راجعة فورية وتقديم بدائل متنوعة تسمح للمستخدم بإكمال المهام المطلوبة، ملاعمة مستوى الألعاب للمستوى العقلى لعينة البحث الحالي، توافق الألعاب العماب

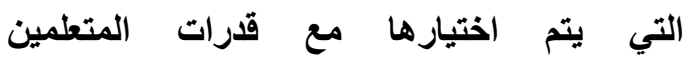
واستعداداتهم وأساليب تفكير هم. rـ - مرحلة التطوير: اشتملت هذه المرحلة

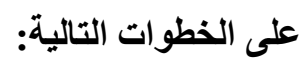

r-1 إعداد تصميمات بيئة الألعاب التعليمية الرقمية على ضوء المعالجات التجريبية للبحث: تم إعداد

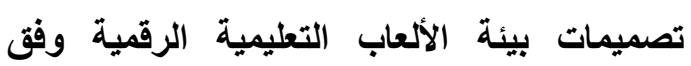
معالجات البحث، حيث تم إعداد تصميمان الأول 
الجمعية الدصرية لتكنولوجيا التعليم

الراجعة للمتعلم، وقد قام الباحث بإجراء هذه

متوافقة مع معالجات البحث التجريبية، وقد أسفرت

التعديلات لتصبح بصورتها النهائية.

هذه العملية عن بعض التوجيهات والتعديلات التي مي

أثشار إليها المحكمين، والتي دارت حول تعديل

واجهة التفاعل، وتنويع المحفزات وأنماط التغذية

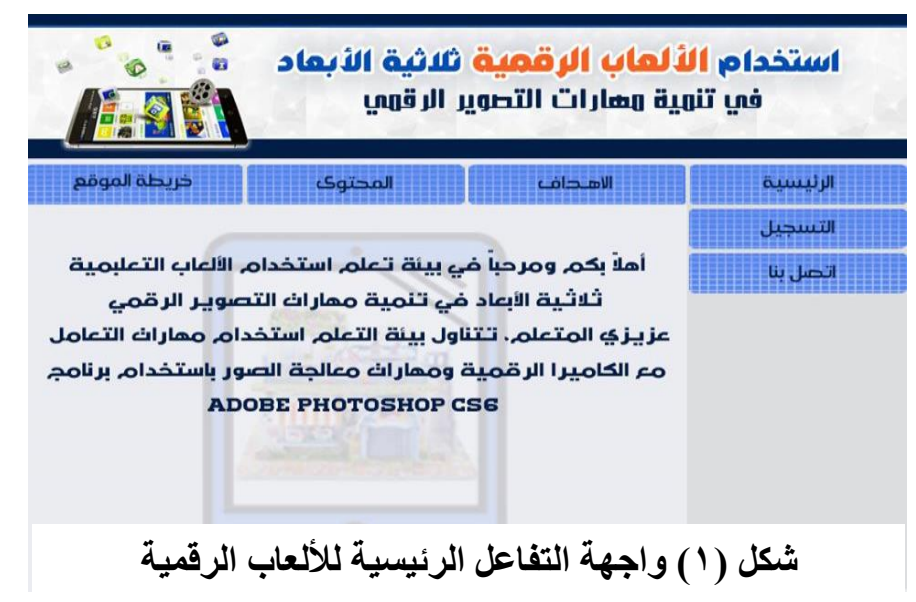

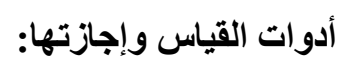

1- إعداد مقياس السيادة النصفية:

بعد الاطلاع على بعض الأدبيات ذات

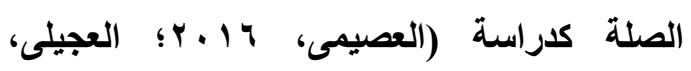

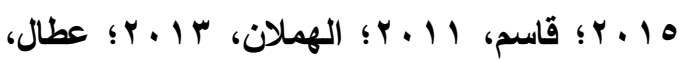

צ ا.Y). تم تبنى مقياس تورانس لصلاح مراد

وتطويعه في ضوء الخطوات التالية:

أـ الهذف من المقياس: يهذف المقياس إلى الكثف

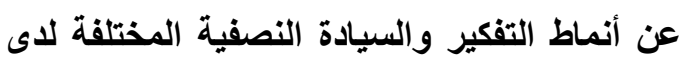

الطلاب (النمط الأيمن، النمط الأيسر، النمط

المتكامل) وتقسيمهم حسب نتائجهم بالمقياس. r-ه عملية الإخراج النهائي للبرنامج: بعد الانتهاء

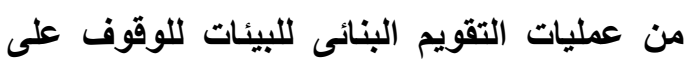
ضبط المتغيرات والتأكد من خلو البيئات من الأخطاء في التصميم من الناحيتين الفنية والتربوية، وتعديل ما يلزم بناء على آراء السادة الخبراء والمحكمين، وطبقا لنموذج التصميم والتطوير التعليمى المتبع تم إعداد البيئات في صورتها النهائية، والتأكد من فاعلية الأدوات المستخدمة داخل كل بيئة وأنها تعمل بدقة، بالإضافة إلى سهولة اتخدام البيئة. ع - مرحلة التطبيق والتقويم : يتم عرض جميع إجراءات هذه المرحلـة في الجزء الخاص بتجربة البحث ونتائجه. $r \cdot \mathrm{V}$ تكنولوجيا التعليم .... سلسلة دراسات وبحوث مُحكّمَة 
0.95, ) وبلغ للنمطين الأيمن والأيسر على التوالي 0.90)، وبطريقة ألفا كرونباخ للتطبيق الأول بلغ الغير النغ (0.81, 0.82) وبلغ الثبات الكلى (0.89) وهذا يدل على أن المقياس على درجة عالية من الثبات، ويمكن الوثوق به في البحث الحالي.

حساب زمن المقياس: اتضح أن الزمن المناسب لانتهاء جميع الطلاب وبحساب متوسط الزمن للعينة الاستطلاعية (· ( ) دقيقة.

الصورة النهائية للمقياس: في ضوء نتائج الدراسة الاستطلاعية، وآراء المحكمين، بلغ عدد مفردات المقياس († اه) مفردة (ملحق ع).

وقد أعطيت كل مفردة درجة واحدة لكل نمط من الأنماط وبذلك تكون الارجة النهائية للنمط

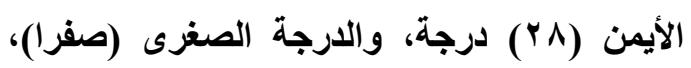
وهذا ينطبق تماما على النمط الأيسر، ويعبر عن

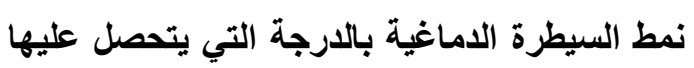

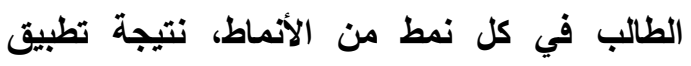
مقياس أنماط السيطرة الدماغية ، فإذا كاتت درجته في الأيمن أعلى صنف ضمن النمط الأيمن، وإذا كانت درجته في الأيسر أعلى صنف ضمن الايمن النمط الأيسر، وعند التساوى في درجة استخدام وظائف فئ الاسير اعلى صناف النمطين صنف ضمن النمط المتكامل. r- الاختبار التحصيلى الموضوعى (اللفظى/

$$
\text { (المصور): - المور) }
$$

تم إعداد اختبار تحصيلى موضوعى لقياس الجوانب المعرفية لمهارات التصوير الرقمية حسب الخطوات

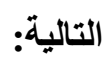

ب أبعاد المقياس: تم تحديد ثلاثة أبعاد للمقياس

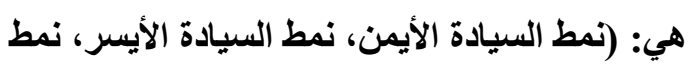
السيادة المتكامل). ج صياغة مفردات المقياس: صيغت مجموعة من المفردات حول محاور المقياس في صورة جدلية تختلف حولها وجهات النظر مع مراعاة التوازن بين مفردات المقياس في النمط الأيمن والنمط الأيسر وكذلك توزيعها بصورة عشوائية، مع ملاحظة وضوح المفردات والصياغة بلغة علمية سليمة، وكية وأن تكون جملا وجدانية شعورية وفق الموضوع

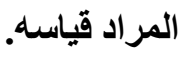

دـ صدق المقياس: تم عرضه في صورته الأولية على مجموعة من المحكمين في مجال تكنولوجيا التعليم وعلم النفس بغرض التحقق من سلامة من مبن

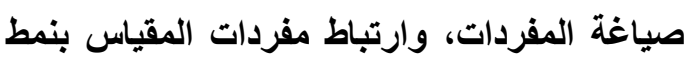
السيادة النصفية وفقا للمحاور الخاصة به، وقد تم التعديل في ضوء آراء المحكمين. هـ صدق الاتساق الداخلى: يقصد بصدق الاتساق

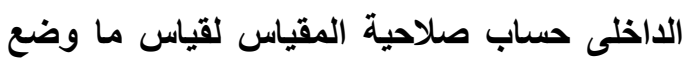
لقياسه، ويتم ذلك بحساب معاملات الارتباط بين درجات المجموعة الاستطلاعية على كل عبارة ودرجاتهم الكلية على المقياس ككل، وتراوحت قيم الاسنط

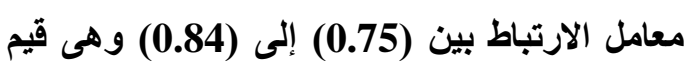
دالة عند مستوى (0.01). التجربة الاستطلاعية للمقياس: تم تطبيق المقياس في صورته الأولية على عينة من الطلاب بلغ عددها لنها

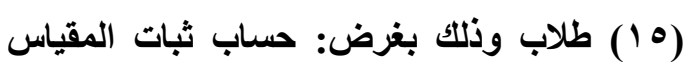

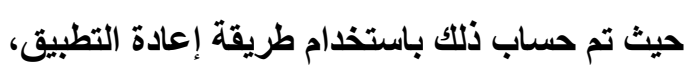


صدق المحتوى: تم الاعتمـاد على الصدق المنطقى

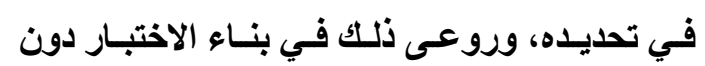

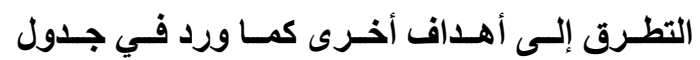

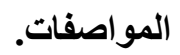

صدق المحكمين: تم عرض الصورة الأولية للاختبار على مجموعـة مسن المتخصصسين فـي تكنولوجيـا التعليم (ملحق 1) حيث أبلوا بعض الملاحظات على إعادة الصياغة اللغوية لبعض العبارات، وتم إجراء التعـديلات المطلوبـة ومراجعـة صـياغة العبـارات وتدقيقها لغويـا بمسـاعدة متخصص في ضوء آراء

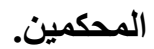
الاتساق الاخلى: تم حسـاب معامل ارتبـاط بيرسون بين كل بعد والاختبار ككل، وجاءت جميعها الارتباط

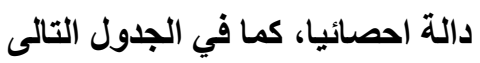

- هدف الاختبـار: اختبار الجوانب المعرفيـة لعيـــة البحــث فـــي المفــاهيم والحقــائق المرتبطة بمهارات إنتاج الصورة الرقمية. تحليـل محتــوى الوحسدة: وذلـــ لحســاب

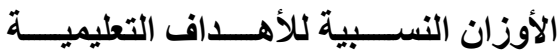
للمحتوى، حيث تم صياغة أسئلة الاختبار في جدول مواصفات وذلك للتأكد من أن

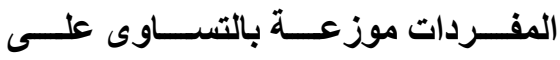

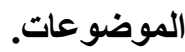
- صـياغة مفـرادت الاختبــار: تـم صـياغة المفردات في صسورة اختيسار مسن متعدد

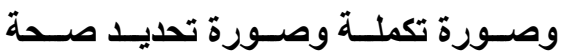
العبارة من خطئها ، وقد بلحغ عدد الأسئلة الاختبار في صورته الأولية (YV) مفردة.

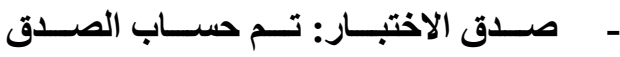

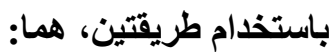
جدول (Y) معامل ارتباط بيرسون لمفردات الاختبار التحصيلى

\begin{tabular}{|c|c|c|c|}
\hline مستوى الدلاية & معامل & 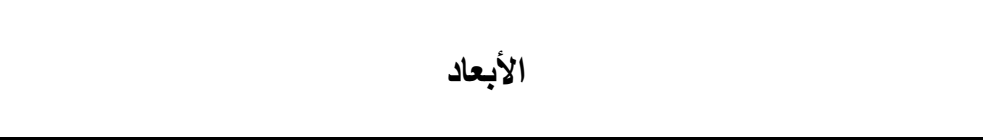 & s \\
\hline 0.01 & $\mathbf{0 . 8 1}$ & أساسيات إنتاج الصورة الرقمية & 1 \\
\hline 0.01 & $\mathbf{0 . 8 0}$ & مكونات معمل إنتاج الصورة الرقمية. & r \\
\hline 0.01 & 0.85 & مهارة تحرير ومعالجة الصور باستخدام برنامج (Photoshop). & $r$ \\
\hline 0.01 & 0.79 & توظف إنكانات البرنامج مثل (Layers)، (الفلاتر) والتأثيرات التي يمكن & $\varepsilon$ \\
\hline 0.01 & 0.82 & يوظف الصور الرقمية المنتجة في برامج الوسائط المتعددة أو على & ○ \\
\hline
\end{tabular}


زمسن إجابـة الاختبـار: تـم حســاب الززمن المناسـب

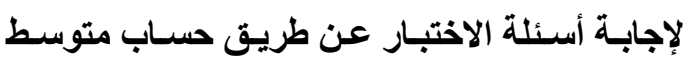
الـزمن لمجمـوع الطـلاب، وكــان الـزمن المناسـبـ

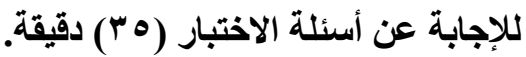

الصسورة النهائيسة للاختبـار: بعـد إجـراء التعديلات المطلوبـة، بلغ عدد مفردات الاختبار († ץ) سؤالا، بحيث يكون لكل سؤال إجابـة واحدة، وذلك لتسـهيل عملية التصحيح. الصيغة الإكترونيـة للاختبـار : تم استخدام برنـامج Quiz Creator r- بناء بطاقة ملاحظة الأداء:

على ضوء الأهد|ف التعليمية وتحليل المهارة والمحتوى التعليمى لبيئة الألعاب التعليميـة الرقمية قـام الباحـث بإعـداد بطاقــة ملاحظــة أداء الطـلاب لمهارات إنتاج الصورة الرقمية، وقد تكونت البطاقة في صورتها المبدئية (9 + 1 ) عبارة تصف الأفعال المطلوبـة مـن المـتعلم في كل خطوة مـن خطوات الأداء بحيـث تثــــل الجوانـب الأدائيـة المختلفــة للمهارة، وقد روعى في تصميم البطاقة الاعتبار ات التالية: أن تكون العبارة دقيقة وواضحة وأن تقيس كل عبارة سلوكا محدداً وواضحاً. أـ الهذف من بطاقة الملاحظة: وتهذف إلى ملاحظة الأداءات السلوكية وقياسها للطلاب في "مهارات التصوير الرقمي" وتضمنت هذه البطاقة (^) مهارات فرعية، وتثتمل كل مهارة منها على عدد من الأداعات السلوكية التي ينبغي أن ينفذها الطالب
ويتضــح مـن الجـدول السـابق أن جميـع

معساملات ارتبـاط أبعـاد الاختبـار دالـة إحصـائيا عند

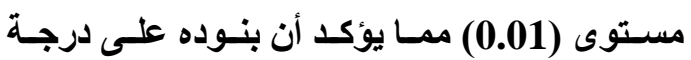

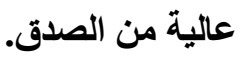

ثبـات الاختبـار: تـم حســاب الثبـات بطريقــة التجزئسة النصـفية حيـث تـم تطبيـق الاختبـار على عينـة استطلاعية قوامها (r I ) طالب، باستخدام معامـل ارتباط سبيرمان مرتفع ودال إحصـائيا (0.92)، كما تم التأكد كنلك مـن الثبات من خـلال التطبيق على عينــة مــن الطــلاب (ه ا طالبـــا) فـــي التجربـــة الاستطلاعية للبحث بخلاف عينـة البحث باستخدام طريقة التجزئة النصفية لمفردات الاختبار إلى أسئلة فرديـة وزوجيـة تم حسـاب الثبات باستخدام معادلـة سبيرمان وبروان، وقد بلـغ معامل الثبات ( V V , • ) وهى قيمة مقبولة لثبات الاختبار. معامـل الصــعوبة: وقعــت معسـاملات الســهولة المصححة من أثر التخمين لمفردات الاختبـار في هي

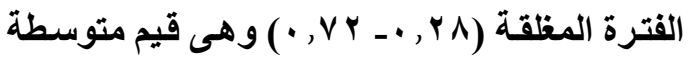

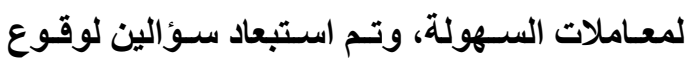
نسبة السـهولة إلى أقـل مـن ( • ب • ))، وتـم إعـادة ترتيـب أســلة الاختبـار وفقـا لمعامـل سـهولة كـل سؤال، بحيث تتدرج من السهل إلى الصعب. معامـل التمييز للمفردات: وقعت معـاملات التمييز

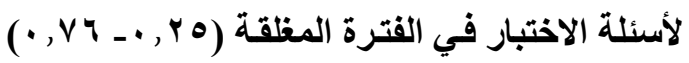
مما يشير إلى أن جميع أسئلة الاختبار مناسبة من لن حيث درجة تميزها. 
درجات، متقن بلرجة متوسطة =درجتان، متقن

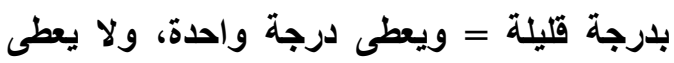
شئ حال عدم تنفيذ المهارة. وقد شملت بطاقة الملاحظة على (1.1) مهارة فرعية ـأداء سلوكي- لتصبح الدرجة العظمى لبطاقة الملاحظة=

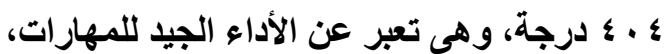
والارجة الصغرى= 1 ـ 1 درجة، وهى تعبر عن الأداء الضعيف لمهارات التصوير الرقمي. ثالثاً: التجربة الاستطلاعية للبحث: قام الباحثان بإجراء تجربة استطلاعية على عينة من طلاب الفرقة الثالثة شعبة تكنولوجيا التعليم من نفس مجتمع البحث عددهم (10 ) طالباً

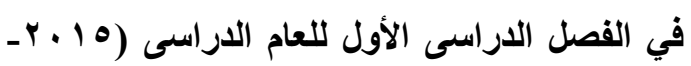

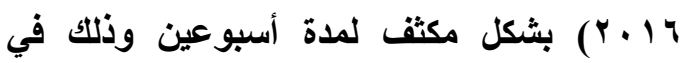
الفترة المسائية ، وذلك بهدف التعرف على لتى الصعوبات التي قد تواجه الباحثان فى أثناء التجربة الأساسية للبحث، والتأكد من الكفاءة الداخلية لمواد المعالجة التجريبية، والتحقق من سلامة وتقدير مدى ثبات الاختبار التحصيلى وبطاقة ملاحظة

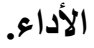

وقت كثفت التجربة عن ثبات كل من

الاختبار التحصيلى وبطاقة الملاحظة، كما تم عرضه في أدوات القياس، كما كثفت عن صلاحية مواد المعالجة التجريبية (بيئة الألعاب التعليمية الرقمية) كما كشفت التجربة عن بعض المشكلات الفنية بموقع بيئة الألعاب الرقمية من قبل عينة الطلاب وتم إصلاحها.
علياً، وبالدقة المحددة، حتى يحصل على درجة تنفيذ الأداء السلوكي، ويلغ إجمالي المهارات

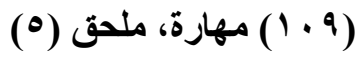
ب- صدق بطاقة الملاحظة وثباتها: تم عرض بطاقة الملاحظة على السادة محكمي الأدوات لتحديد مناسبتها لأهداف البحث الحالي، ودقة صياغتها، وشموليتها للمهارات الممثلة بها،

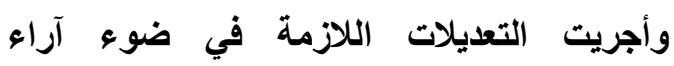
المحكمين. كما قام الباحث بتطبيقها على العينة الاستطلاعية من الطلاب الذين شاركوا في دراسة الوحدة من غير عينة البحث، ثم قام بحساب الصدق الاخلي لبطاقة الملاحظة بحساب مصفوفة معاملات الارتباط بين أبعادها، وقد تراوحت قيم بـاب

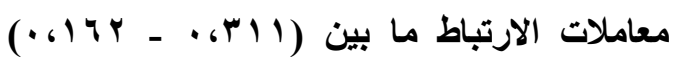
والقيم السابقة لمعاملات الارتباط دالة عند مستوى (1 (.، •) وتدل على مدى اتساق البناء الداخلي لبطاقة الملاحظة. ولحساب ثبات البطاقة؛ تم تطبيق بطاقة الملاحظة على عينة من طلاب الفرقة الثانية بقسم تكنولوجيا التعليم كلية التربية النوعية بأسوان، أثناء التجربة الاستطلاعية، بالتعاون مع بك بله المعيدين بالقسم، وقد حصلت بطاقة الملاحظة على بلى نسبة اتفاق ^VV\%، مما يعنى ثبات البطاقة وصلاحيتها للنبيق ملحق(•)، لتثتمل البطاقة على إجمالي (1 + 1 ( ) مهارة فرعية. ج- نظام تقدير الارجات: صممت بطاقة الملاحظة بحيث يتم قياس مستوى الأداء السلوكي على مقياس ثلاثي الارجة؛ متقن بلرجة كبيرة = ع عان 
مؤشر لفاعلية البيئة، وقد قام الباحث بحساب درجات طلاب المجموعة الاستطلاعية في الاختبار حساب الفاعلية الداخلية لبيئة الألعاب القبلى والبعدى وحساب نسبة الكسب كما في

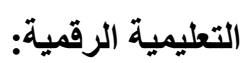

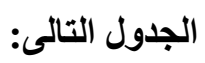

لقياس فاعلية البيئة المنتجة استخدم الباحث معادلة أنوفا Anova لحساب نسبة الكسب المعدل، حيث وصلت إلى (435.، 197.) لكل من الاجن الاختبار التحصيلى ويطاقة الملاحظة وهذا يعتبر جدول(r) متوسط الدرجات القبلية و البعدية ونسبة الكسب للجانبين المعرفى والأدائى لطلاب المجموعة الاستطلاعية

\begin{tabular}{|c|c|c|c|}
\hline نسبة الكسب المعدل المحسوبة & متوسط درجات التطبيق البعدى & متوسط درجات التطبيق القبلى & المتغير التابع \\
\hline .435 & 22.3750 & 5.6250 & تحصيل الجاتب المعرفى \\
\hline 197 & 92.3333 & 14.8667 & الأداء المهارى \\
\hline
\end{tabular}

هدف التطبيق القبلى لأدوات القياس المتمثلة في (اختبار تحصيل الجانب المعرفى-

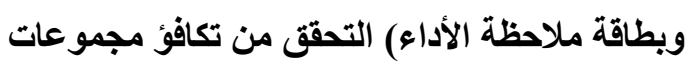

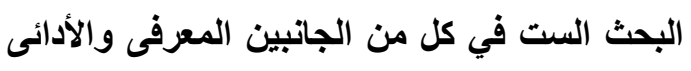

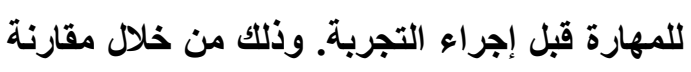

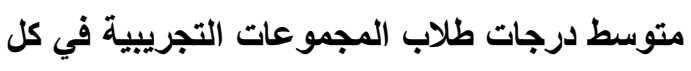
من أداتى القياس. حيث طبق أسلوب تحليل التباين

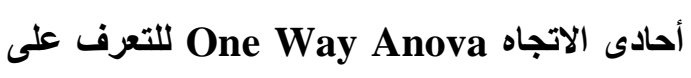
دلالة الفروق بين المجموعات في درجات الاختبار قبليا، وبطاقة الملاحظة قبليا

تحديد عينة البحث: تكونت عينة البحث

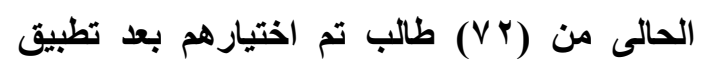

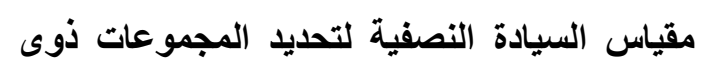

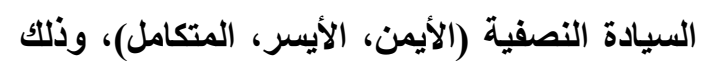
بناء على النتائج التي تم تجميعها على الطلاب.

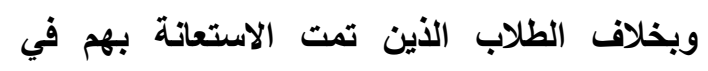
التجربة الاستطلاعية. تطبيق أدوات القياس قبليا: جدول (ء) تكافؤ المجموعات التجريبية بدلالة درجات الاختبار ومعدل الأداء المهارى القبلى

\begin{tabular}{|c|c|c|c|c|c|c|}
\hline الالالة & ف ف & المربعات & الحرية & مجموع المربعات & & المتغير التابع \\
\hline \multirow{3}{*}{ غير دال } & \multirow{3}{*}{. 783} & 2.373 & 8 & 18.983 & بين المجموعات & تحصيل الجاتب المعرفى \\
\hline & & 3.032 & 63 & 191.017 & داخل المجموعات & \\
\hline & & & 71 & 210.000 & المجموع & \\
\hline \multirow{3}{*}{ غير دال 800} & \multirow{3}{*}{9.052} & 30.092 & 5 & 150.458 & بين المجموعات & معدل الأداء المهارى \\
\hline & & 3.324 & 66 & 219.417 & داخل المجموعات & \\
\hline & & & 71 & 369.875 & المجموع & \\
\hline
\end{tabular}


الجمعية المصرية لتكنولوجيا التعليم

الخاصة بالأعضاء داخل كل مجموعة فقط.

وذلك بعد إعطائهم اسم المستخدم وكلمة المرور الخاصة بكل طالب.

- توجيه طلاب المجموعات الست إلى ممارسة

الألعاب حسب توقيت تقديمها ، حيث تعرض

الألعاب قبليا لنصف عدد العينة، وتعرض

الألعاب بعديا بعد عرض الأهداف والمحتوى

ثم خطوات وإجراءات اللعبة، لنصف العينة

$$
\text { تطبيق أدوات القياس بعدياً: }
$$

- تم تطبيق الاختبار التحصيلى، وبطاقة

ملاحظة الأداء بعديا على طلاب المجموعات

الست، وبعد الانتهاء من تطبيق التجربة لإية

الأساسية للبحث، قام الباحثان بتصحيح

ورصد درجات كل من الاختبار التحصيلى

وبطاقة الملاحظة تمهيدا للتعامل معها

$$
\text { إحصائيا. }
$$

المعالجة الإحصائية:

تم استخلام أسلوب تحليل التباين ثنائى

Two Way Anova of Vvariance الاتجاه وذلك على اعتبار أنه أكثر الأساليب الإحصائية مناسبة لمعالجة البيانات في ضوء التصميم التجريبى للبحث، ثم قام الباحثان بإدخال البيانات

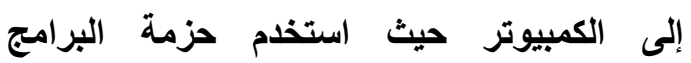
الإحصائية SPSS-22، كما تم الاستعانة بمعادلة توكى Tukey لبيان اتجاه الفروق في حالة اكتثاف وجود فرودق وذلك لتساوى عدد
وتثير قيمة (ف) في الجدول السابق لعدم

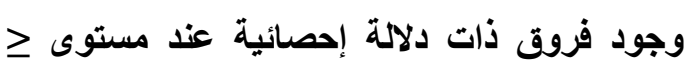

ه., • بين متوسطات درجات التطبيق القبلى

لاختبار تحصيل الجانب المعرفى ومعدل الأداء

المهارى لمجموعات البحث الست، وبالتالي يمكن

اعتبار مجموعات البحث متكافئة قبل اجراء

التجربة، وأن أية فروق تظهر بعد التجربة تعود إلى هي

المتغير المستقل والتصنيفى موضع البحث الحالي.

تطبيق مواد المعالجة التجريبية على

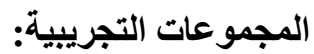

- تم عقد ورشة عمل مع طلاب (مجموعات

البحث) لتعريفهم بطبيعة التجربة وكيفية

السير فيها وفقا لطبيعة التجريب فى كل

مجموعة. ولتدريب الطلاب على استخدام

البيئة حسب توقيت تقديم الأنثطة المتبع مع وعي

كل مجموعة، من خلال تسجيل الاخول

للمجموعة وشرح واجهة التفاعل وطرق

المناقشة و التحميل وتوزيع المهام.

- تم تطبيق مقياس السيادة النصفية على عينة

البحث وحساب الارجات وذلك لتصنيف

الطلاب حب السيادة النصفية بناء على

نتائج المقياس إلى طلاب ذوى السيادة

النصفية (الأيمن، الأيسر، المتكامل).

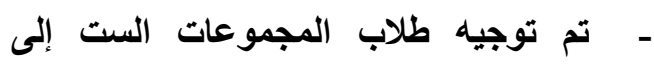

التفاعل والمناقشة من خلال رابط كل

مجموعة على حدة حيث تستطيع كل

مجموعة روية التطليقات والمنافثات 
الرقمية، وذلتك في الجزء الخاص بالإجراءات.

ثالثاً: الإجابة عن الأسئلة من الثالث إلى

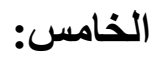

تمت الإجابة عن هذه الأسئلة وفق تسلسل

عرض الفروض التي تمت صياغتها لمتغيرات البحث.

() عرض النتائج الخاصة بالتحصيل

المعرفى لمهار ات إنتاج الصورة الرقمية

$$
\text { وتفسيرها: }
$$

- لمهارات إنتاج الصورة الرقمية:

تم تحليل نتائج المجموعات الست بالنسبة للتحصيل المعرفى لمهارات إنتاج الصورة الرقمية، وذلك بالنسبة للمتوسطات والانحرافات المعيارية وطبقا لمتغيرى البحث الحالي، جدول (0) يوضح

ذلك.
المجموعات التجريبية، كما تم استخدام معادلة أيتا

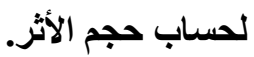
نتائج البحث ومناقشتها وتفسيرها: فيما يلى عرض النتائج التى تم التوصل إليها ومناقشتها وتحليلها وفق تسلسل أسئلة الاراسة: أولاً: إجابة السؤال الأول والأى ينص على: ما مهارات إنتاج الصورة الرقمية لطلاب تكنولوجيا التعليم؟ وقد تمت الإجابة عن هذا السؤال بالتوصل إلى قائمة مهارات إنتاج الصورة الرقمية

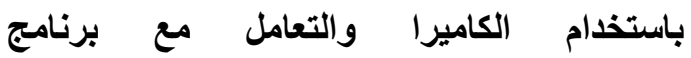
وذلك فى الجزء الخاص بإجراءات (Photoshop) البحث ويمكن الرجوع إليها فى هذا الجزء. ثانيا: إجابة السؤال الثانى والأى ينص على: ما معايير تصميم بيئة الألعاب التعليمية الرقمية؟ فقد تم إعداد قائمة معايير بيئة الألعاب

\begin{tabular}{|c|c|c|c|}
\hline المجموع & الاتحراف المعيارى & المتوسط & المجموعة \\
\hline 19.5000 & 1.16450 & 19.5833 & ألعاب قبلية ونمط أيمن \\
\hline 20.5000 & 1.44600 & 20.5000 & ألعاب قبلية ونمط أيسر \\
\hline 22.6000 & 1.24011 & 22.5833 & ألعاب قبلية ونمط متكامل \\
\hline 19.0000 & 1.04447 & 19.0000 & ألعاب بعدية ونمط أيمن \\
\hline 19.5000 & .79772 & 19.5000 & ألعاب بعدية ونمط أيسر \\
\hline 21.5714 & 1.52753 & 21.8333 & لعاب بعدية ونمط متكامل \\
\hline 20.2759 & 1.76826 & 20.5000 & المجموع \\
\hline
\end{tabular}
التعليمية الرقمية لتتمية مهارات إنتاج الصورة 
يلاحظ أن هناك توجها واضحا نحو الألعاب القبلية، وكنلك نمط السيادة المخية المتكامل في التحصيل المعرفى المرتبط بمهارات إنتاج الصورة الرقمية. المعرفى لمهارات إنتاج الصورة الرقية: يوضح الجدول التالى نتائج التحليل ثنائى الاتجاه بالنسبة للتحصيل المعرفى لمهارات إنتاج الصورة الرقمية
يوضح جدول (0) نتائج الإحصاء الوصفى للمجموعات التجريبية بالنسبة لتحصيل الجاتب المعرفى المرتبط بمهارات إنتاج الصورة الرقية، ويلاحظ من البيانات المعروضة أن هناك فرق واضح بين متوسطات الدرجات بالنسبة لنمط توقيت الألعاب ونوع السيادة المخية، حيث بلغت مجموعة الألعاب القبلية ذات النمط المتكامل (22.58) وكاتت أعلى نسبة مقارنة بباقى المجموعات، بينما بلغت مجموعة الألعاب البعدية ذات النمط الأيمن (19.0) وكانت أقل نسبة مقارنة بباقى المجموعات. كما جدول("): نتائج تحليل التباين ثنائى الاتجاه للاختبار التحصيلى

\begin{tabular}{|c|c|c|c|c|c|}
\hline مستوى & قيمة ف & المربعات & الدرية & 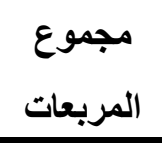 & مصدر التباين \\
\hline .06 & 3.61 & 10.889 & 1 & 10.88 & توقيت تقديم الألعاب \\
\hline .000 & 34.552 & 55.542 & 2 & 111.083 & نمط السيادة المخية \\
\hline \multirow[t]{3}{*}{.000} & 16.251 & 24.500 & 5 & 122.5 & العلاقة بين توقيت تقديم الألعاب \\
\hline & & 1.508 & 66 & 99.500 & الخطأ \\
\hline & & & 72 & 30480.0 & المجموع \\
\hline
\end{tabular}

الصورة الرقمية، ترجع للتأثير الأساسى لاختلاف توقيت تقايم الألعاب التعليمية الرقمية ثلاثية الأبعاد

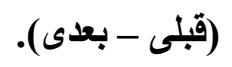

وباستقراء النتائج في جدول (†) في السطر الأول يتضح أنه لا يوجد فرق دال إحصائيا فيما بين متوسطى درجات الكسب في التحصيل المعرفى لمهارات إنتاج الصورة الرقمية نتيجة الاختلاف في توقيت تقايم الألعاب. وبالتالي يتم قبول الفرض
وياستخلام نتائج جدول (†) يمكن استعراض النتائج من حيث أثر المتغيرين المستقل والتصنيفى والتفاعل بينهما على ضوء مناقثة الفروض الثلاثة الأول للبحث وهى كالتالى: الفرض الأول: ينص على أنه: لا توجد فروق ذات دلالة إحصائية عند مستوى 0,05 بين متوسطات درجات المجموعتين التجريبيتين فى الاختبار التحصيلى للجانب المعرفى لمهارات إنتاج 
المعرفة وإعادة هيكتتها وتمثيل ما يعرفونه من

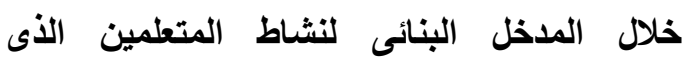
يساعدهم في بناء معارفهم بأنفسهم بدلا من اعتمادهم على المعلم.

كما يمكن تفسير نتائج مجموعات الألعاب البعدية في ضوء نظرية المنظمات اللاحقة التي ترى أن المنظمات اللاحقة أو البعدية أو المتأخرة تقوم بالربط والتلخيص لما تم تعلمه، وهى تماثل المنظمات التمهيدية في كل خصائصها (حسن

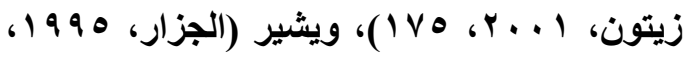

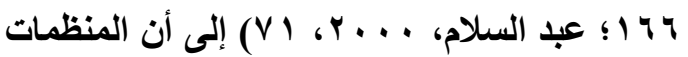
اللاحقة قد تنظم البنية المعرفية للمتعلم بعد مهمة التعلم الجديدة وبالتالي يمكن أن تزيد التعلم. كما

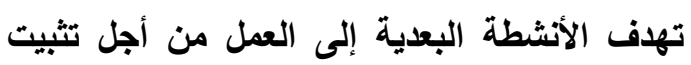
المادة الدراسية الجديدة في وعي المتعلم ودمجها مع عناصر خبرته المعرفية، وتعد هذه المرحلة هامة جداً، لأن نجاحها هو نجاح عملية التعلم،

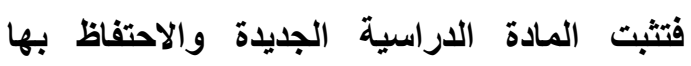
بطريقة تجعلها جاهزة للاسترجاع في المواقف التعليمية التالية، من أهم الدلائل على فعالية التعلم وأحد الإجراءات الهامة في ربط التعلم السابق

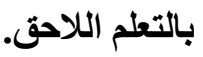

كنلك حرص الباحثان على توفير قدر كبير من الكفاعة في تصميم بيئة الألعاب التعليمية الرقمية

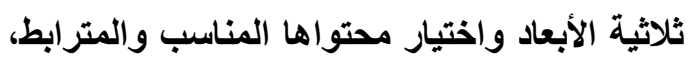
كما يمكن تفسير النتائج في ضوء نظرية معالجة المعلومات البصرية على أساس أن التعلم عملية
الأول لعدم وجود دلالة إحصائية ترجع لاختلاف توقيت تقديم الألعاب الرقمية. تفسير نتيجة الفرض الأول:

وتثثير هذه النتيجة إلى أنه لا توجد فروق دالة بين الطلاب الذين درسوا من خلال الألعاب القبلية وبين من هم درسوا بالألعاب البعدية، وهو الأمر الأى يتيح سعة مرونة في استخدام كلا من النمطين بالألعاب التعليمية الرقمية ثلاثية الأبعاد وإنتاجها

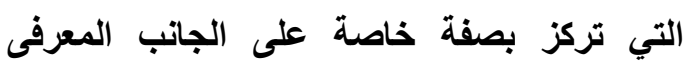

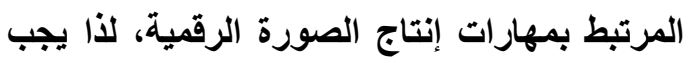
مراعاة هذه النتيجة عند تصميم بيئات الألعاب التعليمية الرقمية خاصة إذا دعمت نتائج الاراسات والبحوث المستقبلية هذه النتيجة. ويرجع الباحثان هذه النتيجة إلى الأسباب التالية: أن السبب الأساسى لهذه النتيجة يرجع للتأثير المتبادل لكل من المنظم المتقدم والمتأخر، ويمكن تفسير ذلك في ضوء نظرية المنظمات التمهيدية Advance Organizers حيث تقوم الألعاب القبلية بوظائف المنظمات التمهيدية من حيث توجيه انتباه الطلاب إلى ما لـابه سوف يعرض عليهم أثناء ممارسة الألعاب، مع تزويدهم بإطار عام للمطلومات المطلوب معرفتها؛ إضافة إلى مساعدتهم في تثبيت المعرفة الجديدة وتدعيمها، كما سدت الفجوة بين ما يعرفه المتعلم وما يحتاج لمعرفته من المادة الجديدة من خلال التعلم القائم على المعنى، كما أنها ترتبط بنظرية التعلم البنائى لأنها تساعد المتعلمين على تنظيم 
المعلومات، ليكون التعلم ذا معنى تام، كما تمكن المتعلم من السيطرة على موضوع التعلم، وتسهر في نموه المعرفي، بحيث يحتفظ بالمعلومات

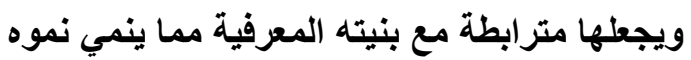
المعرفي. بينما تختلف مع دراسة كل من من بنه - (Jafari, جينفركennifer,2013) في تفوق الألعاب الرقمية كمنظم متقدم، حيث سعت هذه الدراسات إلى قياس أثر الألعاب الرقمية كمنظم متقدم فقط وتوصلت إلى فاعليتها في تنمية جوانب تعلم مختلفة.

الفرض الثانى: ينص على أنه: توجد فروق ذات دلالة إحصائية عند مستوى 0,05 بين متوسطات درجات المجموعات التجريبية فى في الاختبار التحصيلى للجانب المعرفى لمهارات إنتاج الصورة الرقمية، ترجع لتأثير السيادة النصفية للمخ (أيمن- أيسر- متكامل) بمجموعات التعلم.

وباستقراء نتائج الجدول (7) في السطر الثانى، يتضح أن هناك فرق دال إحصائيا فيما بين متوسطى درجات الكسب في التحصيل المعرفى لمهارات إنتاج الصورة الرقمية نتيجة الاختلاف في

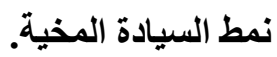
ولتحديد اتجاه هذه الفروق تم استخدام اختبار توكى (Tukey)، كما يتضح من الجدول

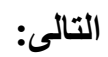

تحدث داخل المتعلم، وتركز على العمليات العقلية التي تجريها لمعالجة المعلومات التي تسنقبلها، حيث يتم نقل المعلومات إلى الذاكرة العاملة، ثم بناء وصلات بين المطلومات الموجودة في الأكرتين العاملة والطويلة المدى، ثم تعالج من خلال الترميز والتخزين والاسترجاع، ويتم التعلم وفق الاستراتيجية من خلال المدخلات، والتي تمثل ولثربن المثيرات البيئية الجديدة (معلومات) ويتم إدراكها من خلال الحواس ثم معالجتها، وبذلك يتم عمل شبكة من التمثيلات ودمج المثيرات الجديدة في بيئة تعلمه السابقة، ثم يتم إصدار المخرجات في صورة استجابات جليدة؛ من خلال عدة عوامل منها: استخدام الاستراتيجيات البصرية من صور ورسوم ثلاثية الأبعاد في تصميم الألعاب التعليمية الرقمية ودمج الصور مع الكلمات دعم اكتساب المتعلم للمعارف والمهارات بثكل بصرى جعلت التعلم أكثر سهولة، اعتماد تصميم الألعاب على المثيرات البصرية أدى إلى زيادة انتباه المتعلم، لكم كبير من النماب المعلومات البصرية واللفظية، مما أدى إلى تنمية الجاتب المعرفى لمهارات إنتاج الصورة الرقمية. وتتفق هذه النتيجة مع نتائج دراسة كل من: (ميركلى Morkley,2010؛ هورتونHen,2011)

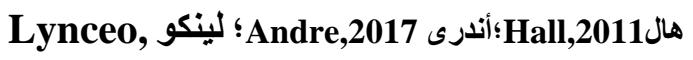
2016) والتي أكدت على أن المنظمات التمهيدية أو المتأخرة تنمي في المتعلم التحصيل والقدرة على القى الاستدلال والاستقراء لإدرات العلاقات وربط 
جدول(V): نتائج اختبار توكى (Tukey) للكثف عن اتجاه الفروق بين متوسطات مجموعات البحث

\begin{tabular}{|c|c|c|c|c|}
\hline المتكامل & الأيسر & الأيمن & المتوسطات & السيادة النصفية \\
\hline دالة & غير دالة & -- & 1900.00 & الأيمن \\
\hline دالة & -- & & 20.0000 & الأيسر \\
\hline-- & & & 22.2083 & المتكامل \\
\hline
\end{tabular}

يؤكد التربويون أن نمط السيادة المتكامل

يجمع ما بين صفات وخصائص النصفين معا الأيسر والأيمن من الاماغ، فهو يتمتع بوظائف النصفين إزاء المثيرات التي يستقبلها والسلوك الأى يقوم بها، وهذا ما يجعله يتفق مع تنمية مهارات إنتاج الصورة الرقمية، فهو يستخدم وظائف الثق الأيسر من حيث التحليل والتصنيف للمعارف والتعامل معها بمنطقية، كما أنه يتسم بأسلوب تعلم جيد وتفكير عقلانى ومنطقى ويعمل وفق منهج تتابعى، ويرتب خطواته وينتقل من الجزء إلى الكل ويبحث في العلاقات التسلسلية والمنطق ويتسم بالثبات والانتظام في التجريب والتعلم والتفكير، ويجيا

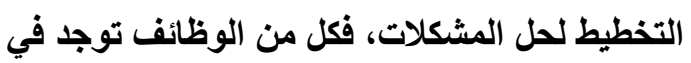
الشث الأيسر يستخدمها النمط المتكامل ويكملها بوظائف الثث الأيمن الذى يتسم بالتركيز الداخلى على المعلومات الموجودة به، والاستفادة من الخبرات والإسهاب في التفسير كما أنه يهتم بالمعالجات الآنية والأفكار ولديه بديهة في حل المشكلات ، ويجيد تنظيم الأثياء لتتضح العلاقات بينها ويرتب الأفكار ليخرج بالاستنباط السريع، وله قدرة على وضع الافتراضات الدقيقة المدروسة، فهذا التكامل بين شقى الدماغ ينتج عنه تفكير يتسم
وياستقراء نتائج جدول (V) يتضح أن نمط السيادة المتكامل هو الأعلى متوسطا حيث بلغ

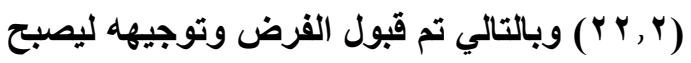
"توجد فروق ذات دلالة إحصائية عند مستوى 0,05 بين متوسطات درجات المجموعات التجريبية فى الاختبار التحصيلى للجانب المعرفى لمهارات إنتاج الصورة الرقمية، ترجع لتأثير السيادة النصفية للمخ (أيمن- أيسر- متكامل) بمجموعات التعلم لصالح المجموعة ذات نمط السيادة

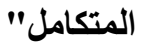
تفسير نتيجة الفرض الثانى: وتثير هذه النتيجة إلى أن الطلاب ذوى نمط السيطرة المتكامل كانوا أكثر إيجابية في تحصيل الجانب المعرفى لمهارات إنتاج الصورة الرقمية في كل من الألعاب القبلية والألعاب البعدية، وعلى ذلك إلكاج يجب مراعاة هذه النتيجة عند تصميم بيئة الألعاب التعليمية الرقمية إذا مادعمت نتائج الاراسات والبحوث المستقبلية هذه النتيجة. ويرجع الباحث هذه النتيجة إلى الأسباب

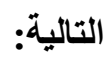

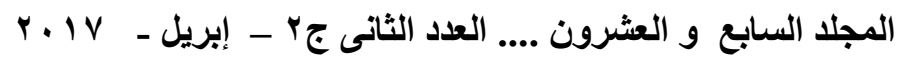
ए। 
للمهارات الدفاعية أكبر من اللاعبين ذوى السيادة النصفية (الأيمن أو الأيسر). بينما تختلف هذه النتيجة مع نتائج (بن فليس،

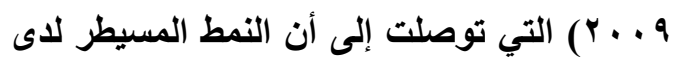

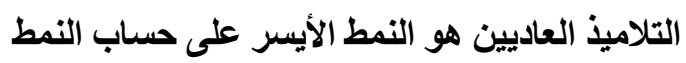
الأيمن أو المتكامل الذي لم يظهر تمامـا لاى أفراد

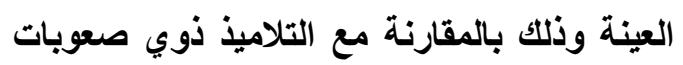
تعلم الكتابة والرياضيات الذين سيطر لديهم النمط

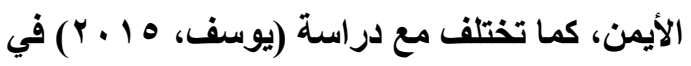
سيطرة النمط الأيسر للمخ. بينما جاعت دراسة

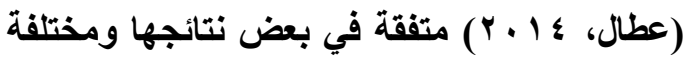
في البعض الآخر، حيث توصلت إلى أن النمط السائد عند طلاب الصف الرابع والخامس العاديين هو النمط الأيسر، بينما النمط المتكامل هو السائد عند الإناث، وأن هناتك دلالة إحصائية في النمط المتكامل بين الطلاب العاديين والمعوقين سمعيا. الفرض الثالث: ينص على أنه: توجد فروق ذات دلالة إحصائية عند مستوى 0,05 بين

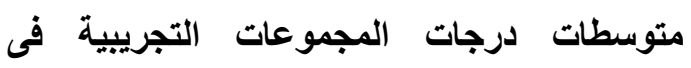
الاختبار التحصيلى للجانب المعرفى لمهارات إنتاج الصورة الرقمية، ترجع للتأثير الأساسى للتفاعل بين توقيت تقديم الألعاب التعليمية الرقمية ثلاثية

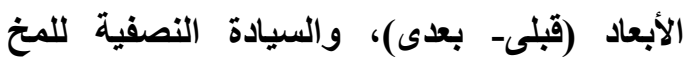

$$
\text { (أيمن- أيسر- متكامل) للطلاب. }
$$

وباستقراء النتائج في جلول (†) في السطر الثالث، يتضح أن هناك فروق دالة إحصائيا عند مستوى > ه.,. فيما بين متوسطات درجات
بالدقة والسلامة من الأخطاب في الغالب، ويولا لاى الأفراد تفكير واعى. لذا كان أصحاب نمط السيادة المتكامل أكثر إنجازا وتحصيلا من ذوى النمط الأيمن والأيسر، وتؤكد هذه النتيجة وجهة النظر

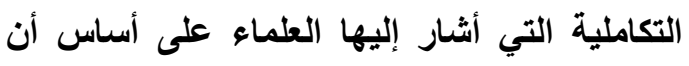
النصفين الكرويين بالمخ يكمل كل منهم الآخرباعتبارهما أساسين للتفكير وحل المشكلات، وأن الفروق الوظيفية فيما بينهما كمية أكثر من نوعية وهذا ما اتفق عليه كل من (النعيمى، צ . . Y ؟ كامل،

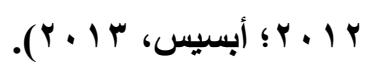

كما أن الطالب تزداد قدرته على التعلم والتفكير كلما كان له دور إيجابى داخل بيئة التعلم، وكلما قام بعمل الأنثطة التي يتعلم من خلالها، وهذا يتطلب استخدام الأساليب والألعاب التعليمية التي تساهم في تحسين التعلم وتنمية التفكير لاى لإب الطلاب، لذا توفر بيئة الألعاب التعليمية الرقمية بيئة تعليمية مثيرة ومزودة بالخيارات المتعددة، وتقدم تغذية راجعة مباثرة، وذلك باستخدام استراتيجيات ووسائل وأنشطة تعليمية تتحدى قدرات الطلاب وتوظف النصفين الكرويين للمخ معا بشكل متكامل، مما يجعلها قادرة على تحسين أنماط التعلم وتنمية التفكير لاى الطلاب. وتتفق هذه النتيجة مع نتائج دراسة (محسن،

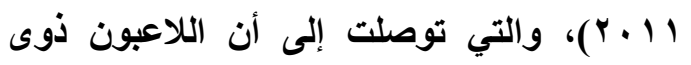
السيادة النصفية (المتكامل) لايهم تفكيرا حاذقا عاليا، ولديهم القدرة على إنجاز اختبارات الدقة 
الفروق تم استخدام اختبار توكى (Tukey)، كما

الكسب في التحصيل المرتبط بمهارات إنتاج

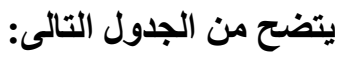
الصورة الرقمية نتيجة التفاعل بين توقيت تقايم الألعاب ونمط السيادة المخية. ولتحديد اتجاه هذه جدول(^): نتائج اختبار توكى للكثف عن اتجاه الفروق بين متوسطات مجموعات الاختبار التحصيلى

\begin{tabular}{|c|c|c|c|c|c|c|c|}
\hline متكامل بعدى & أيسر & بعدى ايمن & متكامل قبلى & قبلى ايسر & قبلى ايمن & المتوسط & نوع التفاعل \\
\hline دالة & غير دالة & غير دالة & دالة & غير دالة & -- & 19.58 & قبلى أيمن \\
\hline دالة & غير دالة & غير دالة & دالة & -- & & 20.50 & قبلى أيسر \\
\hline غير دالة & دالة & دالة & -- & & & 22.58 & قبلى متكامل \\
\hline دالة & غير دالة & -- & & & & 19.00 & بعدى أيمن \\
\hline غير دالة & -- & & & & & 19.50 & بعدى أيسر \\
\hline-- & & & & & & 21.83 & بعدى متكامل \\
\hline
\end{tabular}

المتكامل في كل من الألعاب القبلية والبعدية مقارنة بمجموعات الطلاب ذوى نمط السيادة الأيسر ومجموعات الطلاب ذوى نمط السيادة الأيمن بكل من الألعاب القبلية والبعدية، في تنمية مهارات إنتاج الصورة الرقمية، وعلى ذلك يجب مراعاة هذه النتيجة عند تصميم الألعاب التعليمية الرقمية ثلاثية الأبعاد خاصة إذا ما دعمت نتائج الدراسات والبحوث المستقبلية هذه النتيجة. حملت نتائج هذا الفرض نفس توجهات نتائج الفرضين السابقين حيث تفوق نمط الطلاب ذوى السيادة المتكامل في كل من الألعاب القبلية والبعدية، مع عدم وجود فروق دالة بين كل من الألعاب القبلية والألعاب البعدية. ويرجع الباحثان هذه النتيجة إلى ذات الأسباب التي فسرت تفوق مجموعات الألعاب التعليمية الرقمية ذات نمط السيادة المتكامل ، على كل من نمط السيادة الأيمن

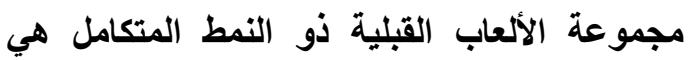

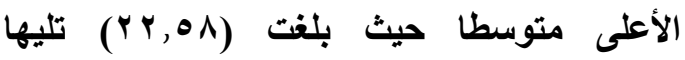

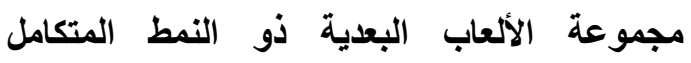

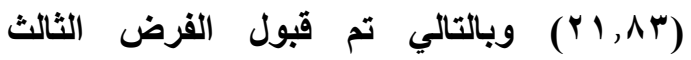
وتوجيهه ليصبح " توجد فروق ذات دلالة إحصائية عند مستوى 0,05 بين متوسطات لدرجات

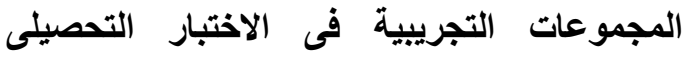
للجانب المعرفى لمهارات إنتاج الصورة الرقمية، ترجع للتأثير الأساسى للتفاعل بين توقيت تقايم الألعاب التعليمية الرقمية ثُلاثية الأبعاد (قبلى لونى

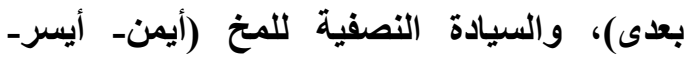

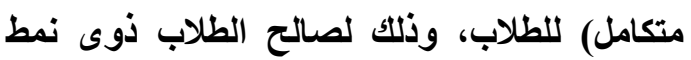

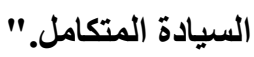
تفسير نتائج الفرض الثالث: تثير هذه النتيجة التي توصل إليها البحث إلى أن تفوق مجموعة الطلاب ذوى نمط السيادة 
ـ الإحصاء الوصفى لبطاقة ملاحظة أداء

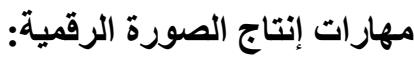

تم تحليل نتائج المجموعات الست بالنسبة لبطاقة ملاحظة أداء مهارات إنتاج الصورة الرقمية، وذلك بالنسبة للمتوسطات والانحرافات المعيارية وطبقا لمتغيرى البحث الحالي، جدول (9) يوضح

ذلك.
والأيسر، وكنلك عدم وجود فروق بين كل من الألعاب القبلية والألعاب البعدية، في تنمية الجاتب المعرفى لمهارات إنتاج الصورة الرقمية. r الأداء لمهارات إنتاج الصورة الرقمية

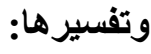

جدول(9) المتوسطات والانحرافات المعيارية لبطاقة ملاحظة أداء مهارات إنتاج الصورة الرقمية

\begin{tabular}{|c|c|c|c|}
\hline المجموع & الانحراف المعيارى & المتوسط & المجموعة \\
\hline 312.5833 & 20.96245 & $3.1383 E 2$ & ألعاب قبلية ونمط أيمن \\
\hline 305.3492 & 16.31972 & 3.0617E2 & ألعاب قبلية ونمط أيسر \\
\hline 355.6684 & 22.69962 & $3.5700 \mathrm{E} 2$ & ألعاب قبلية ونمط متكامل \\
\hline 297.1787 & 19.49514 & 2.9833E2 & ألعاب بعدية ونمط أيمن \\
\hline 298.4162 & 26.15846 & $3.0058 \mathrm{E} 2$ & ألعاب بعدية ونمط أيسر \\
\hline 350.4160 & 26.91555 & $3.5242 \mathrm{E} 2$ & ألعاب بعدية ونمط متكامل \\
\hline 318.2104 & 32.48339 & $3.2139 \mathrm{E} 2$ & المجموع \\
\hline
\end{tabular}

توجها واضحا نحو الألعاب القبلية، وكذلك نمط السيادة المخية المتكامل في التحصيل المعرفى المرتبط بمهارات إنتاج الصورة الرقمية.

r) عرض النتائج الاستدلالية لبطاقة ملاحظة أداء مهارات إنتاج الصورة

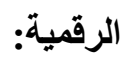

يوضح الجدول التالى نتائج التحليل ثنائى الاتجاه بالنسبة للتحصيل المعرفى لمهارات إنتاج الصورة الرقمية
يوضح جدول (9) نتائج الإحصاء الوصفى للمجموعات التجريبية بالنسبة لبطاقة ملاحظة أداء مهارات إنتاج الصورة الرقمية، ويلاحظ من البيانات المعروضة أن هناك فرق واضح بين متوسطات الدرجات بالنسبة لنمط توقيت الألعاب ونوع السيادة المخية، حيث بلغت مجموعة الألعاب القبلية ذات النمط المتكامل (3.57) وكانت أعلى نسبة مقارنة بباقى المجموعات، بينما بلغت مجموعة الألعاب البعدية ذات النمط الأيمن (2.98) وكاتت أقل نسبة مقارنة بباقى المجموعات. كما يلاحظ أن هناك 
جدول(• (1): نتائج تحليل التباين ثنائى الاتجاه لبطاقة الملاحظة

\begin{tabular}{|c|c|c|c|c|c|}
\hline مستوى & قيمة ف & متوسط & الحرية & مجموع المربعات & مصدر التباين \\
\hline .267 & 1.253 & 1317.556 & 1 & 1317.5 & توقيت تقديم الألعاب \\
\hline .000 & 34.552 & 55.542 & 2 & 111.083 & نمط السيادة المخية \\
\hline \multirow[t]{3}{*}{.000} & 16.669 & 8361.8 & 5 & 41809.3 & العلاقة بين توقيت تقديم الألعاب \\
\hline & & 501.6 & 66 & 33107.8 & الخطأ \\
\hline & & & 72 & 7511856.0 & المجموع \\
\hline
\end{tabular}

تفسير نتيجة الفرض الرابع:

تثير هذه النتيجة التي توصل إليها البحث

الحالي إلى أن الأثر الأساسى لنمطى توقيت تقديم

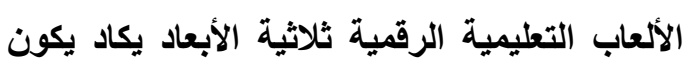

متساويا، وهو الأمر الذى يتيح سعة ومرونة في

استخدام كلا من النمطين مع كلا الأداتين عند

تصميم بيئة الألعاب التعليمية الرقية التي تركز بصفة خاصة على تعلم المهارات، لذا يجب مراعاة هذه النتيجة عند تصميم بيئات الألعاب التعليمية الرقمية خاصة إذا ما دعمت نتائج الاراسات والبحوث المستقبلية هذه النتيجة.

ويرجع الباحث هذه النتيجة لذات الأسباب التي

ذكرت في تفسير الفرض الأول للبحث الخاص بالجانب المعرفى للمهارة، نظرا لاتفاق التوجهات التي أدات لهذه النتيجة ـمن وجهة نظر الباحث بالبحث الحالي- وارتباط التفسير بخصائص الألعاب التعليمية الرقمية ثلاثية الأبعاد والنظريات المرتبطة وانة بها، ويضاف إلى ذلك طبيعة عملية التدريب على المجلد السابع و العشرون .... العدد الثانى جr - إبريل - V V Y
وياستخدام نتائج جلول (· (1) يمكن استعراض النتائج من حيث أثر المتغيرين المستقل والتصنيفى والتفاعل بينهما على ضوء مناقثة الفروض الثلاثة

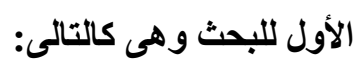
V- الفرض الرابع: ينص على أنه: لا توجد

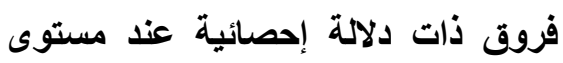
0,05 بين متوسطات درجات المجموعتين التجريبيتين فى معدل أداء مهارات إنتاج

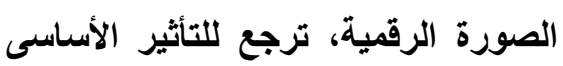
لاختلاف توقيت تقديم الألعاب التعليمية

$$
\text { الرقمية ثلاثية الأبعاد (قبلى - بعدى). }
$$

وياستقراء النتائج في جذول (• 1) في السطر الأول يتضح أنه لا يوجد فرق دال إحصائيا فيما بين متوسطى درجات الكسب في معدل أداء مهارات إنتاج الصورة الرقمية نتيجة الاختلاف في توقيت تقديم الألعاب. وبالتالي يتم قبول الفرض الأول لعدم وجود دلالة إحصائية ترجع لاختلاف توقيت تقديم

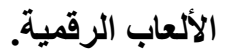


الجمعية المصرية لتكنولوجيا التعليم

نتائج (Lynceo,2016) والذى توصل إلى فاعلية الألعاب كنشاط تمهيدى في التعليم العالى. ودراسة

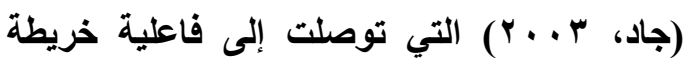
المفاهيم كمنظم متقدم في تحصيل طلاب الاتتصاد

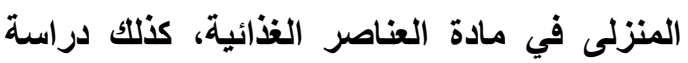
(الميهى، . . . . P) والتي توصل إلى فاعلية خريطة المفاهيم كمنظم متقدم في علاج الفهم الخاطئ

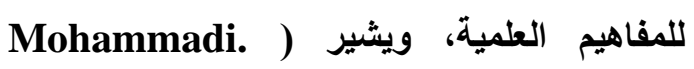
2010) أن توقيت تقليم المنظم ونوعيته يؤثر في التحصيل وتنمية المهارات تبعا لنوع المحتوى والموقف التعليمى، وأنه ليس بالضرورة أن يرتبط تنمية التحصيل أو الاتجاهات أو المهارات بنمط بهرئ المنظم وتوقيت تقديمه.

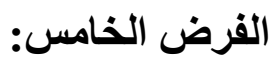

ينص على أنه: توجد فروق ذات دلالة إحصائية عند مستوى 0,05 بين متوسطات درجات المجموعات التجريبية فى بطاقة ملاحظة الأداء

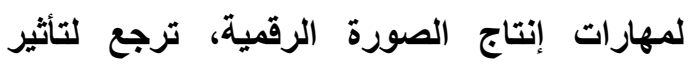
السيادة النصفية للمخ (أيمن- أيسر- متكامل)

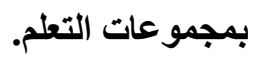
وباستقراء النتائج في جدول (• (1) في السطر الثانى يتضح أنه يوجد فرق دال إحصائيا فيما بين متوسطى درجات الكسب في معدل أداء مهارات إنتاج الصورة الرقمية نتيجة الاختلاف في نمط السيادة المخية (أيمن- أيسر- متكامل) ولتحديد اتجاه هذه الفروق تم تطبيق اختبار توكى كما في

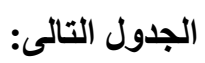

المهارات العملية والمعرفية تعتمد بثكل أساسى على نمط تقديم المحتوى وتنظيمه، حيث يعمل نمط تقديم المحتوى (الألعاب القبلية، الألعاب البعدية)

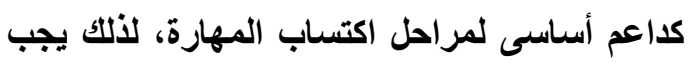
أن يتضمن نمط تقديم المحتوى أكبر قدر من التحفيز وجذب الانتباه وهذا ما توفره بيئة الألعاب الرقمية. وهذا ما تؤكده نظرية التطلم ذي المغنى: من حدوث التعلم عند حدوث المعنى، من خلال الترابط والتكامل الذى يساعد على بقاؤه، ولذا فإن هن بنية المعلوماتية تحتاج إلى نتابع منظم للعلاقات بين الأاكرة العاملة (معلومات جديدة) والذاكرة طويلة الأمد (معلومات قديمة) ومن هنا تأتى أهمية ممارسة الألعاب التعليمية الرقمية في تنظيم الأفكار وتقديم المهارات في شكل مثير مع توظيف للرسوم

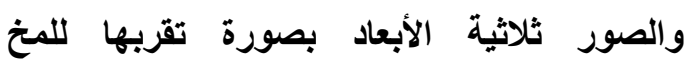
وتستطيع ربطها بالخبرات السابقة للمتعلم ويما تستحث كل من نصفى المخ الكرويين، مع وضوح للأفكار المطلوب تعلمها، حيث تم تدعيم المحتوى دن لهني

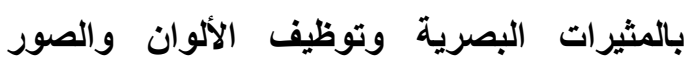
والتغنية الراجعة المباشرة أثناء التقلم للمهمات البسيطة، وتدعيم معدل بقاء المعلومات في الذاكرة،

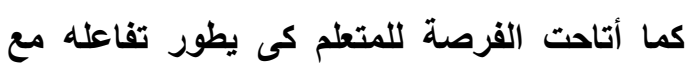
المحتوى لما يبذله من عمليات ذهنية معرفية مطور بذلك خبرات ذاتية خاصة به حددها أسلوب تعلمه. وتتفق هذه النتيجة مع نتائج دراسة (هنداوى،

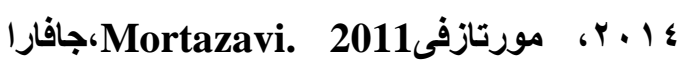
(Jafari. 2012 
جدول(1 (1): نتائج اختبار توكى (Tukey) للكثف عن اتجاه الفروق في بطاقة الملاحظة

\begin{tabular}{|c|c|c|c|c|}
\hline المتكامل & الأيسر & الأيمن & المتوسطات & السيادة النصفية \\
\hline دالة & غير دالة & -- & $3.0608 \mathrm{E} 2$ & الأيمن \\
\hline دالة & -- & & 3.0338E2 & الأيسر \\
\hline-- & & & $3.5471 \mathrm{E} 2$ & المتكامل \\
\hline
\end{tabular}

ذوى نمط التفكير المتكامل والنظريات المرتبطة بها، حيث يفسر ذللك النظرية التكاملية للنصفين الكرويين: التي تفترض أن هناك طبيعة تكاملية للنصفين وأنهما لا يعملان بمعزل عن بعضهما، بل يعملان كمنظومة فائقة التكامل خاصة عند تقايم نمطين مختلفين من المعلومات يوافق كل منها نصف كروى محدد، عندها يحدث توزيع لعبء

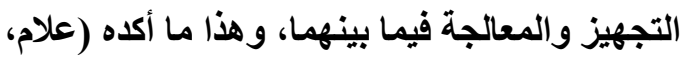
بو 9 1 ) حيث يرى أنه يجب أن تزيد الأهمية الكيفية للفروق الوظيفية للنصفين الكرويين ومراعاة زيادة التنوع في محتوى المناهج واستراتيجيات التطلم الفعالة والتركيز على الأنشطة التي تساعد في تنمية وتكامل الوظائف العقلية، وذلك لأن النظام الحالي ينمى فقط نصف العقل ويهمل النصف الآخر، كما أن فهمنا لعمليات التفكير والأنماط المختلفة في علاقتها باستراتيجيات التعلم وأساليب المعالجة المعرفية للمعلومات يسهل عملية التعلم، لذا يجب التأكيد على بلى

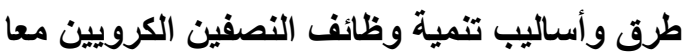
من أجل تظوير الأداء والتحصيل. وتتفق هذه النتيجة مع نتائج دراسة (النعيمى،

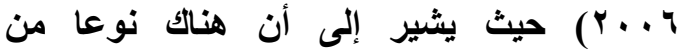
التخص في عمل النصفان الكرويان لمخ الإنسان، ومع ذللك الفعالية الدماغية تعمل وفق أسلوب الإنسان
وياستقراء نتائج جدول (11) يتضح أن نمط السيادة المتكامل هو الأعلى متوسطا حيث بلغ

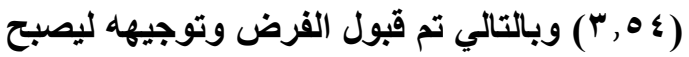
"توجد فروق ذات دلالة إحصائية عند مستوى 0,05 بين متوسطات درجات المجموعات التجريبية فى الاختبار التحصيلى للجانب المعرفى لمهارات إنتاج الصورة الرقمية، ترجع لتأثير السيادة النصفية للمخ (أيمن- أيسر- متكامل) بمجموعات التعلم لصالح المجموعة ذات نمط السيادة

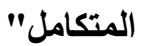
تفسير نتيجة الفرض الخامس: وتثير هذه النتيجة إلى أن الطلاب ذوى نمط السيادة المتكامل أكثر إيجابية في معدل أداء مهارات إنتاج الصورة الرقمية مقارنة مع الطلاب ذوى نمط

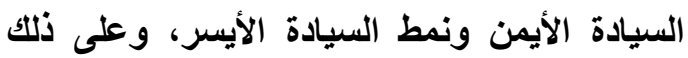
يجب مراعاة هذه النتيجة عند تصميم بيئة الألعاب

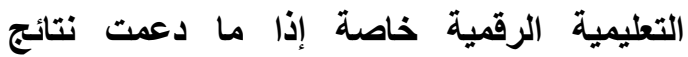
الدراسات والبحوث المستقبلية هذه النتيجة. ويرجع الباحث هذه النتيجة لذات الأسباب التي ذكرت في تفسير الفرض الثانى للبحث بالجانب المعرفى للمهارة، نظرا لاتفاق التوجهات التي أدت لهذه النتيجة، وارتباط التفسير بخصائص الطلاب 
الجمعية المصرية لتكنولوجيا التعليم

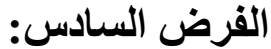

ينص على أنه: توجد فروق ذات دلالة إحصائية

عند مستوى 0,05 بين متوسطات درجات المجموعات التجريبية فى معدل أداء مهارات إنتاج الصورة الرقمية، ترجع للتأثير الأساسى للتفاعل بين توقيت تقديم الألعاب التعليمية الرقمية ثلاثية

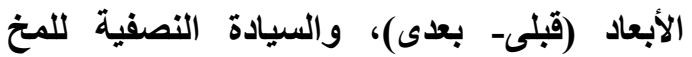
(أيمن- أيسر - متكامل) للطلاب.

وباستقراء النتائج في جدول (†) في السطر الثالث، يتضح أن هناك فروق دالة إحصائيا عند

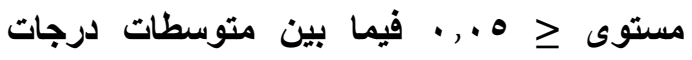
الكسب في معدل أداء مهارات إنتاج الصورة الرقمية نتيجة التفاعل بين توقيت تقديم الألعاب ونمط معاع الكهات

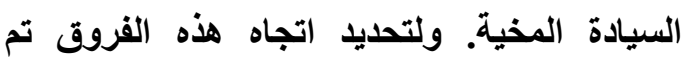
استخدام اختبار توكى (Tukey)، كما يتضح من

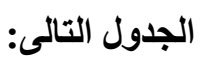

تكاملى من خلال الجسم الجاسى الأى يربط بينهما،

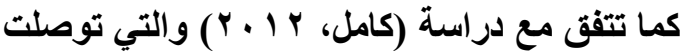
إلى أن نمط السيادة النصفية ليس فقط في شكل وأسلوب العمليات المعرفية للفرد بل يمتد إلى جميع جوانب شخصيته غير المعرفية، لذا يمكن استنتاج أن الدافعية والأداء يرتبطا ارتباطا كبيرا بالتكامل في أداء النصفين معا، وذلك على أساس أن للمتكامل دور في إحداث حالة من التوافق والتوازن في الثخصية، وتلكت بدورها تؤدى إلى استثارة

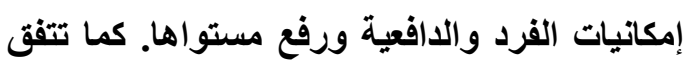

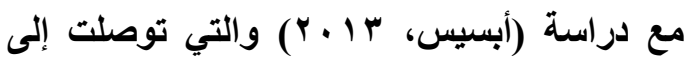
ارتباط النمط المتكامل بكل من مهارة التقويم والارجة الكلية لمهارات ما وراء المعرفة وذللك لأن النمط المتكامل يجمع ما بين صفات وخصائص النصفين معا. وبذلك قدم نمط التفكير المتكامل نمطا فعالا أدى إلى تحسين معدل الأداء المهارى لمهارات إنتاج الصورة الرقمية لاى طلاب تكنولوجيا التعليم.

جدول(r ( ): نتائج اختبار توكى للكثف عن اتجاه الفروق بين متوسطات مجموعات بطاقة الملاحظة

\begin{tabular}{|c|c|c|c|c|c|c|c|}
\hline متكامل بعدى & أيسر بعدى & بعدى ايمن & متكامل قبلى & قبلى ايسر & قبلى ايمن & المتوسط & نوع التفاعل \\
\hline دالة & غير دالة & غير دالة & دالة & غير دالة & -- & 3.1383E2 & قبلى أيمن \\
\hline دالة & غير دالة & غير دالة & دالة & -- & & $3.0617 \mathrm{E} 2$ & قبلى أيسر \\
\hline غير دالة & دالة & دالة & -- & & & $3.5700 \mathrm{E} 2$ & قبلى متكامل \\
\hline دالة & غير دالة & -- & & & & 2.9833E2 & بعدى أيمن \\
\hline غير دالة & -- & & & & & $3.0058 \mathrm{E} 2$ & بعدى أيسر \\
\hline-- & & & & & & $3.5242 \mathrm{E} 2$ & بعدى متكامل \\
\hline
\end{tabular}


الفرضين السابقين حيث تفوق نمط التفكير المتكامل في كل من الألعاب القبلية والألعاب البعدية، ويرجع الباحث هذه النتيجة إلى ذات الأسباب التي فسرت تفوق مجموعة الطلاب ذوى نمط التفكير المتكامل على كل من الطلاب ذوى نمط التفكير الأيمن ونمط

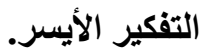

ويرى الباحثان أن ممارسة الألعاب التعليمية الرقمية ثلاثية الأبعاد ساهمت بثكل كبير في تنمية مهارات إنتاج الصورة الرقمية وكان لها أثر فعال في عملية التعلم، كما ساعدت في تفسير المعلومات وفهمها وتذكرها، مما يجعل نتائج التعلم أعمق وأفضل، كما ساعدت على استخلاص الخطوات الرئيسية للمهارة ومعرفة العلاقات بينها من خلال الألوان والصور والأيقونات البصرية لفهم جوانب المهارة وإصدار الأحكام، فقد أتاح ممارسة الألعاب في نقل محور العملية التعليمية إلى المتعلم ليكثف عن ميوله واستعداداته وقدراته ومهاراته الذاتية، بهاف التخطيط لتنميتها وتوجيهها وفقا لوصفة تربوية خاصة بكل متعلم لتقابل ميوله الخاصة وتتماشى مع حاجاته، كما هناك المزيد من المرونة عند تنفيذ الألعاب مما حقق إيجابيات للمتعلم أهمها الاعتماد على نفسه في تنفيذ الأنشطة وتحمل المسئولية، وإتاحة التفاعل الإيجابى مع عناصر الموقف التعليمى.
وباستقراء نتائج الجدول (r I I) يتضح أن مجموعة الألعاب القبلية ذو النمط المتكامل هي الأعلى متوسطا حيث بلغت (r, , (r) تليها مجموعة

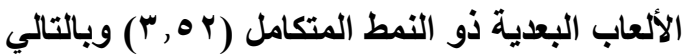
تم قبول الفرض الثالث وتوجيهه ليصبح " توجد فروق ذات دلالة إحصائية عند مستوى 0,05 بين متوسطات درجات المجموعات التجريبية فى معدل أداء مهارات إنتاج الصورة الرقمية، ترجع للتأثير الأساسى للتفاعل بين توقيت تقديم الألعاب التعليمية الرقمية ثلاثية الأبعاد (قبلى- بعدى)، والسيادة النصفية للمخ (أيمن- أيسر- متكامل) للطلاب، وذلك لصالح الطلاب ذوى نمط السيادة المتكامل." تفسير نتائج الفرض السادس: تثير هذه النتيجة التي توصل إليها البحث إلى أن تفوق مجموعة الطلاب ذوى نمط السيادة المتكامل في كل من الألعاب القبلية والبعدية مقارنة بمجموعات الطلاب ذوى نمط السيادة الأيسر ومجموعات الطلاب ذوى نمط السيادة الأيمن بكل من الألعاب القبلية والبعدية، في معدل أداء مهارات إنتاج الصورة الرقمية، وعلى ذلك يجب مراعاة هذه النتيجة عند تصميم الألعاب التعليمية الرقمية ثلاثية الأبعاد خاصة إذا ما دعمت نتائج الداسات والبحوث المستقبلية هذه النتيجة. ويرجع الباحثان هذه النتيجة إلى الأسباب التالية: حملت نتائج هذا الفرض نفس توجهات 
كنظم تمهيدى ومقارنتها بالألعاب الرقمية

وبيان تأثيرها على بعض نواتج التعلم.

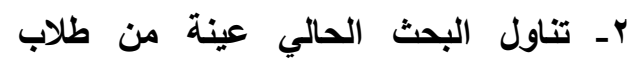

تكنولوجيا التعليم، لذلك من الممكن تغير

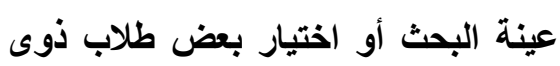

الاحتياجات الخاصة، وذلك عند تقديم

المنظم المتهيدى المتقدم أو المتأخر.

r- تناول البحوث التي تجيب عن إمكانية

الألعاب التعليمية الرقمية ثلاثية الأبعاد

تطوير المهارات التكنولوجية والتربوية

والمحتوى اللازم للامج الألعاب في ولئ

الفصول بشكل صحيح.

ع- من الملاحظ أن البحوث التجريبية غالبا ما

تتضمن فترة زمنية قصيرة، ويستلزم ذلك

تبنى مدخل البحوث المتكررة وعليه

يوصى البحث الحالي ضرورة إعادة إجراء

البحث الحالي من قبل باحثين على مواد البحاد

دراسية مختلفة كمتطلب سابق للتعميم.

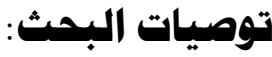

فى ضوء ما أسفرت عنه نتائج البحث

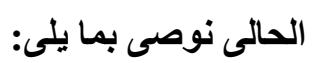

1- الإفادة من نتائج البحث الحالي على

المستوى التطبيقى، خاصة إذا ما دعمت البحوث المستقبلية هذه النتائج.

r- الإفادة من نتائج الاراسات والبحوث هده

السابقة التي تناولت دراسة أثر بعض

متغيرات تصميم بيئات الألعاب التعليمية

الرقمية وإنتاجها في نواتج التعلم المختلفة

عند تصميم هذه البيئات و إنتاجها.

r- الإقادة من نتائج الاراسات والبحوث

السابقة التي تناولت دراسة تأثير التفاعل

بين متغيرات بنائية متعددة خاصة بتصميم

الألعاب التعليمية الرقمية ثلاثية الأبعاد

وإنتاجها على نواتج التطلم المختلفة عند

تصميم وإنتاج هذه البيئات.

؟- مراعاة الاعتماد على نظريات السيادة

المخية وبحوث المخ وأساليب التفكير

والتعلم عند تصميم وإنتاج بيئات التعلم

الرقمية ثلاثية الأبعاد.

الاقترحات ببحمث هستقبلية:

1- تناول البحث الحالي استخدام الألعاب

التعليمية الرقمية ثلاثية الأبعاد كمنظم

متقام ومتأخر، لذلك من الممكن تناول

بيئات ومتغيرات رقمية أخرى للعمل 


\section{Summary of the research:}

The current research aims to identify the effect of the timing of the presentation of instrucation digital 3D games in the development of digital imaging skills in the light of the results of brain research. The research sample consisted of (72) students in the third division of the educational technology department in the Faculty of Specific Education, Aswan University, Based on their results in the modified Torrance TM Scale. The researchers designed two programs for digital 3D games according to the model (Khamis, 2007), One offers games before the skill-related content, and the other offers games after displaying skill-related content, the experment has lasted three weeks, where the six groups students with exposure to a program of digital 3D games, and then the application of research tools.

The results showed that there were no statistically significant differences between the range of pre and post games, and the dominance of the integrated half-sovereignty group on the right and left hemispheric groups 
الجمعية المصرية لتكنولوجيا التعليم

\section{هراجع البحث}

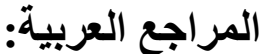

ابراهيم، اسامة محمد عبد السلام(؟ ا • Y). فاعلية تصميم برنامج تدريبى باستخدام نموذج اسامة عبد السلام

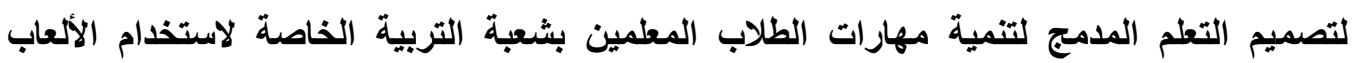
الإكترونية، مجلة كلية التربية، جامعة المنصورة، ع ؟ م، ج ا، يناير.

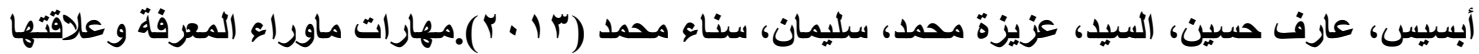
بأنماط السيادة النصفية المخية لاى طلبة الجامعة، فكر وإبداع - مصر، ج77 ، يوليو، ص ص - 380

أبو خطوة، السيد عبد المولى (10 1 ب). أثر برمجية مقترحة قائمة على الألعاب الإكترونية في تنمية بعض مهارات الثقافة البصرية واستخدام الحاسوب لدى الأطفال ذوي الإعاقة السمعية، المؤتمر الدولى لئل

$$
\text { الرابع للتعلم الإكترونى والتعليم عن بعد، الرياض }
$$

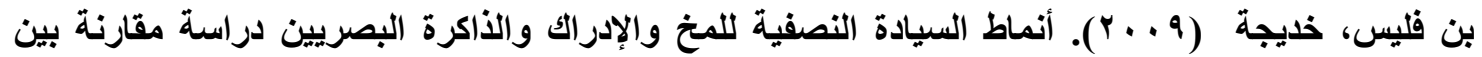
التلاميذ ذوي صعوبات تعلم (الكتابة والرياضيات) والعاديين، رسالة دكتوراه، كلية العلوم الإجتماعية

$$
\text { والإنسانية، جامعة الإخوة منتورى، الجزائر }
$$

توفيق، مروة زكي \& محمد، إيمان مهدي (10 + ب). العلاقة بين ألعاب الشبكات الاجتماعية والدافعية لإنجاز المهام والاتجاه نحو التعلم الاجتماعي لدى المعاقين سمعيا، المؤتمر الدولى الرابع للتعلم الإكترونى

$$
\text { والتعليم عن بعد، الرياض }
$$

جابر، جابر عبد الحميد والثيخ، سليمان وزاهر، فوزى. (râ9). مهارات التدريس. القاهرة: دار النهضة العربية.

جاد، عزه محمد (r . . Y).أثر اختلاف نوع خريطة المفاهيم واسلوب تقديمها على تحصيل طالبات كلية التربية تخصص اقتصاد منزلي لموضوع العناصر الغذائية، دراسات فى المناهج وطرق التدريس- مصر، ع ع

$$
\text { 90، نوفمبر، ص ص } 141 \text { - } 175
$$

الحازمي، هناء بنت محمد سليمان . ( 2006 ) فاعلية استخدام برنامج مقترح في تنمية نمط تعلم النصف الكروي الأيمن للاماغ لاى طالبات العلوم بالمرحلة المتوسطة بالمدينة المنورة، رسالة ماجستير، كلية التربية

و العلوم الإنسانية، جامعة طيبة، السعودية 


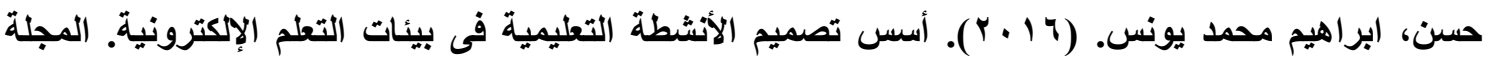
المصرية للمعلومات, مجلة علمية تصدر عن الجمعية المصرية لنظم المعلومات وتكنولوجيا الحاسبات.

$$
\text { العدد السابع عثر يونيو. }
$$

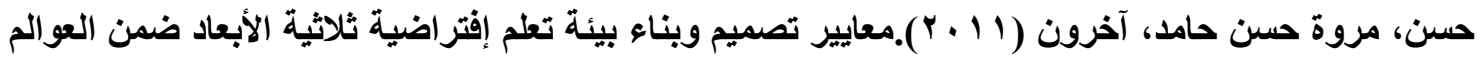
الإفتراضية الحالية Virtual Worlds. تكنولوجيا التربية ـ دراسات وبحوث ـ مصر. أكتوبر. ص

$$
\text { ص } 486 \text { - } 467
$$

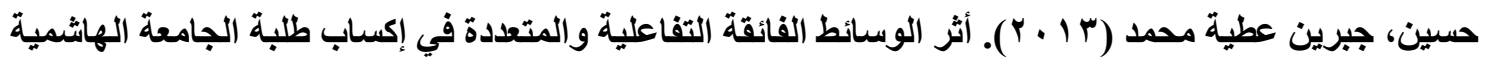

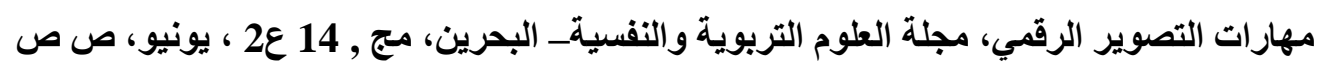

حسين، جبرين عطية محمد(r I ـ Y ). أثر الوسائط الفائقة التفاعلية والمتعددة في إكساب طلبة الجامعة الهاشمية مهارات التصوير الرقمي. مجلة العلوم التربوية والنفسيةـ البحرين. مج , 14 ع2 ـ يونيو. ص ص

$$
284-255
$$

حموده، آلاء زياد (10 (Y). أنماط السيطرة الاماغية وعلاقتها بالتفكير ما وراء المعرفى لاى طلبة جامعة

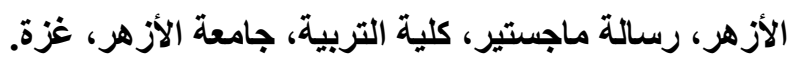

الحيلة، محمد محمود (r ( + Y). الألعاب التريوية وتقنيات إنتاجها سلوكيا وتعليميا وعمليا. عمان. دار المسيرة

$$
\text { للنشر والتوزيع. }
$$

خميس، محمد عطيه (r . .ץ). النظرية والبحث التربوى في تكنولوجيا التعليم. دار السحاب للطباعة والنشر

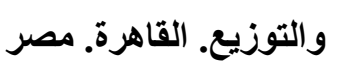

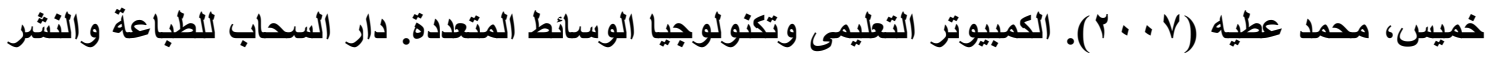

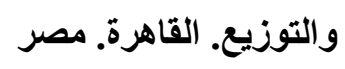

خميس، محمد عطيه (11 (1). الأصول النظرية والتاريخية لتكنولوجيا التعلم الإكترونى. دار السحاب للطباعة والنشر والتوزيع، القاهرة. مصر

خميس، محمد عطيه (10 ( + ). مصادر التعلم الإكترونى، الجزء الأول: الأفراد والوسائط، دار السحاب للطباعة والنشر والتوزيع، القاهرة. مصر 
الرنتيسي، محمود محمد درويش (10 ( P). أثر استخدام التعليم المدمج والوسائط الفائقة على التحصيل المعرفي واكتساب مهارات التصوير الرقمي لاى طلبة الصحافة بجامعة الأمة بغزة، مجلة الجامعة الإسلامية

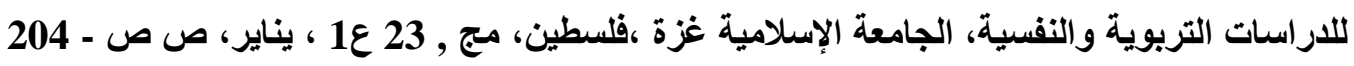

رياض، محمد فوزى (צ 1 • Y): استخدام برامج ومواقع الألعاب التعليمية الإلكترونية لتنمية مهارات التعلم الذاتي والتحصيل في مادة العلوم لاى طلاب المرحلة الإعدادية، مجلة كلية التربية ، جامعة بنها، ع 7 ـ 1 ،

(أبريل ج)

سلطان، منال عيسى حسين (• ( + Y).العوامل التي تؤثر في قوة تحديد الصورة المنتجة بالنظام الرقمي، مع

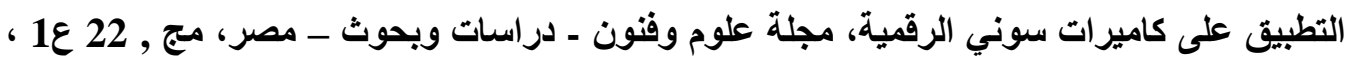

$$
\text { يناير، ص ص } 33 \text { - } 47
$$

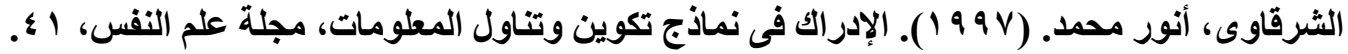

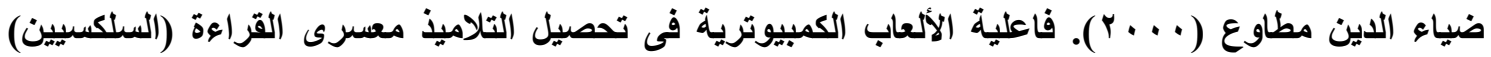
لبعض مفاهيم العلوم بالمرحلة المتوسطة فى المملكة العربية السعودية. مجلة التربية العلمية. المجلد

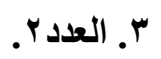

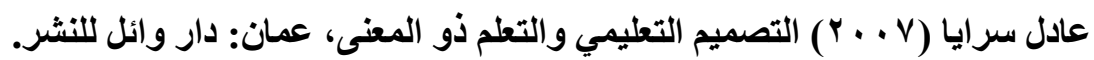

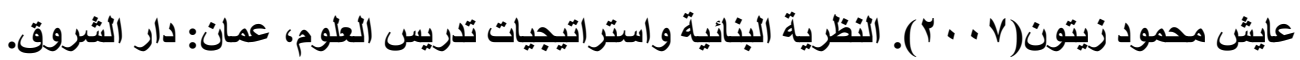
عبد الحميد، وائل رمضان(V V . . P). تصميم برنامج تعليمى متكامل لتهيئة طقل الروضة للتعامل مع مصادر التعلم الإكترونية وقياس فعاليته. رسالة دكتوراه، كلية التربية، جامعة حلوان.

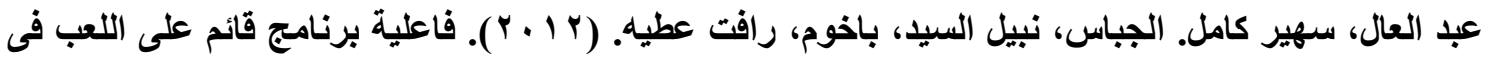
تنمية بعض مهارات التفكير الناقد لاى طقل الروضة. مجلة البحث فى التربية وعلم النفس، كلية

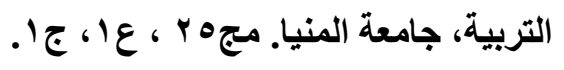

عبد الواحد، سليمان يوسف إبراهيم (V . . . P). المخ وصعوبات التعلم - روئية فى إطار علم النفس العصبى المعرفى، طا ، القاهرة، مكتبة الأنجلو المصرية. 
عبدالسميع، حنان كمال فتحي، وآخرون (7 1 • Y) أثر إستخدام مدخلي الألعاب التعليمية والقصص في إكتساب الأطفال بعض مهار ات الحس العددي بمرحلة رياض الأطفال. مجلة كلية التربية بالفيوم - مصر.

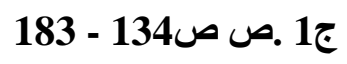

العبسى، محمد مصطفى(9 . . . ). الألعاب والتفكير في الرياضيات، طا ـ عمان: دار المسيرة.

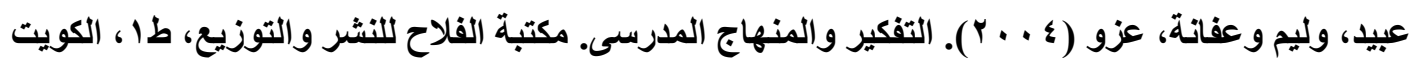

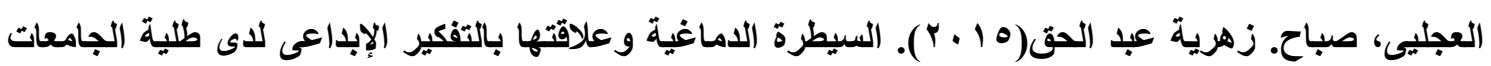

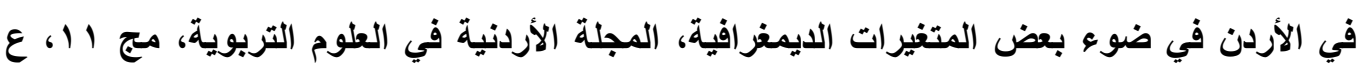

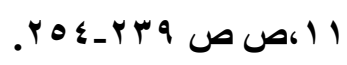

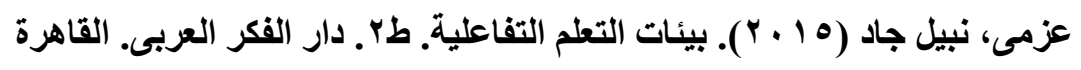

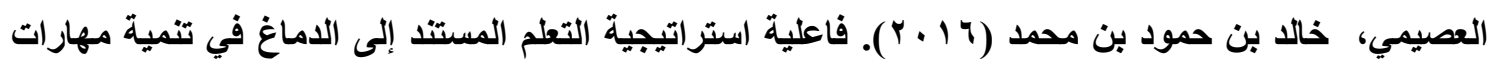
التفكير الابتكارى والثقافة العلمية لاى طالبات العلوم ذوات أنماط السيطرة الدماغية المختلفة بدامعة

$$
\text { الطائف، المجلة الدولية التربوية المتخصصة، المجلا (•)، العدد (ب). }
$$

عطال، يمينة (ع ا + Y). أنماط السيادة النصفية للمخ ودرجة الفقدان السمعى ومهارات الكتابة (الخط، الإملاء، التعبير الكتابى) دراسة ميدانية مقارنة على المعوقين سمعيا والعاديين، كلية العلوم الإنسانية

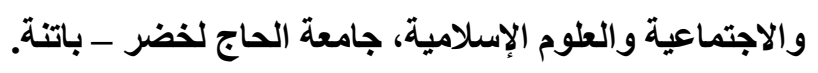

عفيفي، محمد كمال عبدالرحمن (9 . . . †) فاعلية تصميم وحدة دراسية في تنمية مهارات التصوير الفوتوغرافي الرقمي لاى الطلاب المعلمين، مجلة تكنولوجيا التعليم- مصر، مج , 19 ع1 ، يناير، ص ص ص 4 - 75

عفيفي، محمد كمال عبدالرحمن(9 . . . ). فاعلية تصميم وحدة دراسية في تنمية مهارات التصوير الفوتوغرافي

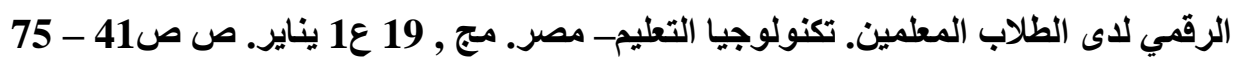

علام، حسن أحمد عمر (ب 99 (1) السيادة النصفية وعلاقتها بكل من استراتيجيات وأساليب التعلم، مجلة كلية

$$
\text { التربية بأسوان - مصر، ع9 عمبر ، ديسمبر، ص ص } 156 \text { - } 187
$$

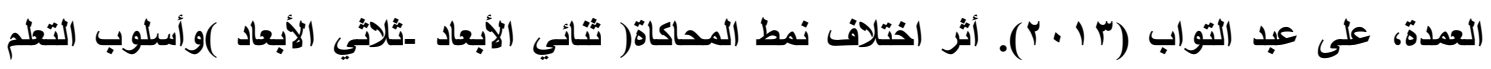
(تعاوني -تنافسي ) في ألعاب الفيديو على التحصيل الرياضي وتنمية بعض المهارات الاجتماعية لاى الدي

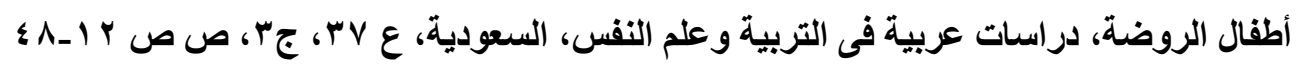


الجمعية المصرية لتكنولوجيا التعليم

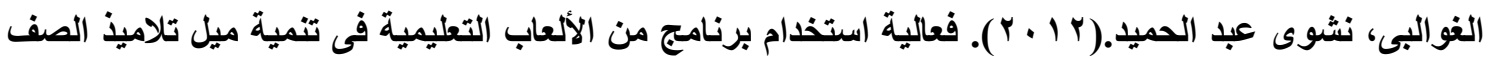

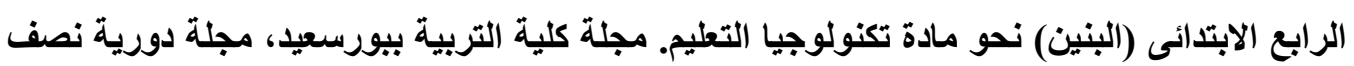

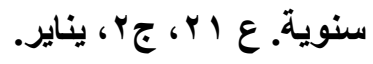

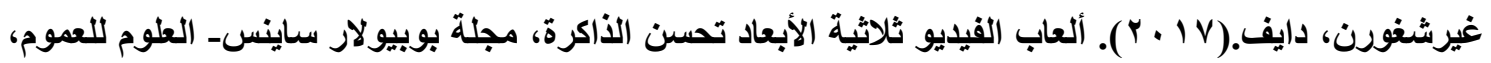

\section{https://www.popsci.ae/}

فارس، نجلاء محمد(V . . †). المعايير البنائية اللازمة لتصميم برمجيات الألعاب التعليمية الرقمية التعليمية ،

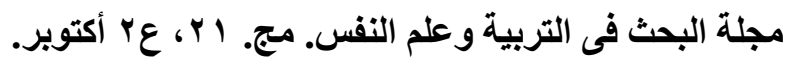

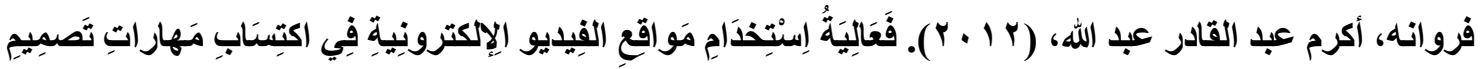

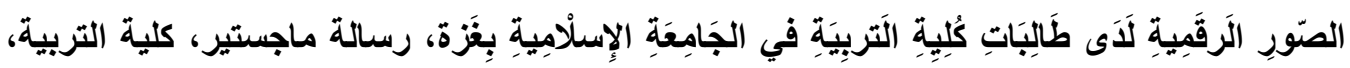

$$
\text { الجامعة الإسلامية بغزة. }
$$

قاسم، أزهار يحيى. (11 (1) أنماط التفكير المرتبطة بنصفى الاماغ الأيمن، الأيسر لاى طلبة المرحلة الإعدادية

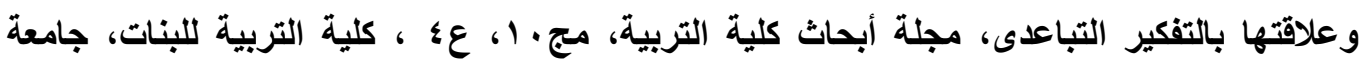

الموصل.

القرني، عبدالله أحمد عبدالله(7 1 • Y). أثر استخدام الألعاب التعليمية الإكترونية كمنظمات تمهيدية على التحصيل

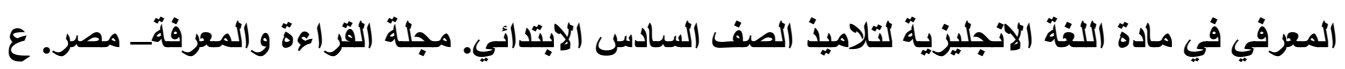

$$
\text { 173. مارس. ص ص: } 273 \text { - } 304
$$

كامل، أميمة مصطفى(Y Y † Y) أنماط السيادة النصفية و علاقتها بيعض الأساليب المعرفية واللامعرفية لاى طلاب

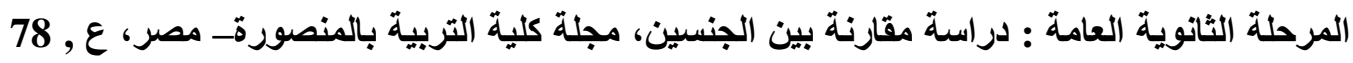

3ج

محسن، بسمة نعيم (11 + (1) التفكير الحاذق وفقاً لتفضيل السيادة المخية النصفية وعلاقته بدقة أداء المهارات

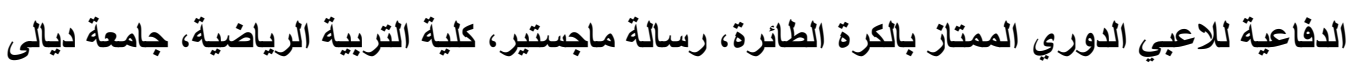

$$
\text { العراق }
$$

محمد، تامر محمود السعيد(7 1 • Y). تأثير استخدام الألعاب التمهيدية على تعلم بعض المهارات الهجومية لبراعم

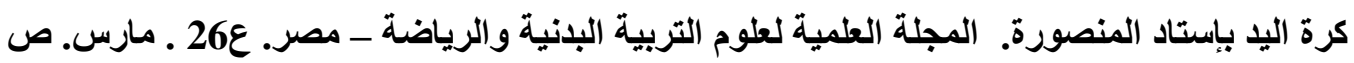

$$
227-205 \text { ص }
$$




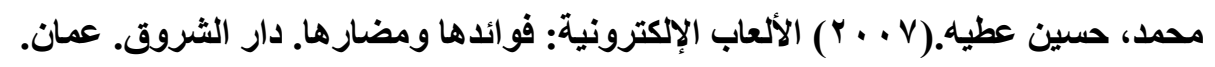

محمد، محمد عبدالعظيم(7 17 • Y). تأثير برنامج باستخدام الألعاب التمهيدية على سرعة تعلم بعض المهارات

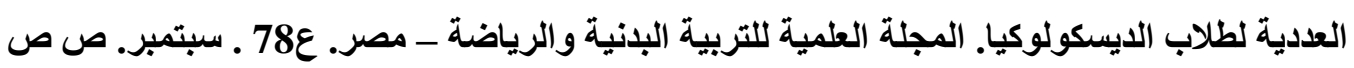

$$
319-301:
$$

محمد، منصور سعيد (11 (Y)مدى افادة طلبة المرحلة الجامعية الاولى بجامعة اسيوط من مصادر الويب ثلاثية

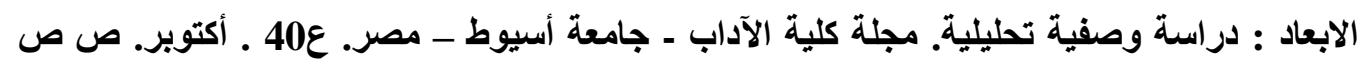

$$
208 \text { - } 161
$$

مختار، أمينة محمد، عبد القادر، أشرف أحمد، محمد، صلاح محمود (· ( ·). فعالية اللعب التخيلى وألعاب

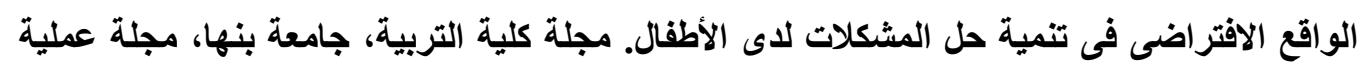

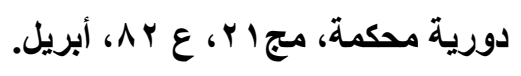

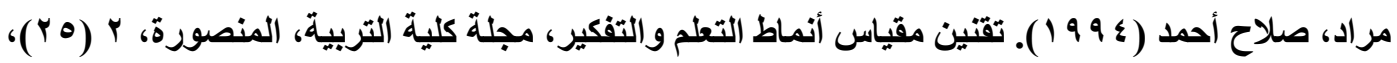
مصطفى، سوزان عطية(7 + . Y). تطوير مقرر في التصوير الرقمي لطلبة تخصص تكنولوجيا التعليم بكليات التربية النوعية في ضوء معايير الجودة الثاملة، المؤتمر العلمى الثانى للجمعية العربية لتكنولوجيا

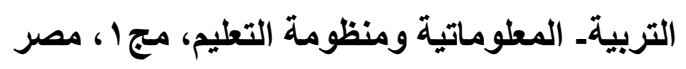

معمرية، بشير(q . . ץ). علاقة المخ بالتحكم في السلوك الإنساني، بحوث ودراسات متخصصة في علم النفس جه، ط1 ، مصر، المكتبة العصرية للنشر والتوزيع.

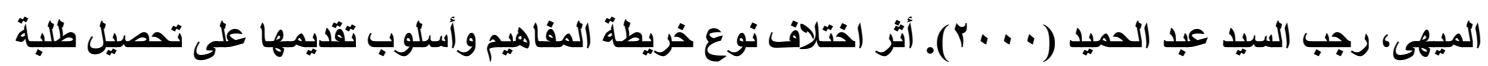

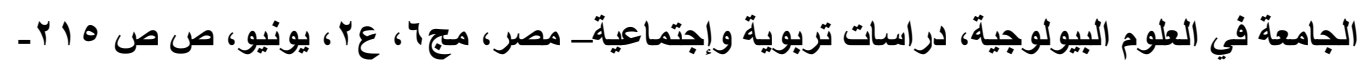

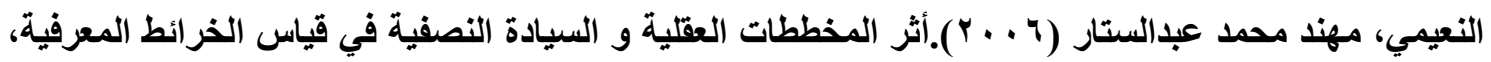

$$
\text { مجلة كلية الآداب جامعة بغداد - العراق، ع74 ، صل ص ص } 131 \text { ـ } 172
$$

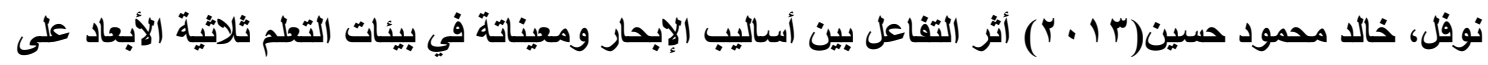
التصور البصري المكاني والثعور بالحضور من بعد لاى طلاب تكنولوجيا التعليم. دراسات فى المناهج

$$
\text { وطرق التدريس- مصر. ع194 ـ ص ص } 83 \text { - } 83
$$


الجمعية المصرية لتكنولوجيا التعليم

نيفيل بينت، ليزوود، سو روجرز(9 . . ب). التعليم من خلال اللعب. ترجمة. خالا العمرى. دار الفاروق للنشر والتوزيع. الطبعة العربية. القاهرة.

هلال، أحمد هلال طلبة(^ . ㄷ). الصورة الرقمية ودورها في مواجهة المشكلات البيئة، مجلة علوم وفنون -

$$
\text { دراسات وبحوث - مصر، مج , } 20 \text { ع } 1 \text { يناير، ص صد صد } 69 \text { - } 82
$$

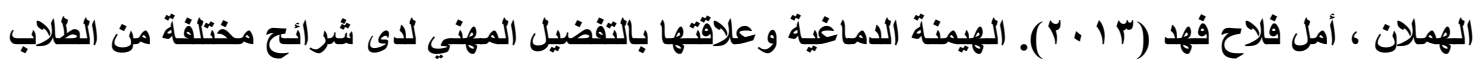
في المجتمع الكويتي، رسالة دكتوراه غير منشورة، معهل الدراسات التربوية، جامعة القاهرة.

هنداوى، أسامة سعيد على( 1 ـ ب). أثر التفاعل بين نمط وتوقيت ممارسة الأنثطة فى وحدة تعليمية إلكترونية حول إدراك الألغاز والخدع البصرية الرقمية على مهارات التمييز البصرى ومستوى قراعة البصريات

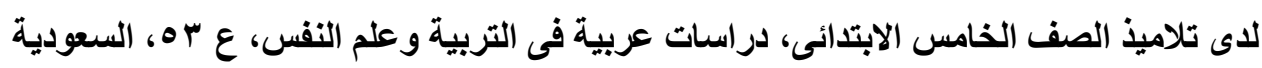

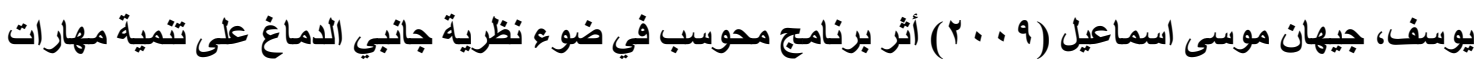
التفكير فوق المعرفي لاى طالبات الصف الحادي عشر بمادة تكنولوجيا المعلومات بمحافظات غزة. رسالة ماجستير. كلية التربية، الجامعة الإسلامية بغزة.

يوسف، سليمان عبد الواحد (0 ( ب ). اتجاهات معلمات رياض الأطفال بجمهورية مصر العربية نحو الأطفال المعرضين لخطر صعوبات التعلم وعلاقتها بالسيادة النصفية للمخ، مجلة التربية الخاصة والتأهيل

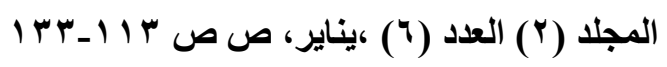

المراجع الأجنبية: - إن

A. A. Zakirova, B. A. Ganiev, R. I. Mullin (2015), Using Virtual Reality Technology and Hand Tracking Technology to Create Software for Training Surgical Skills in 3D Game, New Operational Technologies, AIP Publishing LLC

Anissa All, (2016). Assessing the effectiveness of digital game-based learning: Best practices. Computers \& Education journal. journal homepage: www.elsevier.com/locate/compedu 
Anja, Hawlitschek, Sven, Joeckel(2017). Increasing the effectiveness of digital educational games: The effects of a learning instruction on students' learning, motivation and cognitive load. Computers in Human Behavior. Contents lists available at ScienceDirect. journal homepage: www.elsevier.com/locate/comphumbeh

Becker, Katrin(2017) Using Digital Games in the Classroom, A Practical Guide. Advances in Game-Based Learning. Library of Congress. Springer International Publishing Switzerland

Clark, K., Hosticka, A., Bedell, J. (2000). Digital cameras in the k-12 classroom. Paper presented at the Society for Information Technology \& Teacher Education International Conference: Proceedings of SITE 2000 (11th, San Diego, CA, February 8-12, 2000). Retrieved Thursday, July 5, 2007 from ERIC/EBSCO database(Eric Document Reproduction Service No. 444523)

Connell, D. (2002). Left brain/ Right brain: by better understanding our own neurological strengths and weaknesses we can adopt our lessons to reach all of our student, Instructor, 112(2).

David, Kaufman(2017). Socioemotional Benefits of Digital Games for Older Adults. Springer International Publishing AG . Part II, LNCS 10298, pp. 242-253.

Denham, Andre. (2017). Using a digital game as an advance organizer. Association for Educational Communications and Technology. Department of Educational Leadership, Policy and Technology Studies, The University of Alabama, USA

Douglas B.C, Satyugjit S. V, Jackie .B., Deanne M. A (2016).Self-explanation and digital games: Adaptively increasing abstraction. Computers \& Education journal homepage: www.elsevier.com/locate/compedu. Contents lists available at ScienceDirect

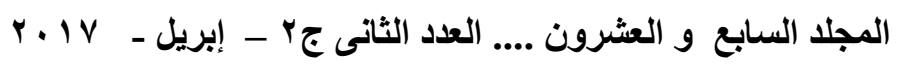


الجمعية المصرية لتكنولوجيا التعليم

Ebru, Yeniman, Yildirim(2018). The Positive Effect of Digital Game Based Programming on Students. Springer International Publishing AG. Advances in Human Factors in Training, Education, and Learning Sciences, Advances in Intelligent Systems and Computing 596.

Edrisinha, Chaturi.(2011). 'Say Cheese': Teaching photography skills to adults with developmental disabilities. Research in Developmental Disabilities 32 (2011) 636-642. Published by Elsevier Ltd. Contents lists available at ScienceDirect

Fellicia. P. (2009). Digital Games in school: a handbook for teacher, European school net, EUN partnership AISB.

Gary, M (2011). Exploring professional learning: a case study of developing elearning for teachers (DEFT), University of Manchester, Available at: http://www.education.manchester.ac.uk/research/centres/lta/LTAResearch /SocioculturalTheoryInterestGroupScTiG/SocioculturalTheoryinEducatio nConference2007/Confrencepapers/GroupTwoPapers/_Files/File upload max10Mb,13 5173,en.pdf.

Grable, L., Overbay, A., Osborne, J. (2005).Instructional Activities, Use of Technology, and Classroom Climate: What Lies Beneath. In C. Crawford et al. (Eds.), Proceedings of Society for Information Technology \& Teacher Education International Conference 2005 (pp. 858-862). Chesapeake, VA: AACE. Retrieved from http:// www.editlib.org/p/19123

Green, David (2006). Using digital images in teaching and learning: Perspectives from LiberaL Arts Institutions. Academic Commission by National Institute 
Hakan T., Meryem Y., Turkan K., Yavuz I., Gonca K. (2009). The Effect of Computer Games on Primary School Students' Achievement and Motivation in Geography Learning, Computer \& Education Journal, Vol 52 Issue 1, January, Pages 68-77

Hall, T, Strangman, N. (2011). Graphic Organisers. National Center on Accessing the General Curriculum, available at: http://www.cast.org/ncac [419\2016]

Hamalainen, R., Oksanen, K. (2014). Collaborative 3D learning games for future learning: teachers' instructional practices to enhance shared knowledge construction among students. Technology, Pedagogy and Education, 23 (1), 81-101

Hooshyar, Danial (2016). Applying an online game-based formative assessment in a flowchart-based intelligent tutoring system for improving problem-solving skills. Computers \& Education journal. journal homepage: www.elsevier.com/locate/compedu

Horton, S.V., Lovitt, T.C., Bergerud, D. (2011). The effectiveness of graphic organisers for three classifications of secondary' students in content area classes. Journal of Learning Disabilities, vol. (23),no.(1),.

Jafari. K., Hashim, Fatimah(2012) The effects of using advance organizers on improving EFL learners' listening comprehension: A mixed method study, system magazine, Volume 40, Issue 2, June, Pages 270-281

Jennifer J. Vogel-Walcutt, (2013). Using a Video Game as an Advance Organizer: Effects on Development of Procedural and Conceptual Knowledge, Cognitive Load, and Casual Adoption. MERLOT Journal of Online Learning and Teaching. Vol. 9, No. 3, September.

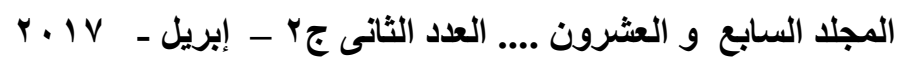


الجمعية المصرية لتكنولوجيا التعليم

Lucas G., Florence M, Michele A.(2009). Effects of 3D Video Game on Middle School Student Achievement and Attitude in Mathematics, The Electronic Journal of Mathematics and Technology, Vol 4, No 1, ISSN1933-2823

Lynceo, Falavigna, Braghirolli (2016).Benefits of educational games as an introductory activity in industrial engineering education, Computers in Human Behavior 58, 315-324, Contents lists available at ScienceDirect

Matthias .G., Vivian B., Jan B., Peter N.(2017). Employee qualification by digital learning games. 7th Conference on Learning Factories, CLF 2017. Science Direct. Available online at www.sciencedirect.com

Mautone, J. A., DuPaul, G. J., \& Jitendra, A. K. (2005). The effects of computer assisted instruction on the mathematics performance and classroom behavior of children with ADHD. Journal of Attention Disorders, 9(1), 301-312.

Merkley, D.M., Jefferies, D. (2010). Guidelines for implementing a graphic organizer. The Reading Teacher, Journal of Research in Science Teaching, Vol, (28).,no(l).

Ming-Puu Chen, Yu-Ting Wong, Li-Chun, Wang (2014). Effects of type of exploratory strategy and prior knowledge on middle school students' learning of chemical formulas from a $3 D$ role-playing game, Association for Educational Communications and Technology, Education Tech Research Dev

Mittchel, A., Savill- Smith, C(2004).The Use of Computer and Video Games for Learning and Skills Development Agency, London. retrieved from http://www.mlearning.

org/docs/The\% 20 use $\% 20$ of $\% 20$ computer $\% 20$ and $\% 20$ video\% 20 games $\% 2$ 0for \% 20learning.pdf 
Mohammadi., Moenikia, Mahdi, Babelan., Adel Zahed (2010).The role of advance organizer on English language learning as a second language, Procedia Social and Behavioral Sciences 2. pp 4667-4671, Available online at www.sciencedirect.com

Mortazavi. Seyed-M (2011). The relationship between time lapse between introducing lexical advance organizers and video viewing, and comprehension in a foreign language classroom, Procedia Social and Behavioral Sciences 15, pp. 2023-2027. Available online at www.sciencedirect.com

Oflaz, M. (2011). The effect of right and left brain dominance in language learning, Proscenia social and Behavioral Sciences, 15, 1507-1513.

Papastergiou M.(2009).Digital Game-Based Learning in high school Computer Science education: Impact on educational effectiveness and student motivation. Computers \& Education. Contents lists available at ScienceDirect. journal homepage: www.elsevier.com/locate/compedu

Rowe. E.l (2016). Assessing implicit science learning in digital games. Computers in Human Behavior journal homepage: www.elsevier.com/locate/comphumbeh. Contents lists available at ScienceDirect

Share, Jeff (2015). Cameras in Classrooms: Photography's Pedagogical Potential. Graduate School of Education and Information Studies, University of California, Los Angeles, Los Angeles, CA, USA. Springer International Publishing Switzerland

Sitzmann, traci. (2011). A meta-analytic examination of the instructional effectiveness of computer-based simulation games, personnel psychology,64,489-528, Wiley Periodicals.

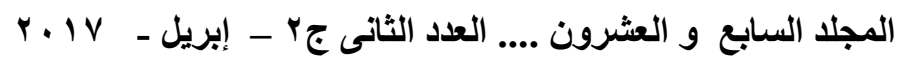
$r \varepsilon$. 
الجمعية المصرية لتكنولوجيا التعليم

Slussareff, Michaela. (2016). Entertainment Computing and Serious Games: Games for Learning. Springer International Publishing

Soflano, Mario, Thomas M. Connolly, Thomas. H. (2015). An application of adaptive games-based learning based on learning style to teach SQL. Computers \& Education 86. pp 192-211. journal homepage: www.elsevier.com/locate/compedu

Supon, Viola (2006). Using digital cameras for Multidimensional learning in $k$ 12classrooms. Journal of Instructional Psychology, vol.33, no.2, p.154-156

Torrance, E.P. (1982) : Hemisphericity and Creative Functioning, J. of Res \& Development in Education, Vol. 15(3).

Torrente, J., Moreno-Ger, P., Martínez-Ortiz, I., \& Fernandez-Manjon, B. (2009). Integration and Deployment of Educational Games in e-Learning Environments: The Learning Object Model Meets Educational Gaming. Educational Technology \& Society, 12 (4), 359-371.

Walter R. Boot (2016). The Gamification of Cognitive Training: Older Adults' Perceptions of and Attitudes Toward Digital Game-Based Interventions. Springer International Publishing Switzerland. pp. 290-300.

Yang, NaSu(2011). Development and Application of the Virtual Intelligent Digital Camera Teaching System. Advances in MSEC Vol. 2, Springer-Verlag Berlin Heidelberg. pp. 521-527. 